\title{
Wayfinding Experience of Persons with Autism Spectrum Disorder Within a Museum Context
}

\author{
by
}

\author{
Amina Balaa \\ A thesis submitted to the Faculty of Graduate and \\ Postdoctoral Affairs in partial fulfillment of the \\ requirements for the degree of \\ Master of Design \\ in the \\ School of Industrial Design \\ Carleton University \\ Ottawa, Ontario
}

(C) 2020 Amina Balaa 


\section{ABSTRACT}

Designing for disabilities may present great challenges but the potential rewards that result may benefit a wider population. This study investigates whether the wayfinding available within a specific museum setting accommodates the needs of persons with Autism Spectrum Disorder (ASD). Identifying the 'wayfinding' needs and/or preferences of the group that was studied in this research is an important first step in developing a knowledge base to further this area of research and perhaps assist designers to facilitate more inclusive wayfinding experience within museum settings. To obtain some insight on the personal experience of people with ASD, three qualitative methods were used: an anonymous survey to gather basic insight about museum visit experience showing that most respondents do visit museums and the majority do not use any assistive devices during their visits; an observational study revealed how participants navigated this particular environment and that visual memory played a large role when traveling through the museum; and finally, a workshop revealed environmental preferences and aversions highlighting the differences between individuals, and how an understanding of diversity is an important consideration in design. The findings of this case study support the notion that it is challenging to design a space to support a diversity of needs and preferences, but that improving our knowledge of diversity as well as commonalities can better support the movement and aspiration toward universal design.

Keywords: wayfinding, autism spectrum disorder, user experience, museum, exhibit, navigation, universal design. 


\section{ACKNOWLEDGMENTS}

This work could not have been achieved without the support and consistent guidance from my supervisors Chantal Trudel and Dr. Boris Vukovic. They showed great interest in my topic and helped me navigate through a new and difficult path. I am appreciative of their patience and help throughout these years.

I would also like to thank the Canada Science and Technology Museum for all their support, offering their resources, time, and help throughout the course of this journey.

There is no doubt my husband was my greatest supporter, seeing me both at my best and during times of struggle to achieve my research goals. Your unwavering belief, love, and trust in me kept me going despite all the obstacles that arose.

My family, my parents, and my sisters: You all kept my spirits up and never doubted I would succeed and reach my goals. You were always a great support, lending an ear and a helping hand.

My dear friend and study partner, Christel, you encouraged me to do this. We got each other through it all, from undergrad to masters; we can achieve anything we set our minds to.

To all the participants and experts that took part in my studies and offered their help and knowledge, you made it possible for me to hopefully make an impact and a positive change in the right direction for the Autism Spectrum Disorder (ASD) community.

Thank you all, your roles enabled my success and I could not have done it without you. 


\section{TABLE OF CONTENTS}

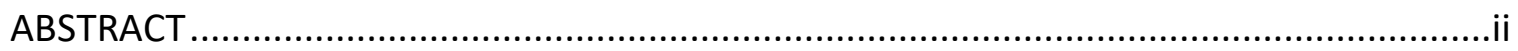

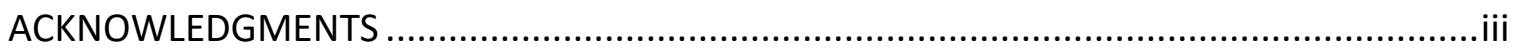

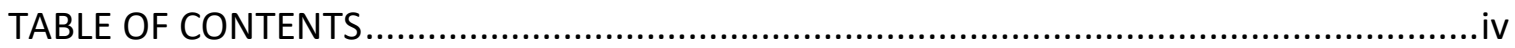

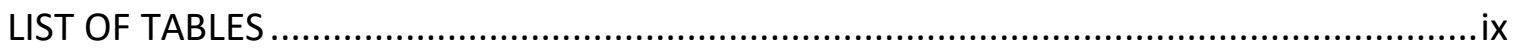

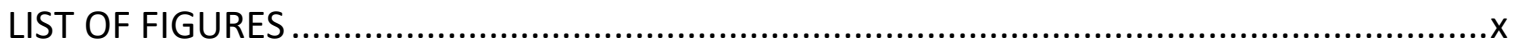

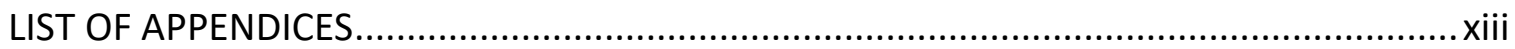





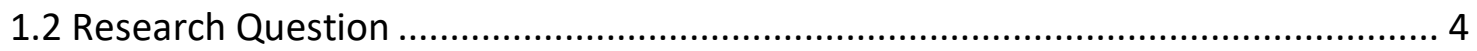

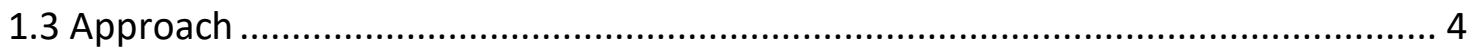

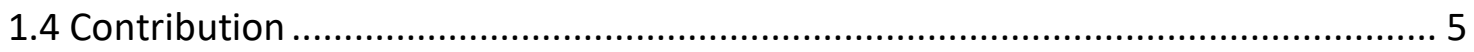



2.1 Defining Autism Spectrum Disorder ........................................................... 6

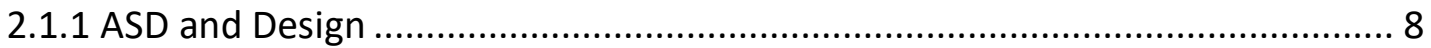

2.1.2 Identifying Existing Support Systems and Gaps ..................................... 11

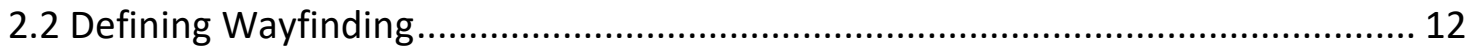

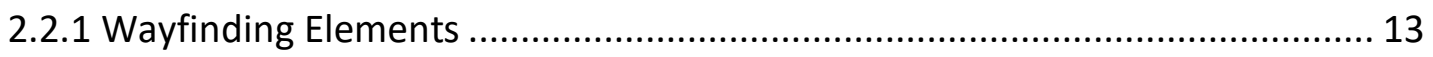

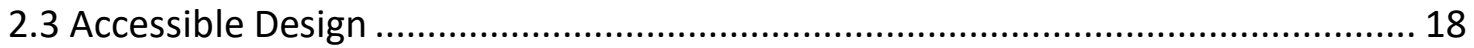


$2.4 \quad$ Review of Methods

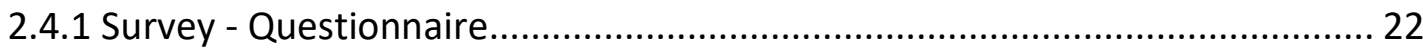

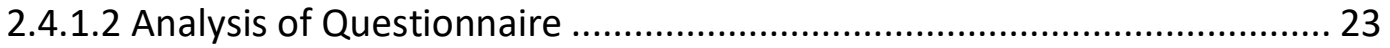

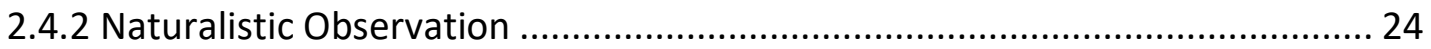

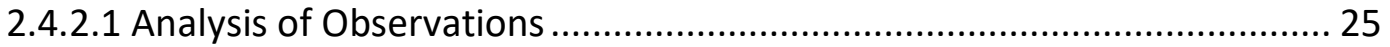

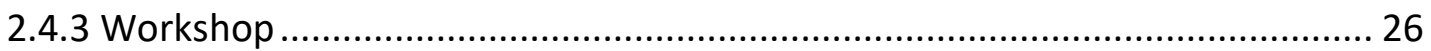



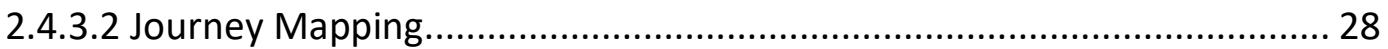

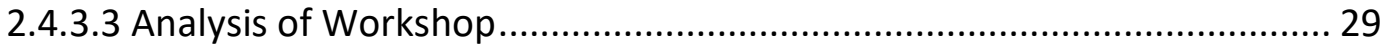

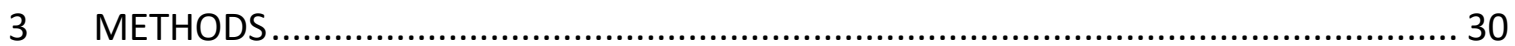

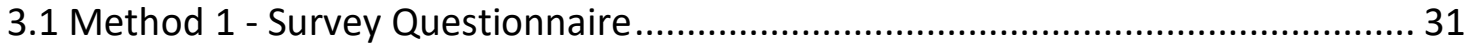

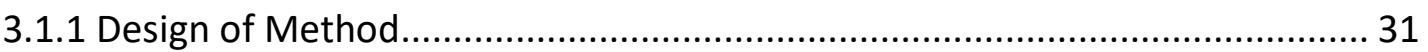



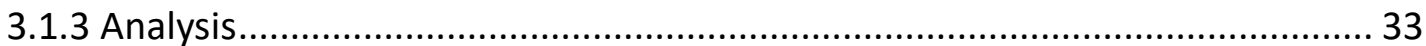

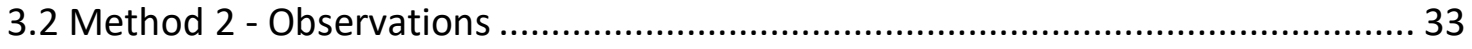

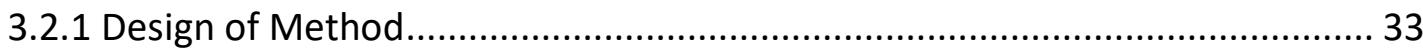

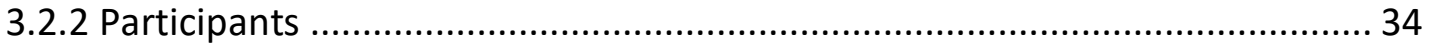

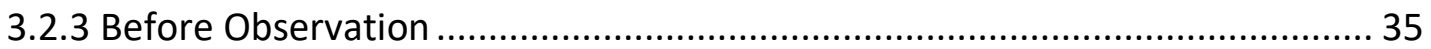

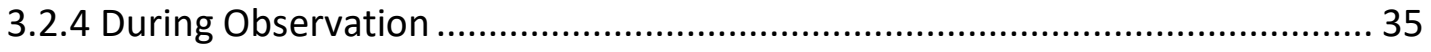


3.2.6 Analysis 36

3.3 Method 3 - Workshop 39

3.3.1 Card Sorting 40

3.3.2 Journey Map. 41

3.3.3 Adjustments 41

3.3.4 Participants 42

3.3.5 Analysis 43

4 RESULTS AND ANALYSIS 45

4.1 Results and Analysis: Method 1 - Survey Questionnaire 45

4.1.1 Close-Ended Survey Questions Results and Analysis .... 45

4.1.2 Open-Ended Survey Questions Results and Analysis 48

4.1.2.1 Question 10 - Open-ended Question about Museum Preferences 49

4.1.2.2 Question 11 - Open-ended Question about Museum Comments and Experience. 51

4.2 Results and Analysis: Method 2 - Observations ......................................... 54

4.2.1 Museum Visit Observation Results ............................................................. 54

4.2.1.2 Museum Visit Observations Behavioural Mapping ................................ 54

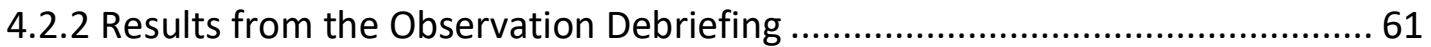


4.3 Results and Analysis: Method 3 - Workshop 65



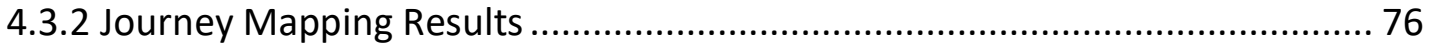

5 DISCUSSION

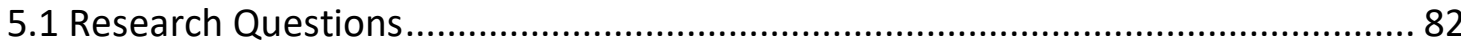

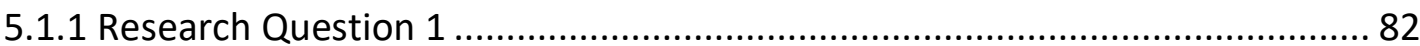

5.1.1.1 Potential Influence of Environmental Factors on Experience and

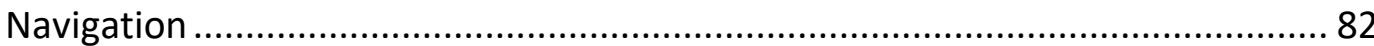



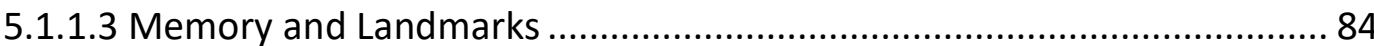

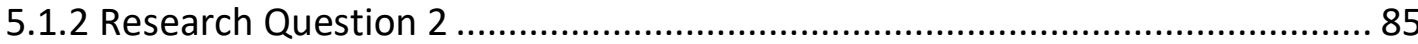

5.1.2.1 The Use of Maps and Associated Landmarks ...................................... 85

5.1.2.2 The Use of Landmarks from Memory ................................................ 86

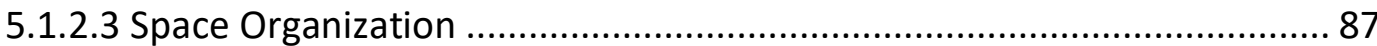

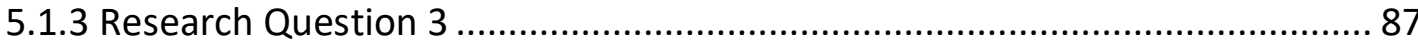

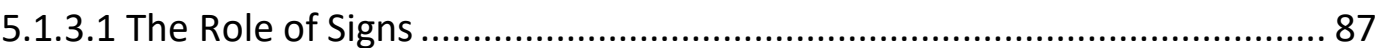

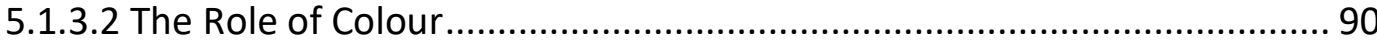

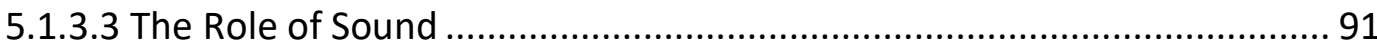

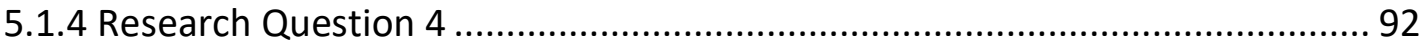




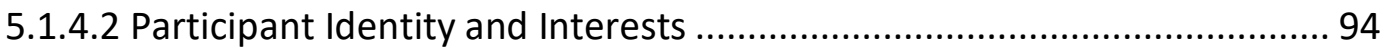

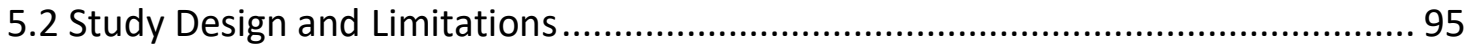



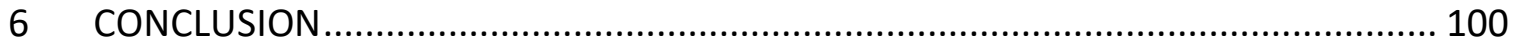

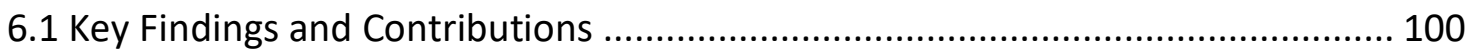

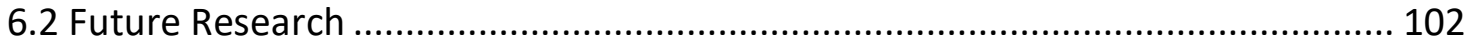

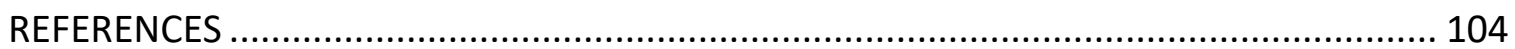

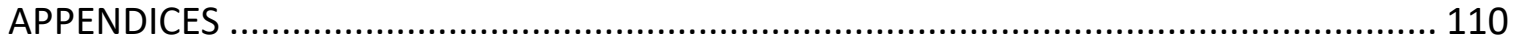




\section{LIST OF TABLES}

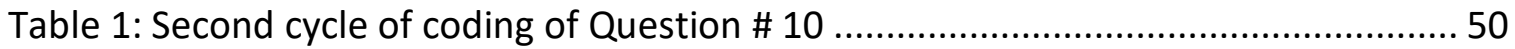

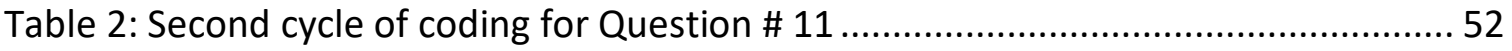

Table 3: Data collected from the two rounds of card sorting in the workshop. ..............68

Table 4: Data collected during card sorting activity with museum picture cards ............ 76

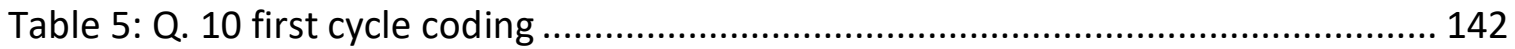

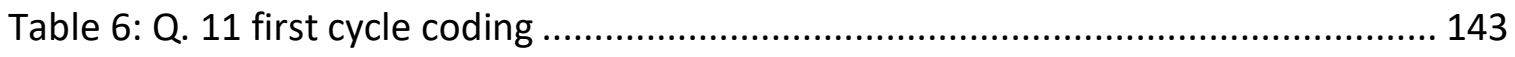

Table 7: Journey map data of ten participants, enumerating the steps/places taken in

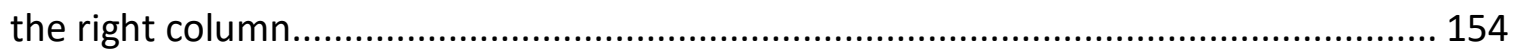




\section{LIST OF FIGURES}

Figure 1 \& 2 (left to right): Images of a 'natural' pathway created by visitors through a patch of grass leading to the entrance of the Ottawa Public Library, viewed from the parking lot (left) and viewed when exiting the library entrance (right). These pictures demonstrate how people will create their own path or choose a shortcut versus using a

'designed' pathway.

Figure 3: A child notices his mother's gaze is fixated on an object and then looks to see what is catching her attention (an example of triangulation) (Gillespie-Lynch, 2013)..... 8

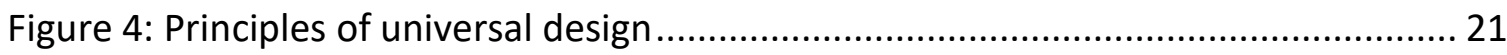

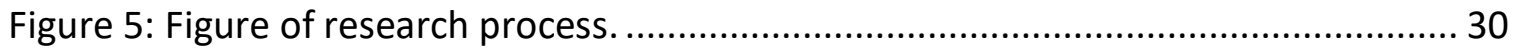

Figure $6 \&$ 7: Example of preliminary affinity diagram of observation sessions and a close up of a portion of the affinity diagram clustering one participant's session. ................. 37

Figure 8: Example of a map sketch conducted on site of a participant's visit................. 38

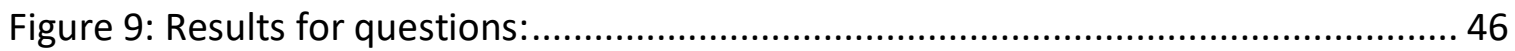

Q.1 Do you self identify as a person with Autism Spectrum Disorder? ........................ 46

Q.2 Do you have a support person (family member, friend, assistant, etc.) that helps you in your daily life? 46

Q.3 Have you ever visited the Canada Science and Technology Museum? 46

Q.6 Have you visited other museums? 46 
Q.7 Did you bring along a support person with you on your visit(s) (e.g. family, friend,

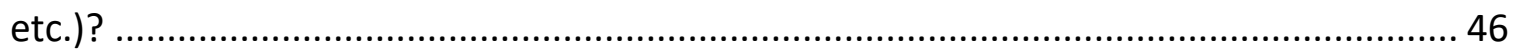

Q.8 Did you bring along or use any items or devices that supported your visit?............ 46

Q.9 Would you like to visit the Canada Science and Technology Museum (again)? ........ 46

Figure 10: Q.4 How would you rate your most recent visit to the Canada Science and

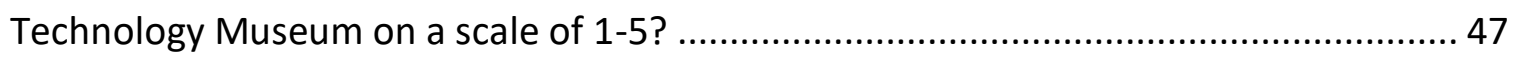

Figure 11: This diagram shows the participants who had or did not have a support person with them compared to whether they had a support item with them.............. 48

Figure 12: Analysis of the open-ended responses from the survey. ............................ 54

Figure 13: Map of the Canada Science and Technology Museum .................................55

Figure 14: Illustration of behavioural map sketches of the 10 participants' movement

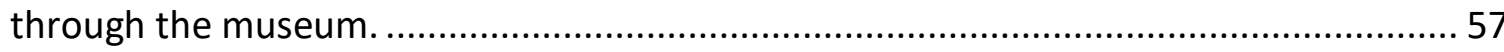

Figure 15: A representation of all the trajectories taken by 10 participants visiting the

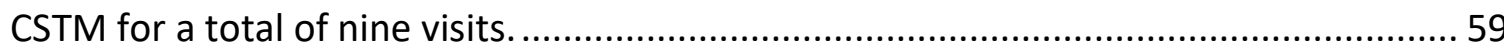

Figure 16: A representation of the high traffic areas in red and the low traffic areas in blue. 60

Figure 17: Data analysis of the ten debriefing interviews following the observation sessions. 64 
Figure 18-21: (18-19 top left to right, and 20-21 bottom left to right): 18-Card sorting activity sorted by a participant; 19-close up of card sorting images; 20,21-participants performing card sorting activities. 65

Figure 22: Picture cards that were commonly sorted into the Like or Dislike piles amongst the 10 participants, in the Daily Life or CSTM categories

Figure 23: Journey map of participant 1 (P1). 78

Figure 24 (for reference only, identical to figure 14): A juxtaposition representation of all the trajectories taken by ten participants visiting the CSTM 83

Figure 25, 26: Images of overhead signs taken at the CSTM. 89

Figure 27, 28: Signage post present at the entrance of the museum before entering

Artifact Alley. 91

Figure 29: Ear plugs 145

Figure 30: Squeeze star 145

Figure 31: Map of the museum. 145

Figure 32: Daily Life category Title..... 147

Figure 33: Canada Science and Technology Museum category title 147

Figure 34: Like (seek), Dislike (avoid), and OK pile titles 147

Figure 35: Kingwood Sensory Picture Cards 148

Figure 36: Museum Picutre Cards 149

Figure 37: Journey Mapping Cards. 150 


\section{LIST OF APPENDICES}

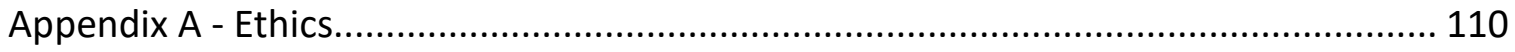

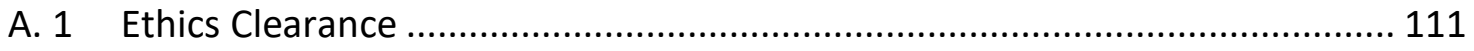

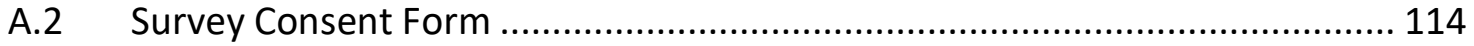

A.3 Observation Consent Form .............................................................. 116



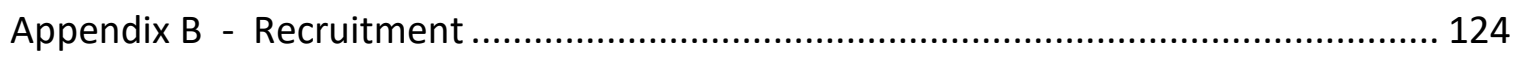

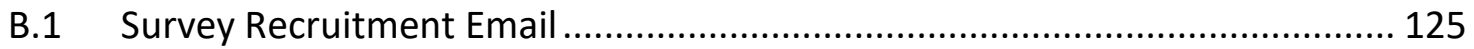

B.2 Observation Recruitment Email ......................................................... 127



B.4 Observation and Workshop Recruitment Poster .................................... 131

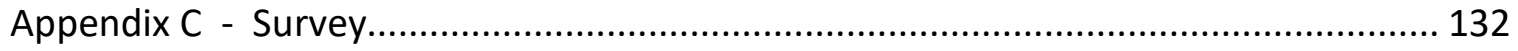

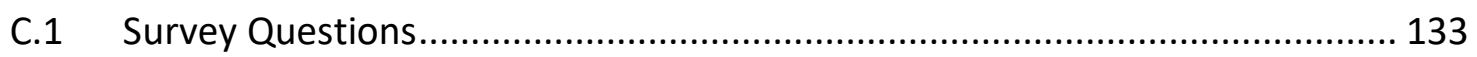

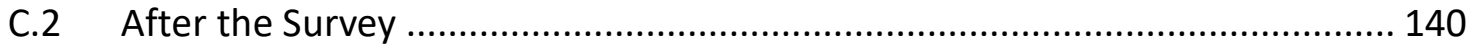

Appendix D - First Cycle Coding Results from Questionnaire .................................. 141

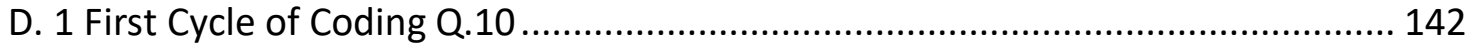

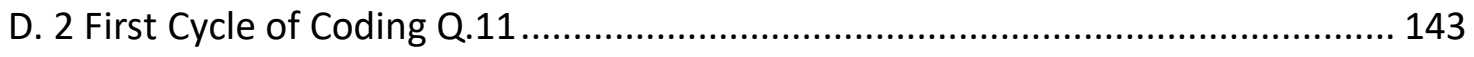

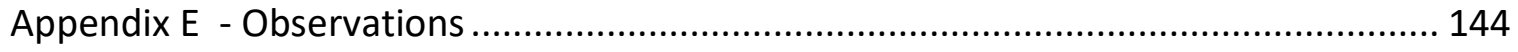


E. 1 Observation Briefing \& Support Tools

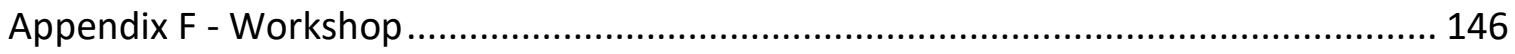

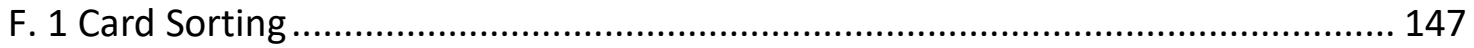

F. 2 Kingwood Sensory Picture Cards............................................................ 148

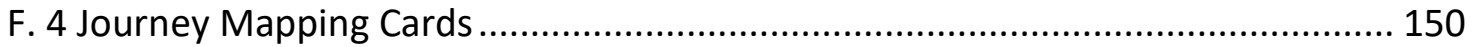

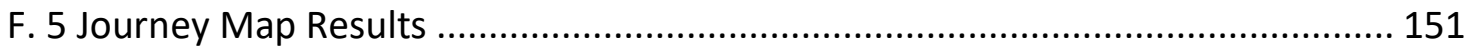




\section{$1 \quad$ INTRODUCTION}

Wayfinding is an integral aspect of many industries and organizations. It is defined as "the process or activity of ascertaining one's position and planning and following a route" (Oxford Dictionary, 2019). Whether it is done through signage, words, colours, maps, apps, symbols, or other mediums, wayfinding is fundamentally a collection of prompts used to help guide someone through an unfamiliar context. Environmental elements such as landmarks can help distinguish an environment, entrance, exit, destination, or path and make it easily recognizable. A good example of this can be found at the National Gallery of Canada where a 10.24 metre (33.6 foot) sculpture of a spider envelopes the entrance area, acting as a prominent landmark for the gallery entrance experience. Figures 1 and 2 below are an example that demonstrates how people will create their own path instead of following a designed path. Other examples abound, whether it be signage in a supermarket or an amusement park, or design features throughout a doctor's office to help guide patients, wayfinding is omnipresent.

While the term is widely used, wayfinding design, in and of itself, may not always be developed to its full potential. Wayfinding is an extremely useful tool that can shape the user experience. Although the common objective of museums is to support discovery, learning, and exploration, appropriate wayfinding must also be present to support this experience for a variety of visitors, based on their abilities, developmental stages, and potential physical limitations, whether such personal characteristics are temporary or 
long-term. This case study focuses on the wayfinding experience of people with Autism Spectrum Disorder (ASD) within an existing museum setting.



Figure 1 \& 2 (left to right): Images of a 'natural' pathway created by visitors through a patch of grass leading to the entrance of the Ottawa Public Library, viewed from the parking lot (left) and viewed when exiting the library entrance (right). These pictures demonstrate how people will create their own path or choose a shortcut versus using a 'designed' pathway.

\subsection{Rationale}

From my personal interest in the field of wayfinding and subsequent communication with the Canada Science and Technology Museum (CSTM), I discovered our interests aligned as the museum was curious about the accessibility of their new wayfinding system and wanted to study the system with groups that may not be currently well studied in museum design, such as the ASD community. Therefore, my aim was to provide a preliminary picture of the perceptions, preferences, and behaviours of a 
group of adults with ASD within the CSTM, and more specifically within the context of wayfinding. People on the spectrum may not be adequately considered in and served by current wayfinding standards and/or guidelines for public spaces (Gaines, Bourne, Pearson, \& Kleibrink, 2016). This may be due to our limited understanding of this population's characteristics, needs, and preferences with respect to wayfinding design. This research study consists of a literature review related to ASD, followed by field methods with subject matter experts in ASD, and, most importantly, people on the spectrum to study the influence of wayfinding and environment design on user experience. This case study reveals if and how wayfinding within a specific museum setting is being used by a group of participants on the spectrum, as well as their environmental or sensory preferences which may impact future considerations in wayfinding design. It is my hope that this study can inform further research questions and studies to better serve people with ASD within public recreational and leisure settings such as museums. To achieve this goal, I conducted a general questionnaire about museum experience, observed participants with ASD during their visit to the Canada Science and Technology Museum (CSTM) and conducted a workshop to evaluate and observe how these individuals reflected on wayfinding elements and associated environmental elements according to their preferences and needs. This study was reviewed and received clearance from the Carleton University Research Ethics Board and the Algonquin College Research Ethics Board. 


\subsection{Research Question}

As people with ASD vary greatly in characteristics and ability, I am interested in developing a better understanding of how a group of adult participants with ASD navigate the CSTM with a focus on the design of the museum's wayfinding and general environment. Specifically, the study will investigate:

1. How do participants move through and navigate the environment?

2. Do participants use the current wayfinding system? And if so, how?

3. What does wayfinding at the museum, and environmental elements potentially related to wayfinding, mean to participants?

4. What may designers need to pay attention to in order to support future research and design development in museum wayfinding in consideration of ASD?

\subsection{Approach}

To achieve this goal, I conducted a survey to reach people with ASD and to get a sense of whether they visit museums and if they have a support person or use any helpful devices during their visits. I also observed participants visit the Canada Science and Technology Museum (CSTM) to see what actions they took while navigating the space and comments they made during their journey. Lastly, I developed a workshop to evaluate how people on the spectrum reflect on a variety of elements related to wayfinding in terms of their preferences or things they dislike or avoid. 


\subsection{Contribution}

This study aims to bring awareness to how wayfinding in a specific museum setting is viewed, used, and understood by a group of persons with ASD to gain an understanding of what works well for this group; but also, what may make the experience more enjoyable or accommodating. This may contribute to the ASD community by having more tailored and thoughtful design with their characteristics and preferences in mind. In turn, designing environments in response to factors revealed in this study may contribute to ongoing research in accessible and inclusive wayfinding. In reviewing this study, designers may also question and challenge the accessibility of spaces, the needs and usefulness of wayfinding approaches and apply more thoughtful processes to improve future projects. The way we go about our day can be greatly improved if we embrace the concept of universal design that is applied not just from a rule book or guides, but by listening and working with people that should be part of the whole process and not just 'considered' in design. 


\section{LITERATURE REVIEW}

\subsection{Defining Autism Spectrum Disorder}

A report from 2015 states that "1 in 66 children and youth from 5-17 years of age were diagnosed with [Autism Spectrum Disorder] ASD" in Canada, according to the National Autism Spectrum Disorder Surveillance System (NASS), making ASD one of the more prevalent developmental disabilities (Ofner, Coles, \& Decou, 2018). ASD is described as "persistent deficits in social communication and social interaction across multiple contexts" which include "deficits in social-emotional reciprocity", "deficits in nonverbal communicative behaviors used for social interaction", and "deficits in developing, maintaining, and understanding relationships" according to the Centers for Disease Control Prevention (2019). ASD is more commonly reported in males, with one in 42 males being diagnosed with ASD compared to one in 165 females (Ofner et al., 2018). The percentage of the population diagnosed with ASD continues to grow and should be given more attention by organizations and industries, especially in the field of design.

"Today, designers must think and act like strategists to enable overall success, end-user happiness, and project longevity" (Picanza, 2018).

ASD is a neurodevelopmental disorder which impairs communication skills and social interactions. People with ASD may have language delays and difficulty with non-verbal communication (Autism Canada, 2019). They may lack the ability for 'joint attention' which may manifest itself by not sharing common interests with others, not sharing experiences or playing together with objects. An example of 'joint attention' is the 
ability to triangulate which is a developmental milestone. Triangulation occurs when a child shifts their gaze back and forth from an object to another person whom they want to communicate with, indicating that they want that person to notice the object too (Figure 3) (Tamara, 2016). They may also display repetitive behaviours such as rocking, hand flapping, repeating what they hear or self-injurious behaviours such as selfpinching. People on the spectrum may enjoy routines, be inflexible, and show distress in the face of any deviation (Augustyn, 2019). "Individuals with ASD do not easily pick up hidden meanings or unspoken social cues" (Gaines, Bourne, Pearson, \& Kleibrink, 2016, p.7). However, as mentioned in the name itself, Autism Spectrum Disorder, people vary in terms of the level of functional impairment or limitation which places each individual at a different range on the spectrum. Therefore, the need for support can vary greatly from a low functioning (severe ASD) to a high functioning (mild ASD) person on the spectrum. In the latest edition of the Diagnostic and Statistical Manual (DSM-5), Asperger Disorder, Autism Disorder, and Pervasive Developmental Disorder are all categorized under the term Autism Spectrum Disorder (Anagnostou et al., 2014). This is a life-long condition that has no treatment but can be improved by focusing on children's communication skills in hopes of strengthening and alleviating potential future difficulties as they become more exposed to daily life encounters. 


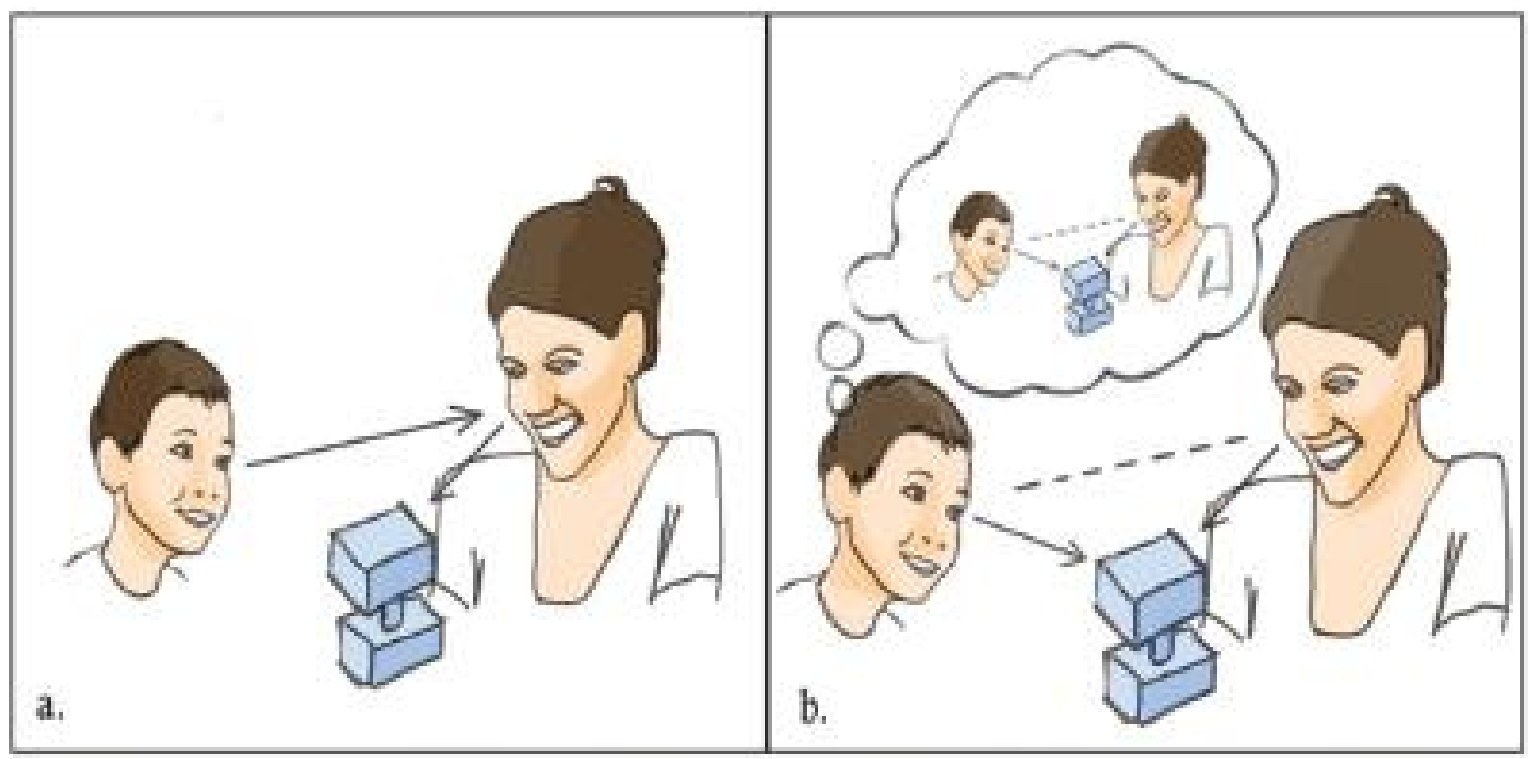

Figure 3: A child notices his mother's gaze is fixated on an object and then looks to see what is catching her attention (an example of triangulation) (Gillespie-Lynch, 2013).

\subsubsection{ASD and Design}

It is best to prepare persons on the spectrum before new encounters or surroundings.

Explaining the situation they are about to experience can help prepare them and prevent or minimize any discomfort (Autism Speaks, 2018). Researchers have noted that persons with ASD have difficulty with daily navigation and finding their way when a familiar route has been blocked or changed (Smith, 2015). This phenomenon may apply to navigating novel environments, such as museums which may be unfamiliar depending on the frequency of visits or changes introduced to the museums (e.g. new exhibits). Also, it can be a challenge to adapt to an environment for persons with cognitive disabilities due to challenges with interpreting a space (Martin, 2016). People 
on the spectrum also have varied responses to sensory stimuli. For example, they may be obsessed with shiny objects or be resistant to certain material textures (Augustyn, 2019). A particular challenge with this population is the need for more than one method of communication or orientation when it comes to designing the same path or space. For example, one person may have an aversion to bright lights while others may enjoy them (American Psychiatric Association, 2018). Therefore, a space ideal for one individual may not be ideal for another.

A recent publication from 2016 entitled Designing for Autism Spectrum Disorders mentions that "there is very little information on how to design spaces for [people with ASD]" (Gaines et al., 2016, p.3). The book shares different methods and suggestions for designing ideal spaces in various contexts but does not include the design of museum environments. Starting with designing for the senses, the book outlines how sight, hearing, touch, and proprioceptive and vestibular senses all play a role when designing an environment for individuals with ASD (Gaines et al., 2016). More specifically, when it comes to sight, aspects such as lighting, colour, space organization, and designing for visual sensitivity need to be considered.

According to Gaines et al. (2016), lighting can greatly affect how one perceives a space with the use of natural light versus artificial light. They also note that colour may influence an environment through the use of warm, cool or subdued hues. Space organization is also an important consideration according to the authors, as it can create a visually legible environment to promote routine using "spatial sequencing" which 
involves organizing spaces in specific zones meant for specific activities (p.58). Designing for visual sensitivity by using principles of design which include scale, proportion, balance, rhythm, emphasis, and harmony, while respecting specific elements of design such as space, shape and form, mass, line, texture, pattern, light, and colour, may make the perception of an environment more appealing (Gaines et al., 2016).

In terms of hearing, persons on the spectrum may be affected by high pitched noises. Therefore, the soundscape of a space is important to consider such as background noise produced by machines or electronics. Having elements to control the noise should be considered, which may include using sound-absorbing materials to compose the space relative to noisy equipment in the environment, or providing areas where sounds are more muted (Gaines et al., 2016).

As for touch, "[f]or people with ASD, engagement of the tactile sense is especially important, as they learn by engaging physically with materials" (Gaines et al., 2016, p.81). Furthermore, they may also "rely on the sense of touch to make their way through a space" (Gaines et al., 2016, p.103). Finally, proprioceptive and vestibular senses, which refer to our balance and spatial orientation, can be distorted for individuals on the spectrum. This can be addressed through design by using contrasting elements between the walls of a room and the flooring which can consist of hardwood, carpeting, or a different colour, all of which may reinforce the process of orientation and wayfinding (Gaines et al., 2016). 


\subsubsection{Identifying Existing Support Systems and Gaps}

To encourage positive user experience, service providers may develop a service design model to better support their client's journey. Beyond designing a service, which involves creating a user journey from the beginning to the end of a client experience, service design at a larger level involves understanding what has to be done behind the scenes to implement and facilitate that journey (Gibbons, 2017).

Occupational therapy researchers Silverman and Tyszka (2017) suggest a progressive model to better serve people on the spectrum which includes: providing dedicated visiting days for an audience with sensory processing differences; having the support of trained occupational therapy students to guide these visitors; and/or offering special activities. Similarly, at the Dallas Museum of Art, there is an event called Autism Awareness Family Celebrations that takes place four times a year before opening hours on Saturdays (Kulik \& Fletcher, 2016). These occasions offer a comfortable environment to visit museums. However, there are limitations to these service models, such as the infrequency or availability of such events, and the limited times they are offered within a day. It is not always convenient for families to visit museums at early and select times as this can conflict with their daily schedules and routine. Another factor noted by Kulik and Fletcher (2016), is that staff may be unaware of how to accommodate visitors with ASD or may not be familiar with this disorder. They go on to emphasize that staff need to be better educated on this population to better understand how to react in certain situations, situations which can differ with every child or adult (Kulik \& Fletcher, 2016). A similar study by Lussenhop et al. (2016) aimed to understand the museum experience 
of children with ASD in collaboration with occupational therapy researchers. The authors highlight key factors in their findings associated with social participation. They reported that environmental features helped facilitate social participation of families' visits such as "interactive exhibits that were multi-sensory", "spacious exhibit halls with many options for engagement", and "clear signage related to wayfinding or sensory information" (Lussenhop et al., 2016, p. 129). They also mentioned the benefits of signage and sensory related information that informed visitors of areas with loud noises which allowed families to make an informed decision on whether they want to enter certain exhibits or not (Lussenhop et al., 2016). This research is one of the few studies which discusses some aspects of wayfinding and associated environmental elements that may help and benefit visitors with ASD when planning to go to a museum. Although these studies can be of great value to museum designers, the lack of studies focused on this area highlights the need to further investigate the relation between wayfinding and ASD in museum settings.

\subsection{Defining Wayfinding}

The extent to which an environment can be learned will depend on its legibility through wayfinding (Golledge, 1999, p.6). Symonds, Brown, \& Lo lacono (2017) define wayfinding as "the cognitive and corporeal process and experience of locating, following or discovering a route through and to a given space" (p.9). Wayfinding can be found anywhere from supermarkets, to airports, and museums and its success can be measured by how easily one can navigate such spaces and the extent to which the wayfinding elements and orientation cues are seamless and may even go unnoticed or 
be taken for granted. This includes permanent landmarks, the adjacency or organization of spaces, and having places dedicated for movement and others for rest (Gaines et al., 2016). Landmarks can act as reminders to find one's way in an environment through the use of architectural elements such as "columns, archways, and views to a garden" which "leave a lasting impression on people" (Gaines et al., 2016, p.103). Considering this, planning spaces for people on the spectrum may help contribute to and influence their quality of life as well as encourage independence while having security (Gaines et al., 2016).

\subsubsection{Wayfinding Elements}

David Gibson's (2009) book The Wayfinding Handbook: Information Design for Public Places discusses principles and elements to support effective wayfinding design. The first consideration in wayfinding according to Gibson is branding or placemaking which are not necessarily evident wayfinding markers but do play an important role in navigation. Brand identity can be a strong factor in wayfinding as it projects a company's image throughout the signage. "Coordinated symbols, colours, names, signage, architecture, and landscaping together reinforce the institutional identity and express a specific sense of space, of being somewhere in particular. The practice of branding an environment to feel distinctive is also known as placemaking." (Gibson, 2009, p.73). Similar to branding, a typeface can be iconic to an environment. Typography and layout can also render a place to be kid-friendly, for example, if a cursive or bubbly type is selected. This is a subtle form of communicating to the intended audience or purpose of the place without having to include more explicit information through an organization's 
title for example (Gibson, 2009). Colour is also an important aspect of wayfinding.

Factors to consider with colour include the context, available lighting (day and night), and mixing colours (Gibson, 2009).

Additionally, maps and symbols are important instruments for navigating around an environment. A map may help someone locate themselves within an environment. A symbol may visually communicate something without the use of words (e.g. the universal icon for restrooms) and it can also help to locate someone in a space (e.g. identifying the Nike store in a mall by spotting the iconic swoosh design) (Gibson, 2009).

Other aspects of wayfinding include form, material, and media. Adding dimension or three-dimensional form can elevate and add character to an environment compared to a flat sign with printed letters. Curving a poster, raising lettering, using glass instead of plastic, or incorporating digital media, can make the wayfinding more interesting and effective as it may have a lasting impression on people (Gibson, 2009).

Additionally, many cognitive aspects must be considered in the design of wayfinding such as making the best use of one's memory, and/or sense of direction through elements such as landmarks, or other striking features (Hund \& Gill, 2014). Hund \& Gill (2014) also shed light on spatial anxiety and that people perform wayfinding tasks better using route cues (left-right directions and landmarks) over spatial cues (distance measures or cardinal directions). For example, one would perform better getting from point A to point B with directions like 'take your first right and when you see the lighthouse take the next left' versus directions like 'turn east in 25 meters and when you 
see a lighthouse on the north side then you turn west'. Experiencing spatial anxiety can affect one's wayfinding abilities. Having a 'good' sense of direction and ability to mentally rotate an environment in one's mind increases a person's wayfinding performance as these qualities may help them adapt to their environment more easily, learn a map more readily, and/or mentally picture an environment from different views (i.e. by being able to mentally rotate it and understand it) (Hund \& Gill, 2014). Verbal (remembering words said) and spatial (stored environmental information) working memory both play a role in wayfinding and individuals have different skill levels and abilities related to sense of direction and mental rotation that can affect wayfinding (Hund \& Gill, 2014). Similarly, spatial navigation varies greatly for persons on the spectrum (Wolbers \& Hegarty, 2010). Carefully thought out environment designs using organization, colours, and textures, "can help people create mental maps, which is challenging for individuals with ASD" (Gaines et al., 2016, p.103).

In studying museums, Foltz (1998), defined certain principles to support effective wayfinding which include:

\section{- Creating an identity at each location.}

This means that each location in a space has an identifiable and unique identity which allows people to associate cues to that location and gives them the ability to "recover [their] position and orientation" (p.60).

\section{- Using landmarks to provide orientation cues and memorable locations.}


This allows people to find their position according to a landmark (which is visible and viewable from a large surrounding area) they may recall from memory.

- Create well-structured paths.

The path should be continuous having a clear beginning and end. The path should have different regions with different visual character, visual attributes, function, or use, with a space that can be subdivided into regions.

- Don't give people too many choices in navigation.

This principle is used when a story is being conveyed to people, and the associated design should be coherent.

- Use survey views.

A map is a valuable visual aid putting the space in perspective for the user.

- Provide signs at decision points to help wayfinding decisions.

Signs should be available at points where people may change paths.

- Use sight lines to show what's ahead.

Sight lines give information about what is ahead that can encourage people to pursue a direction.

Wayfinding is not always intuitive when it comes to exhibits as they are usually a new experience to visitors. Whether an individual is not aware of which way to go, how to exit, the length of the exhibition, or even what the exhibit is about, these are all issues that should be addressed and solved by the museum (Nicholas, 2000). Different types of interactive design elements may come into play to accommodate those issues. Button activated displays and touch panels can supply information to participants about the 
structure or content of the exhibit and could enhance their learning or exhibition experience in general (Sparacino, Davenport, \& Pentland, 2000). Sensors can also be used to create spotlights on objects and/or trigger displays which may be intriguing or capture one's attention. Audio tours can be provided with headphones guiding participants and providing information about the artifacts as they move throughout the museum. Audiovisual media may engross visitors' attention by engaging their hearing and visual senses as they pass by displays equipped with motion sensors.

Interaction design is related to wayfinding, as both can be represented visually and are capable of engaging people in different ways beyond the visual modality, whether it be tactile or auditory for example. By integrating interactive aspects into an exhibit, people are encouraged to engage themselves in that environment, with the intent of supporting a more memorable and positive experience. This may also help people absorb information which may not have been retained or understood otherwise. Interactive/interaction design is largely present in museums as they attempt to stay current with advancements in technology, providing more attractive and appealing exhibits to the public, all the while aiming to accommodate and educate numerous visitors, while preserving artifacts (Sparacino et al., 2000). Visitor preferences will vary from those who want to get close to objects and capture the moment through media (if the museum permits), to those who take their time reading text and taking in the displayed objects, to those who like to engage in interactive displays and touch objects (Nicholas, 2000). 


\subsection{Accessible Design}

Accessibility is a level of quality that is more commonly discussed now in design and implemented in the design of our everyday interactions (Persson, Åhman, Yngling, \& Gulliksen, 2015). People are considering a wider population when facilitating new processes and experiences. However, there may be a limit to the extent of accessibility available due to a lack of understanding of what this term really means (Persson et al., 2015). For example, being disabled by one's environment and situation does not boil down to someone's observable physical characteristics, but this is often how it may be understood by designers or portrayed in their work. Accessible design is not limited to serving people with physical traits/abilities or cognitive states that are readily seen or perhaps easier to identify as disabilities. Accessible designs can serve a wide range of people and can also serve people with long-term or temporary disabilities. How the term is applied and in what context can signify different meanings to different people, yet finding a concise and widely accepted definition can "promote awareness, facilitate discussion, enable implementation and promote the development of better methods for increasing accessibility" (Persson et al., 2015). Article 2 in the United Nation's Convention on the Rights of Persons with Disabilities (2006) explains that "[u]niversal design means the design of products, environments, programmes and services to be usable by all people, to the greatest extent possible, without the need for adaptation or specialized design" and "shall not exclude assistive devices for particular groups with disabilities where this is needed". 
Similarly, the American Disabilities Act (ADA) (2010) discusses requirements for public service, stating that "[n]o individual shall be discriminated against on the basis of disability in the full and equal enjoyment of the goods, services, facilities, privileges, advantages, or accommodations of any place of public accommodation by any private entity who owns, leases (or leases to), or operates a place of public accommodation."

But within this scope, there are disabilities that may go unnoticed like someone who has suffered from a brain injury, disabilities associated with the normal aging process, people implicated in the lives of others who have certain needs (e.g. caregivers), and even language barriers (de Paolis \& Guerini, 2015). In Canada, Bill C-81, also referred to as the proposed Accessible Canada Act which is an act to ensure a barrier-free Canada, was introduced in June 2018. "Bill C-81 would implement a proactive and systemic approach to identifying, removing, and preventing barriers that might deprive persons with disabilities of an equal opportunity to make for themselves the lives that they are able and wish to have" (Department of Justice, 2019). Part of the bill's principles include a barrier-free government, inclusive design, and meaningful involvement (Government of Canada, 2019). As of June 2019, Canada received Royal Assent for its first federal accessibility legislation, making Bill C-81 an official Act. Also, the Accessibility for Ontarians with Disabilities Act (AODA), which has been law since 2005, enforces that public spaces should comply to certain standards. For example, service counters must have at least one counter available for individuals with mobility aids, all counters must be visibly identified with signs, and counters must be made available for every service the organization may offer (Ontario, 2019). 
There are a number of wayfinding standards that designers must implement. In Ontario for example, section 3.8. Barrier-Free Design in the 2012 Building Code Compendium is designed to guide the design community in creating a barrier-free environment. With regards to wayfinding, the standard requires a certain number of barrier-free entrances according to the number of pedestrian entrances, and one of the barrier-free entrances must be a main entrance (2015). There are also design standards for accessibility signs and it states that "Where a building is required to have a barrier-free entrance, signs incorporating the International Symbol of Access shall be installed to indicate the location of, a) that entrance, b) ramps located in a required barrier-free path of travel serving that entrance..." (Ontario, 2015, p.186). The international symbols of access serve to indicate "to persons with disabilities that they will have reasonable freedom of movement within the building" (Ontario, 2015). Although such standards and similar municipal guidelines are important, they focus primarily on physical access.

Finally, there are seven principles of universal design that designers should use in their design process (Connell et al., 1997) which includes consideration to wayfinding design: 
when the product and/or service can be marketed towards everyone, including individuals with disabilities

Flexibility in use

when the product can be used differently according to a person's preference and capability

\section{Simple and intuitive use}

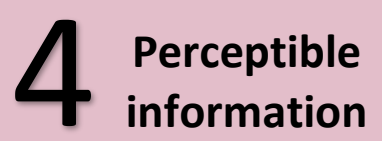

\section{5}

Tolerance

for error

5 Low physical effort
Size and space for approach and use encourages that products can be used across different skill levels and can be easily understood

information should be easy to understand and see despite ambient conditions

the product or system presents little to no hazard and is clearly labelled for safety reasons

there should be minimal to no physical effort needed to use the product and the design should ensure it can be maneuvered comfortably

considers the necessary space needed to handle or operate the product no matter the user's body size and the ability to accommodate assistive devices if necessary

Figure 4: Principles of universal design 


\subsection{Review of Methods}

A number of methods were reviewed to develop the methodology for this case study which are discussed below. This study qualifies as a case study as it investigates a single group of participants to explore the research questions. The results are not generalized towards the ASD community, but rather, focus on the results from the select adult participants that took part in the study in the context of the CSTM. This can provide the opportunity to learn from this study to inform future design work and research with larger sample sizes.

\subsubsection{Survey - Questionnaire}

The value of using surveys was explored in the literature review on methods to support the following research question.

\section{What may designers need to pay attention to in order to support future research and design development in museum wayfinding in consideration of ASD?}

Surveys can be used to develop a preliminary understanding of the habits and preferences of participants within the context of museum experience. A survey can also be a means to recruit participants for subsequent methods of inquiry. Surveys are a simple and unobtrusive way to receive information on a participant group as it is anonymous, and accessible online so participants are not required to commute. A higher response rate may be possible due to the ease of online access coupled with 
receiving responses quickly, or more quickly than a written questionnaire (Milton \& Rodgers, 2013).

\subsubsection{Analysis of Questionnaire}

In reviewing the literature on survey analysis, tabulating responses to close-ended questions and coding participant responses to open-ended questions was considered the best approach. In tabulating the closed-ended responses, similarities might emerge in the data which may present information on participant tendencies (Goodman, Kuniavsky, \& Moed, 2012). As for coding, when there are blocks of information such as long-form interview responses, it is helpful to "code" that information by assigning a word or short sentence/label (code) that best encompasses the information. More than one code can be associated with a passage which can later on be refined through a second cycle of coding (Saldana, 2016). Pre-coding is a technique used to highlight passages of information to determine what data is most valuable which will then be coded by highlighting, bolding, underlining, circling, or using a different colour text to differentiate this information from the rest (Saldana, 2016). From there, in vivo coding may be used to emphasize a person's voice by using their words as the code itself. This is also part of first cycle coding where codes then go through a second cycle of coding to refine and create categories (Manning, 2017). As mentioned by Morrow (2005), "the writing or other presentation of the findings should exemplify a balance between the investigator's interpretations and supporting quotations from participants" (p.256). Carefully choosing a person's words as codes is necessary to instill transparency from the researcher to the reader. 


\subsubsection{Naturalistic Observation}

To answer the following research questions, different observation methods were explored in the literature. Naturalistic observation facilitates observation in real time in the real context which can help answer the questions:

1. How do participants move through and navigate the environment?

2. Do participants use the current wayfinding system? And if so, how?

Also, in debriefing participants after the observation about their experience in the museum, these research questions can be examined in more detail:

3. What does wayfinding at the museum, and environmental elements potentially related to wayfinding, mean to participants?

4. What may designers need to pay attention to in order to support future research and design development in museum wayfinding in consideration of ASD?

Naturalistic observation is similar but less intensive than ethnography as in the latter

method, participants from a certain cultural group are observed in a natural setting such as a home or work environment, observing their day-to-day lives over an extensive period of time (Milton \& Rodgers, 2013). Observations can also present more valuable information to aid in design as the information may be more accurate than what could 
have come out of an interview, for example. What people say they do is often different than their actions observed in a real life scenario (Goodman, Kuniavsky, \& Moed, 2012). This method is therefore useful for providing observed qualitative information about participants and their actions during a visit at the CSTM.

\subsubsection{Analysis of Observations}

Behavioural mapping will be one of the methods for systematically documenting and analysing the observations through a process of place-centered mapping as well as individual-centered mapping (Hanington \& Martin, 2012) to explore research questions 1 and 2. The value of this technique is that it visualizes participant's navigation through the context being observed as well as how they use or don't use the wayfinding available. As the observations are site-specific, this entails place-centered mapping where the researcher observes and documents the use of a particular space (the CSTM). Also, since we are interested in developing a better understanding of the potential wayfinding, navigation and/or orientation activities of each participant relative to the museum's design, an individual-centered mapping analysis can provide a visualization of each participant's journey throughout the museum.

Some may argue that what findings emerge from these observations may be assumptions as the motivations behind a person's behaviour or how to accurately qualify a person's behaviour are truly unknown (Hanington \& Martin, 2012). But the value offered by this technique is that it serves to verify what 'we think' we may be observing by getting feedback from participants throughout their journey and 
debriefing participants after each museum visit to help us to better understand their behaviour, and potentially, motivations behind the behaviour. As previously described in section 2.4.1.2, a coding method will also be used to analyze the participant responses during this activity. Additionally, these observations are analyzed through a preliminary affinity diagram which is a process to extrapolate and cluster observations from the research (Hanington \& Martin, 2012).

\subsubsection{Workshop}

To answer the following research questions, a workshop technique was explored in the literature review on methods. Through card sorting museum related pictures, participants can share their thoughts and reasoning as to why they may 'Like' or 'Dislike' certain aspects.

\section{What does wayfinding at the museum, and environmental elements potentially related to wayfinding, mean to participants?}

Also, by having participant's share their thoughts and opinions about wayfinding elements at the museum this technique can also provide insights on:

4. What may designers need to pay attention to in order to support future research and design development in museum wayfinding in consideration of ASD? 
This method consists of working with people on the spectrum and getting them involved in preliminary activities in the design process. By presenting participants with tangible picture cards (card sorting) of potential or real wayfinding elements, they may be able to more easily point out and talk about what they prefer regarding wayfinding or what is missing, for example. This qualitative method may help gather insight on how a design is interpreted by people with ASD and what they understand (Banks, 2015). Another workshop activity which can help answer our research question involves participants creating a journey map of their museum experience by using available picture cards or ones they create, to plot across a visit and engaging in dialogue as they do the activity. This mapping of the museum journey allows participants to reflect openly on previous visits or a future desired visit. These activities may support the research question by helping us learn about what works well in the current design or discovering untapped considerations or new areas to explore in wayfinding design.

\subsubsection{Card Sorting}

Card sorting is used within the field of design to observe the way people are stimulated by images or words. People can be asked to rank images according to preference, and the researcher can learn what people value about the images ranked and why. There are generally two types of methods in card sorting. The first technique is called open card sorting, where the person participating organizes the cards into categories based on personal preference (e.g. 'Like' or 'Dislike' piles). The second is called closed card sorting, where the person organizes cards according to chosen categories by the researcher (Goodman et al., 2012). Card sorting is not limited to imagery but can be 
used with words as well. It encourages grouping items into categories, brainstorming, and exploring how a person thinks (Spencer, 2009).

Card sorting methods are also used with persons with various cognitive challenges, including ASD. Picture Exchange Communication System (PECS) was developed by Bondy \& Frost (Pyramid Educational Consultants, 2019) with the goal of teaching communication skills through six phases: 1) How to Communicate; 2) Distance and Persistence; 3) Picture Discrimination; 4) Sentence Structure; 5) Responsive Requesting; and 6) Commenting. Similar to PECS, Autism at Kingwood (2019) offers sensory profiling cards with different sensory experience images accompanied by a short description. These cards can be used to prompt people on the spectrum about sensory interactions and allow them to organize the cards according to preferences.

\subsubsection{Journey Mapping}

Journey mapping (sometimes called storyboarding in other disciplines) is another design tool that can help uncover information that may be hidden or not considered in other inquiry methods such as surveying. Journey maps are an overview of a person's interaction with a product or environment communicated on paper (or a surface) with drawing tools (and/or other aids), which creates tangible data for designers and researchers to review and analyse. It is a "valuable tool for communication and collaboration" for user experience (Howard, 2014). Outlining a story or journey (trajectory, routine, etc.) may highlight moments of interest related to specific research questions by outlining the steps drawn out which are personal to the participant. 
Designers use journey mapping to help depict a narrative that can support more understanding or empathy with participants and can also bring design alternatives to light (Hanington \& Martin, 2012).

Similar methods are used in ASD research and practice to illustrate or map out experience in daily living. For example, a school for children with ASD in Drogheda, Ireland, uses storyboards or user journeys to help individuals "deal with anxiety in everyday life" by illustrating steps of their daily lives or the steps they would take when visiting new environments (Autism Support Louth, 2016).

\subsubsection{Analysis of Workshop}

A spreadsheet can be used to organize the sorted cards into the categories chosen by participants (Lamantia, 2003). This can help us systematically see what cards are sorted into 'Like' or 'Dislike' piles and what cards may have changed location when participants reflect on these cards in their 'Daily Life' category to their experience at the 'Canada Science and Technology Museum' category. As for the analysis of the journey mapping exercise, the data can be organized in a table to examine the order of the participant's visit in comparison to the behavioural observation mapped out in the observation study to see if there are similarities, differences and their thoughts underlying these choices (if expressed by participants). Participants' responses throughout the card sorting and journey mapping activity can be coded in the same manner as previous methods to allow for comparison with previous analysis. 


\section{$3 \quad$ METHODS}

Three methods were conducted in this study: 1) a survey, 2) observation sessions, and

3) workshop sessions. The survey was designed to develop a general idea of participant experience at museums. Observation sessions took place at the CSTM after the survey was conducted. The workshops were conducted with individuals who participated in the observations, after their visit to obtain feedback on the wayfinding at the museum and environmental elements potentially related to wayfinding. Adults, 18 years of age and older, were recruited for this study.



Figure 5: Figure of research process. 


\subsection{Method 1 - Survey Questionnaire}

\subsubsection{Design of Method}

Qualtrics Survey Software was used to gather basic descriptive data about adult participants at a higher education institution and other information such as whether participants with ASD visit museums and what their visits entail regarding their engagement, needs, and preferences. A total of 11 questions were created, starting from whether the participant self identifies as living with ASD, if they have visited the Canada Science and Technology Museum, the level of engagement they had, and if they used any devices during their visit. The questionnaire ended with two open-ended questions giving participants the chance to express themselves about what kind of museum they prefer and if they had any other comments to add. I conducted a pilot test with six participants to help clarify, simplify, and eliminate any unnecessary questions and errors. This also helped to arrange the flow of questions and ensure the formulation was clear and easy to understand. To access the questionnaire, participants clicked on a link which was sent to their email by a Disability Services Office at a higher education institution which acted as a third-party recruiter for the questionnaire part of the study. The students recruited were high functioning adults on the spectrum which facilitated the process as they consented on their own behalf to participate in the studies.

At the start of the survey, an information page was present to brief the participant and obtain their consent to participate in the study which would then bring them to the first question. Participants were then asked if they self identify as a person with Autism 
Spectrum Disorder. Participation was anonymous and responses could not be withdrawn. The survey consisted of seven to 11 questions depending on how participants answered them. The last two questions gave participants the chance to voice their opinions on museum design and to share any other comments they may have. The first part of the survey consisted of close-ended questions and according to responses could be skipped if the next question(s) was not relevant (a feature called 'skip logic' in the software). The final two questions were presented to all participants and an exit button was always available if someone did not wish to continue the survey. The final screen asked participants if they would like to participate in an observation study and workshop at the CSTM which they could respond to by sending me an email. The survey was open for a duration of 4 months (July to October 2019) with the most traffic occurring during the month of September, perhaps because it was the start of the school year. The results of the survey did not contribute to the subsequent methods.

\subsubsection{Participants}

A total of 16 respondents initiated the survey, with 13 consenting and self-identifying as having ASD. One consented but did not self-identify as having ASD, and two did not consent. Additionally, there were two respondents who completed $93 \%$ and $80 \%$ of the questions, respectively, but did not submit their response. Therefore, a total of 15 responses were taken into consideration for this study (which includes the two people who did not submit assuming this was an error). As the study is directed towards persons with ASD, a low response rate was expected as the ASD population registered with the Disability Services Office that assisted with recruitment is small relative to 
other disabilities that have a higher presence. As a point of reference, 3402 students are registered at the Disability Services Office of which 125 are students with ASD or $3.7 \%$ of the population. The response rate of students with ASD was $12 \%$ from this group $(15 / 125)$.

\subsubsection{Analysis}

The responses from the survey were totaled and organized in a table for each question. The open-ended responses were also organized in a table and highlighted for relevant information pertaining to wayfinding and user experience, and then manually coded using in vivo coding. A final table was created to present all the data organized from the open-ended questions under categories which emerged from the coding.

\subsection{Method 2 - Observations}

\subsubsection{Design of Method}

This method entailed visiting the Canada Science and Technology Museum with participants while I observed their visit, while paying close attention to whether they used or did not use the wayfinding system or other potentially relevant elements. A few were first time visitors while others had visited before. These sessions allowed me to observe how visitors with ASD navigate the exhibits, and how they interact or don't interact with the space and the wayfinding available at the museum. Being present during the activity allowed me to also ask questions as I saw things occur in real time. During the visit, I recorded what I saw on paper and mapped the participant's trajectory around the museum using the museum map. 


\subsubsection{Participants}

As noted above, recruitment for this method was sent by email through the higher education institution's Disability Services Office with a message displayed at the end of the survey asking participants if they would be interested in participating in an observation as well as a workshop at the CSTM. As there were very little responses, a request was sent to recruit elsewhere through another higher education institution's Disability Services Office and through a community-based ASD consultation office working with clients with disabilities.

A total of 10 participants were recruited for this part of the study, including one observation session that included two participants in the same visit. They ranged from 18-28 years of age, with eight male participants and two female participants. All participants were welcome to bring along a support person, companion, family member, or friend. Participants received a family pass to the museum for participating.

Prior to conducting the observations, a pilot test was conducted with a couple of people to see how they go about the museum. These testers were not on the spectrum. Throughout the pilot test I asked the visitors questions as they went along. After observing the visitors, I did not end up asking the debriefing questions that I asked participants when completing the observation sessions. I had asked the visitors a few questions while they were visiting exhibits but I did not find the need to pose debriefing questions as the visit was short and I expected to have possible different outcomes when conducting the future sessions with participants. 


\subsubsection{Before Observation}

Before starting the museum visit, I went through the consent form with each participant and gave them a second copy for their records. Afterwards, the activity was explained, and a few objects were offered to the participants that could assist them during their visit (earplugs, and a squeeze toy) which they could accept or decline. Finally, each participant was offered a map of the museum as well if they wanted. The map of the museum is usually given to visitors at the front desk if they ask for one, otherwise, there is no other place to get once inside the exhibits.

\subsubsection{During Observation}

During the museum visit, I would ask questions to prompt participants such as: What are you doing? Why are you doing that? Why are you looking there? Are you looking for something? These questions were to get participants to elaborate on their actions. Along with the questions, I would note the actions or directions participants would choose to pursue, which they would sometimes voice to the person accompanying them. I noted what information they saw and heard. I also mapped out the course the participants took around the museum on my own map which helped me recall what participants did during the visit and allowed me to compare the layouts for each person afterwards when analyzing data.

\subsubsection{After Observation}

After the museum visit, participants would tell me when they were done looking around which ranged between 45-60 minutes. Afterwards, I asked a few more questions such 
as: What did you think of the wayfinding? Did you need to use the map? What helped you remember or find where you were located in the space? Did you find the signs helpful? Did you feel like you were lost? Was it easy to navigate around? Were there any issues while you went around the exhibit? Upon reflection, after having conducted observations with half of the participants, I revised my questions as some of the previous ones were leading and specific to certain elements or yes/no questions. Therefore, I altered the questions to be broader. I then asked questions such as: What did you think of the signs? How did you orient yourself in the space? What did you think of the map? How do you feel about your sense of direction? Tell me about navigating through the museum? The answers were recorded using an audio recorder to document the information for analysis. As debriefing questions were adjusted, there is the possibility that results were changed or affected. From the data I collected I do not believe there was any effect to the results. The initial questions may have been leading but I believe they were also more direct and clearer in terms of understanding what I was asking participants.

\subsubsection{Analysis}

A preliminary affinity diagram was created for each participant's narrative using sticky notes. This first step involved extracting all the information from the observation into singular units of data with each colour below representing one participant's observation session (Figure 6 \& 7). 

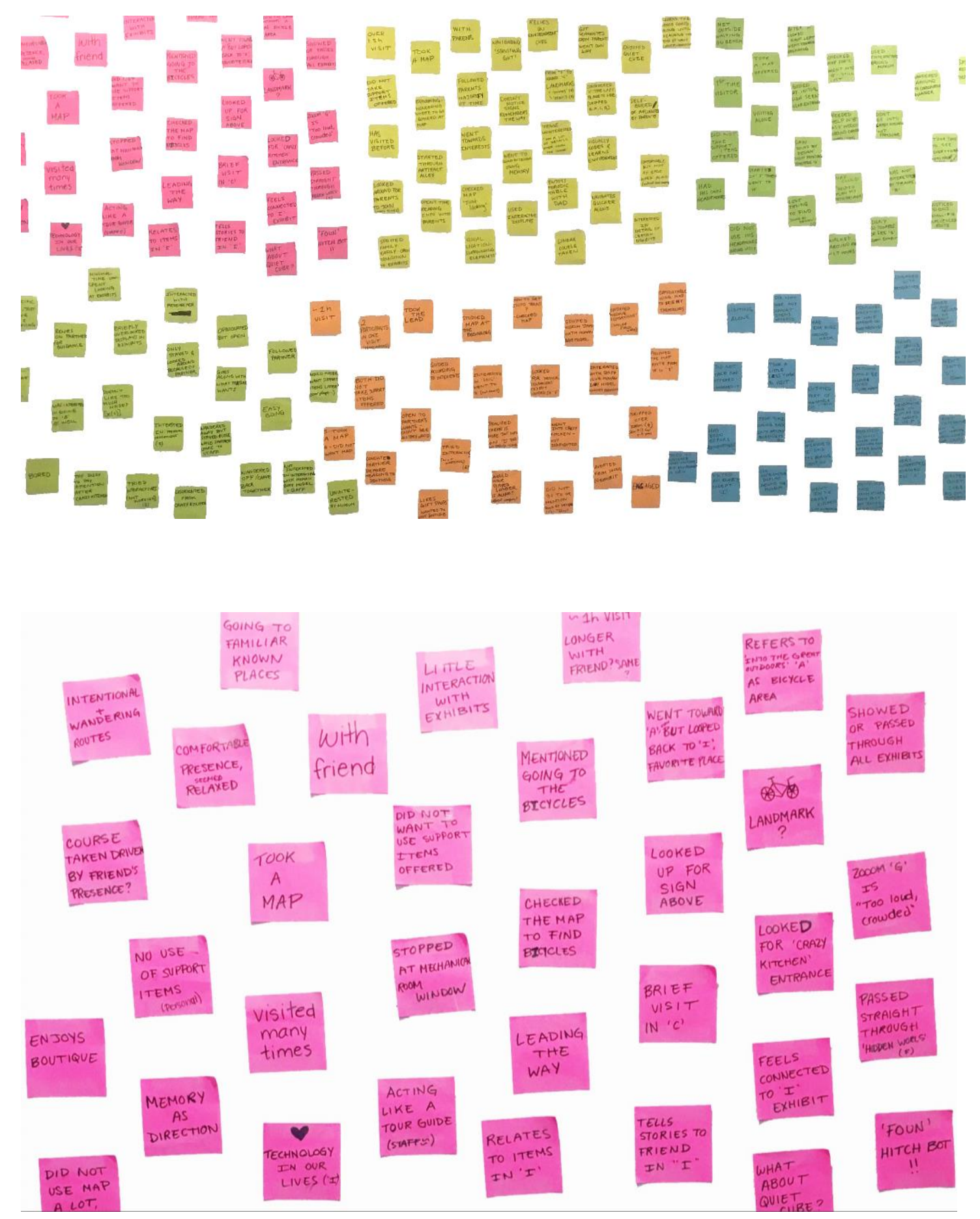

Figure 6 \& 7: Example of preliminary affinity diagram of observation sessions and a close up of a portion of the affinity diagram clustering one participant's session. 
For the behavioural analysis, I sketched each of the participants' trajectories from the start of their visit to the end (Figure 8 ) in real-time during the observations, which allowed me to later take my drawings into Adobe Illustrator to refine the maps and assign a colour to each participant. I then combined all the participant maps to highlight high and low traffic areas of the museum, similarities, and differences.

Finally, in de-briefing participants after the observation, I transcribed their responses to a digital document, highlighting information of potential relevance to wayfinding and used in vivo coding to manually analyze and categorize the data. A table was then created to capture this analysis in one document.

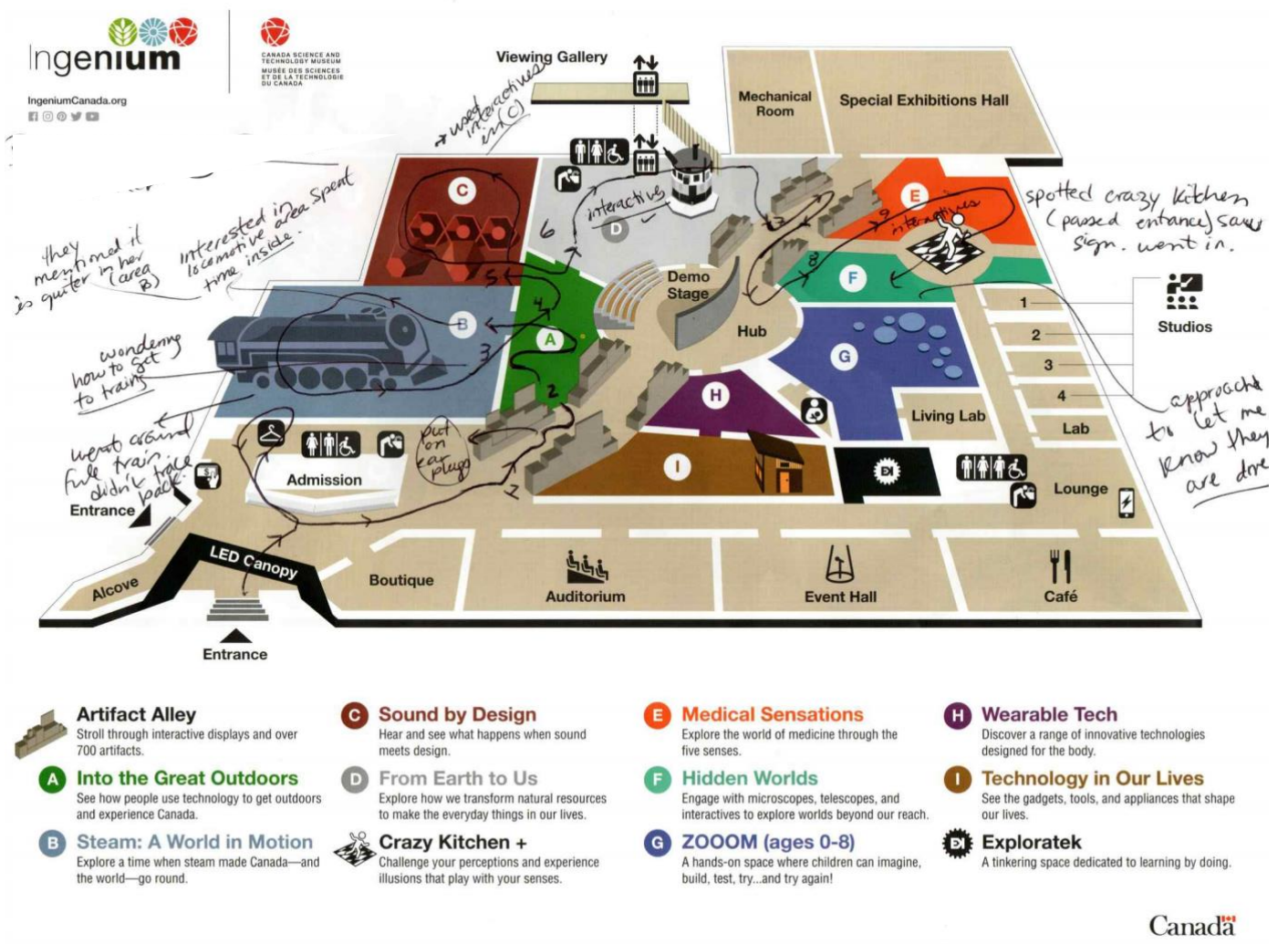

Figure 8: Example of a map sketch conducted on site of a participant's visit. 


\subsection{Method 3 - Workshop}

The workshop was used to develop a better understanding of what sensory aspects as well as potential wayfinding aspects participants may pay attention to, prefer or avoid/not prefer in their everyday life and in a museum setting. Additionally, by having participants map out their museum journey visually, this could help them recall aspects they experienced and discuss them upon reflection. The rationale for conducting this method after the observation method was to help facilitate a deeper connection for participants between methods, as their visit to the museum and experience was recent in their minds and could perhaps make the activities easier to complete.

Before conducting the workshop, I conducted a pilot test with four people. While starting to design the process, I realized that it would present difficulties to manage more than one participant at a time, since initially, I was going to do the workshop with upwards of three participants. Having more than one participant would require that I pay attention to each participant and facilitate as they went through the activity which would defeat the purpose of observing their actions and asking questions during the activities. Therefore, the method was adjusted so that one participant would perform the workshop at a time, starting by card sorting and then completing a journey map. As the workshop conducted was activity-based and participants discussed their work while interacting with objects, the initial decision of referring to this as a workshop remained.

The workshop sessions were recorded to later analyze the data and recall the events that occurred. They ranged from 60-90 minute sessions. Participants were given 
refreshments and snacks during the activities and received a family pass to the museum for their participation.

\subsubsection{Card Sorting}

The first task involved having participants sort a deck of 42 picture cards into three piles: Like (seek), Dislike (avoid), and OK (see Appendix F, section F.1 \& F.2). These cards were selected from a set of 75 cards from the Kingwood Sensory Preference Cards titled What Do You Like? These cards were selected as they are used with adults with ASD, and of the total 75 cards, 42 of them were more closely related to museum environments.

The first round of this activity was to be organized under the category 'Daily Life', whereas the second round was organized under the category 'Canada Science and Technology Museum' and a set of 26 new cards were introduced to the original 42 cards, which were specific to the museum in terms of exhibits and wayfinding totalling 68 cards to sort. I designed these additional cards to best resemble the Kingwood Sensory Preference Cards by printing them on a thick cardstock, making them the same size, rounding the corners so they match up when stacked together, and giving each card a short descriptive title. These two categories were selected as I anticipated there may be a possibility that cards could be sorted differently from one category to the other. For example, what participants consider comfortable in a home environment may be different than what they consider acceptable in another environment. In doing the activity, participants would also get the chance to describe why certain cards may be 
sorted differently which I anticipate may contribute to addressing the research questions.

\subsubsection{Journey Map}

The second task was to have participants create a journey map or storyboard of a visit to the museum. This could represent a past experience, their visit from the observation, or a future visit (depicting how they would visit the museum next time). I presented participants with an enlarged map (11"x17") of the CSTM placed in the middle of a large piece of brown paper, with a set of 24 cards I designed comprising of each exhibit in the museum as well as other elements like the parking lot, pay station, water fountain, cafeteria, seating area, etc. (see Appendix F, section F. 4). In addition, participants were given writing and drawing tools, blank pre-cut paper squares, and sticky notes. They were asked to relate their experience going to the museum from the point of arrival until the end of their visit on the large brown paper with the museum map and could draw freely on it. They had the liberty to use the pre-made cards available and add places or steps to the journey with the tools available to create a journey map.

\subsubsection{Adjustments}

Prior to the first workshop, I discussed the activities with a subject matter expert (a counsellor for clients with ASD). The expert recommended omitting the 'OK' category as this might present a section of uncertainty or a place to possibly sort many of the cards as participants would not have to decide whether the card belongs in the 'Like' or 'Dislike' pile according to their preferences. Also, the expert proposed that in the second 
round of card sorting, the museum specific cards should be sorted first following the initial 42 cards as participants could find the transition of categories going from 'Daily Life' to 'Canada Science and Technology Museum' unclear or repetitive without having a clear distinction to differentiate the two. These suggestions were taken into consideration and applied to the workshop that was about to take place and all the workshops that followed. However, as participants completed the card sorting activity, they were inclined to create an 'OK' pile. Therefore, it was accepted if they wished to do so.

\subsubsection{Participants}

There was a total of 10 participants recruited for the workshop. They ranged from 18-28 years of age, with eight male participants and two female participants. As mentioned, recruitment was done through the higher education institution's Disability Services Offices as well as a community-based consultancy. Participants were asked if they were interested in participating in the workshop after having completed the observation. Fortunately, all participants who took part in the observation session, participated in the workshop. At first, participants that attended the observation study were asked to come back for the workshop on another day, if they consented to do so, and return to the museum a second time. After conducting two observations, I realized it would be more beneficial to combine both the observation and workshop in one day. This alleviated preparation work for both sessions and would also mean that participants only had to travel once to complete my studies. 
In addition to having participants with ASD involved in the workshop, experts (e.g. counsellors) were recruited for their knowledge and experience with persons on the spectrum so they could comment during the workshop or assist with asking questions. In the first workshop, there was an expert present but there was little to no input from the expert or interaction as the session progressed without the need for their comments or assistance. The study was adjusted so that experts were not required at each session and this adjustment also eliminated the difficulties of coordinating a participant's schedule with the subject matter expert's schedule for several workshop sessions.

\subsubsection{Analysis}

To analyze the data, I organized the participants' card sorting activity (first and second round) in a table totalling how many people sorted each picture card under the 'Like; and 'Dislike' pile. Interestingly, almost all participants created a middle 'OK' pile. Although the initial 'OK' pile was deliberately omitted from the design of the activity, participants had the choice to create this pile without any objection. The majority felt it was necessary because some cards depended on context and could fall under either the 'Like' or 'Dislike' pile, and therefore, some cards might be placed under 'OK' since they were conditional. Then, in listening back to the recordings of the workshop sessions, manual in vivo coding was used once more to get a better sense of why they may have sorted each card under the 'Like', 'Dislike', or 'OK' pile. 
The journey map of each participant was photographed and organized into a comparison chart enumerating all the places they selected to visit on the map as well as the cards that were not part of their journey. These charts were also compared to the behavioural maps from the observation sessions to see if there were similarities and/or differences. 


\section{$4 \quad$ RESULTS AND ANALYSIS}

This chapter presents the results from each method: 1) survey, 2) observation sessions and 3) workshop sessions. The results start by revealing some general information about participant experience in museums. This is then followed by results which were specific to participant experience at the CSTM, results which reveal the potential influence of explicit wayfinding elements but also less explicit environmental factors on participant experience and navigation (locating, following or discovering a route).

\subsection{Results and Analysis: Method 1 - Survey Questionnaire}

\subsubsection{Close-Ended Survey Questions Results and Analysis}

The following are the results from the survey. The access link was sent through the University's Centre for Students with Disability and a total of 15 participants responded.

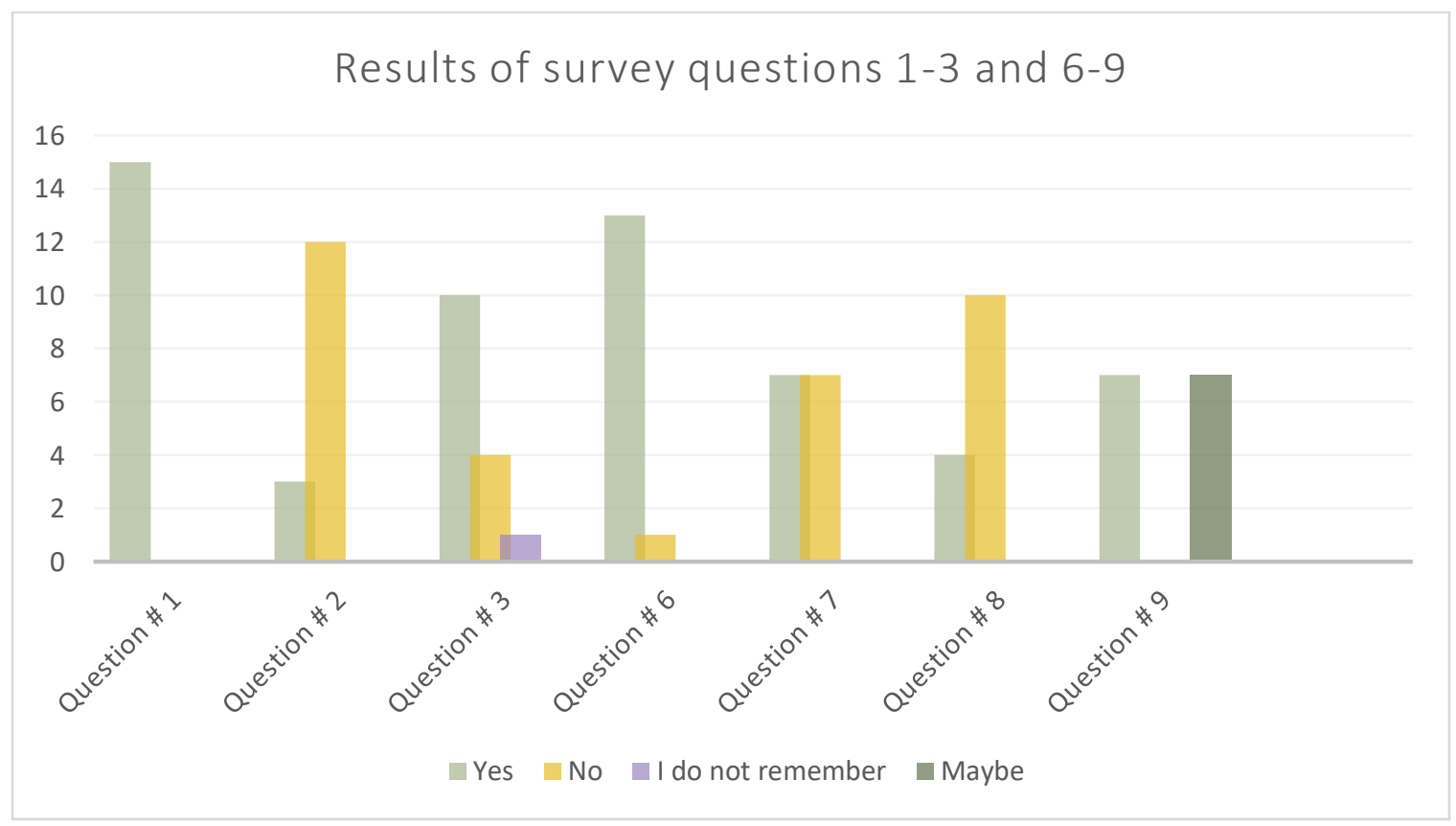


Figure 9: Results for questions:

Q.1 Do you self identify as a person with Autism Spectrum Disorder?

Q.2 Do you have a support person (family member, friend, assistant, etc.) that helps you in your daily life?

Q.3 Have you ever visited the Canada Science and Technology Museum?

Q.6 Have you visited other museums?

Q.7 Did you bring along a support person with you on your visit(s) (e.g. family, friend, etc.)?

Q.8 Did you bring along or use any items or devices that supported your visit?

Q.9 Would you like to visit the Canada Science and Technology Museum (again)?

Participants had to answer 'Yes' to question 1, identifying as a person with ASD in order to continue with the questionnaire. In question 2, participants were asked if they have a support person that helps them in their everyday life. This question was intended to identify the level of independence of the participants and whether they rely on someone. Three of 15 participants answered yes to this question.

Regarding question 4, participants who had previously visited the CSTM were asked how they would rate their most recent visit to the museum on a scale from 1-5. Two participants out of nine selected ' 3 ' describing their visit as 'being engaging'. Six participants out of nine selected ' 4 ' describing their visit as 'being very engaging'. One participant selected ' 5 ' describing their visit as 'being extremely engaging'. This question represents the level of satisfaction experienced by participants during previous visits. 


\section{How would you rate your most recent visit to the Canada Science and Technology Museum on a scale of 1-5? \\ IIII Number of participants}

(5) Extremely engaging

(4) Very Engaging

(3) Engaging

(2) A little engaging

(1) Not engaging at all

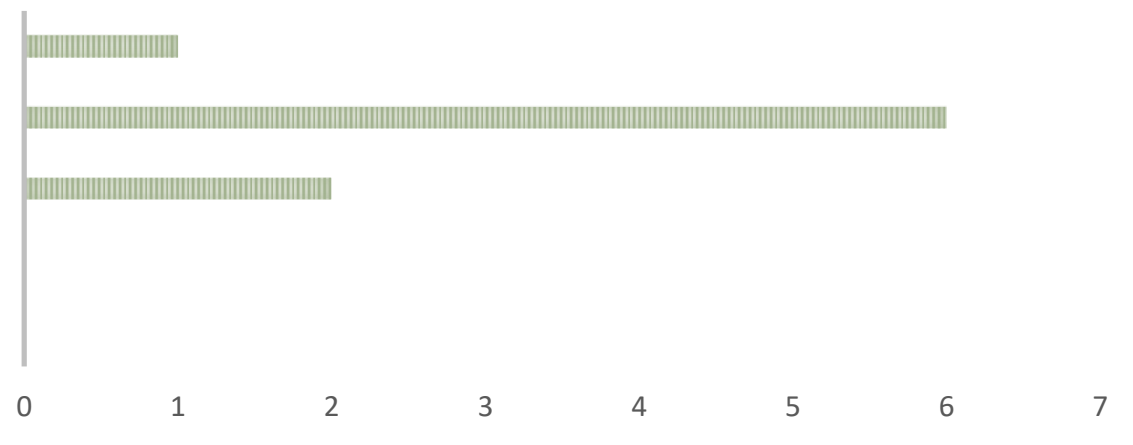

Figure 10: Q.4 How would you rate your most recent visit to the Canada Science and Technology Museum on a scale of 1-5?

In question 5, participants were asked when was the last time they visited the museum (CSTM), and six out of nine participants reported visiting the museum in the past 3 years, and two participants specified visiting during a special exhibit.

When participants were asked if they brought along a support person to the museum in question 7, seven participants out of 14 answered 'Yes, I had a support person (family, friend, etc.) with me'. When asked if they brought along or used items/devices that supported their visit at the museum in question 8 , four participants out of 14 answered 'Yes I had an item(s)/device(s) to help me' and 10 participants answered 'No I did not'. Participants who answered 'yes' were asked to specify what item/device they had: a participant inserted "headphones/ear plugs", another participant inserted "fidget jewelry" and the last participant inserted "spinner ring". Three of four participants who answered 'Yes' to this question did not have a support person with them, and six of the 
seven participants who had a support person (question 7) did not have an item/device to support their visit. Therefore, only four participants who stated they did not have a support person, also stated they did not have a support item with them during their visit.

\section{Participants who had a support person/used a support item} in the same visit to a museum

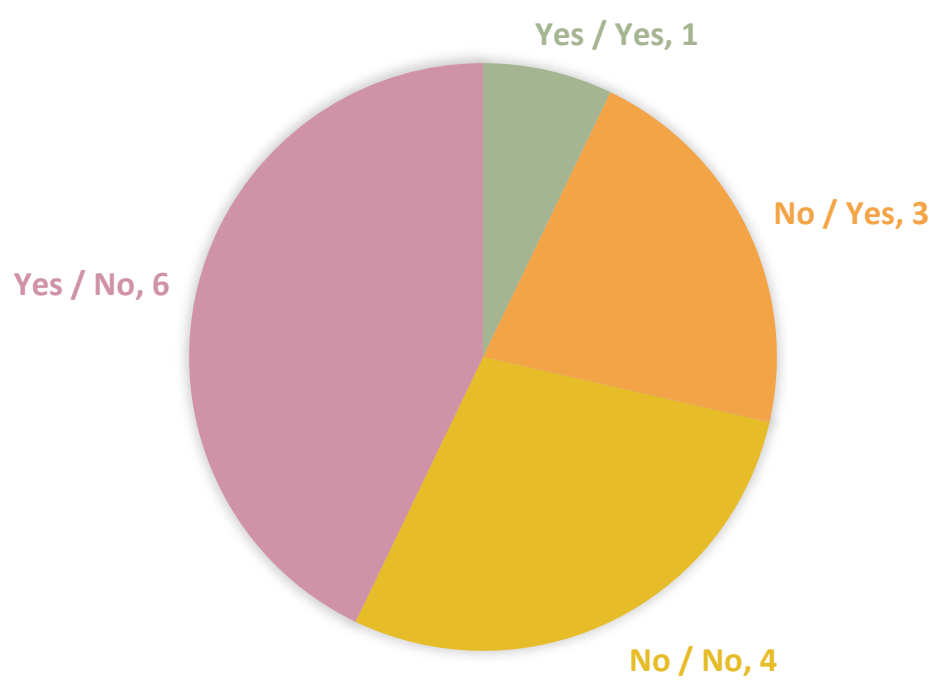

Figure 11: This diagram shows the participants who had or did not have a support person with them compared to whether they had a support item with them.

When asked if they would like to visit the Canada Science and Technology Museum, or visit again, seven participants out of 14 answered 'Yes' and the remaining participants answered 'Maybe'.

\subsubsection{Open-Ended Survey Questions Results and Analysis}

The following two questions were open-ended and were coded to extract potential patterns in participants' responses. These questions were included to give participants 
the opportunity to voice their opinion about what they like or dislike in an exhibit space and comment about their previous museum experiences. This provided additional information from participants that could not otherwise be captured through the closeended questions to help answer the following research question:

\section{What may designers need to pay attention to in order to support future research and design development in museum wayfinding in consideration of ASD?}

\subsubsection{Question 10 - Open-ended Question about Museum Preferences}

In this question participants were asked "If given the chance, what type of museum would you love to visit and/or invent? Think about what would be an ideal space for you to be most comfortable in when navigating new surroundings." 10 participants answered this question.

Participants mentioned types of museums they would like according to their interests such as a: "Museum for Engineering", "Museum of Anthropology", Museum of "Aerospace Feats and Achievements"; and a Museum of "Set Design and Props". Five responses mentioned that a quieter space is needed noting for example "...as a dozen excited kids all screaming their heads [off] can be unpleasant..." and "noise from other attendants is a personal problem". Also, regarding the design of the environment, participants mentioned having "...open space to limit crowding...",

“...hallways...should...be distinguishable...through dimensions, furniture, or even a line 
of sight that reaches the next room", and "...a linear design, so as to have a sense of progression".

The responses were organized into a table and passages of relevance to wayfinding were highlighted in a different font colour. This was the first cycle of coding where in vivo codes (Saldana, 2016) or codes that actually capture people's voices were applied to the data. A second cycle of coding was completed to sort the codes into potential patterns or categories, in order to highlight the key information revealed in this part of the study.

The categories that were developed from the second cycle of coding are presented in Table 1.

\begin{tabular}{|c|c|}
\hline Categories that relate to wayfinding & In Vivo Codes \\
\hline Impact of Noise & $\begin{array}{l}\text { - } \text { Sound suppression } \\
\text { - } \text { Quieter } \\
\text { - Noise level }\end{array}$ \\
\hline Impact of Lighting & $\begin{array}{l}\text { - Well lit } \\
\text { - } \quad \text { Darkness }\end{array}$ \\
\hline Impact of User Experience/Interaction Design & $\begin{array}{l}\text { - Interactive exhibits } \\
\text { - Interact with }\end{array}$ \\
\hline Impact of Layout/spatial Organization & $\begin{array}{l}\text { - } \text { Radial floor plan } \\
\text { - Easy access } \\
\text { - Open concept } \\
\text { - Signs are helpful } \\
\text { - Enjoy getting lost } \\
\text { - Separate rooms } \\
\text { - Open space } \\
\text { - Open and linear } \\
\text { - Linear design } \\
\text { - Progression }\end{array}$ \\
\hline
\end{tabular}

Table 1: Second cycle of coding of Question \# 10 


\subsubsection{Question 11 - Open-ended Question about Museum Comments and Experience}

In Question 11, participants were asked to comment on any other relevant information or story that they would like to share about their experience visiting museums.

Four participants answered this question. Here participants discussed their experiences at the CSTM as well as at the National Art Gallery, and the Museum of Nature in answering this question. There were recurring comments that were found among the responses. A few comments mentioned that at the CSTM "they had virtually no sound dampeners in place (apart from the exhibit on silence)" and "the main area was loud mainly because of children's groups. The special exhibit was in a separate part with less people, so it was quieter...I spent most of my time in there". Others mentioned that the Museum of Nature "is somewhat ornate, but you only really take notice when inside the lobby. The exhibits still get your undivided attention" and at the National Art Gallery, "[it is] very minimalist, and the art draws your attention by being void of sorts. There are spots there where the art gallery asserts its own identity, with tall walkways and rooms, complete with plants and large windows, as well as a handful of pieces, which complement and add to its calm, restful character".

Responses to this question were also organized into a table and relevant passages were highlighted in a different font colour to develop in vivo codes as previously mentioned in 4.1.2.1 (see Appendix D, sections D.1 \& D.2). After the first cycle of coding, a second cycle of coding was completed to sort the codes into categories, in an effort to synthesize patterns or information of relevance to wayfinding. 
Below is the second cycle of coding organized into categories presented in Table 2.

\begin{tabular}{|c|c|}
\hline Categories that relate to wayfinding & In Vivo Codes \\
\hline Impact of Sound & $\begin{array}{l}\text { - } \text { No sound dampeners } \\
\text { - } \text { Discomfort } \\
\text { - Hearing sensitivities } \\
\text { - Loud } \\
\text { - Quieter }\end{array}$ \\
\hline Impact of Layout/Spatial Organization & $\begin{array}{l}\text { - Separate part } \\
\text { - } \text { Spent most time in there } \\
\text { [special exhibit] } \\
\text { - } \text { Explore more of the } \\
\text { museum rather then just the } \\
\text { quiet areas } \\
\text { - } \quad \text { Crowded }\end{array}$ \\
\hline Impact of Environment & $\begin{array}{l}\text { - } \text { [Architecture] should not } \\
\text { distract from it [exhibit } \\
\text { subject matter] } \\
\text { - The exhibits still get your } \\
\text { undivided attention } \\
\text { - Minimalist [environment] } \\
\text { [exhibits that are crowded } \\
\text { are] too stimulating }\end{array}$ \\
\hline
\end{tabular}

Table 2: Second cycle of coding for Question \# 11

The following figure shows categories of participant preferences (what participants expressed liking or choosing to do); participant concerns (what participants expressed not liking or avoiding); the possible influence of interaction design/the interactivity of exhibits on their experience; and finally, wayfinding and/or design elements that participants discussed. The categories summarize the responses from the open-ended questions from the survey. Some relevant excerpts from participants are also reported along with the associated in vivo codes. Overall, the findings show a recurring concern 
about sound at museums, and that participants appreciate a calm minimalist environment with a linear progression, general openness and/or open sight lines to other exhibits. Also, a concern for crowding was mentioned which may cause overstimulation and inhibit the view of artifacts and descriptions. These are important aspects to consider in wayfinding design. Having access to target populations that may not be represented in current standards and guidelines gives us the opportunity to hear their voices and consider these preferences or concerns in future designs.

\section{Research Question 4}

"What may designers need to pay attention to in order to support future research and design development in museum wayfinding in consideration of ASD?"

\begin{tabular}{|c|c|c|c|}
\hline \multicolumn{4}{|c|}{ Categories } \\
\hline $\begin{array}{c}\text { Visitor } \\
\text { Preferences }\end{array}$ & Visitor Concerns & $\begin{array}{l}\text { Influence of } \\
\text { interaction } \\
\text { design on UX }\end{array}$ & $\begin{array}{c}\text { Acknowledge- } \\
\text { ment of best } \\
\text { practice }\end{array}$ \\
\hline \multicolumn{4}{|c|}{ Associated In Vivo Codes } \\
\hline $\begin{array}{l}\text { Quieter } \\
\text { Minimalist } \\
\text { Calm } \\
\text { Restful } \\
\text { Open space }\end{array}$ & $\begin{array}{l}\text { Crowded } \\
\text { No sound dampeners } \\
\text { Discomfort } \\
\text { Hearing sensitivities } \\
\text { Loud }\end{array}$ & $\begin{array}{l}\text { Too stimulating } \\
\text { Interactive - } \\
\text { exhibits }\end{array}$ & $\begin{array}{l}\text { Well lit } \\
\text { Signs } \\
\text { Easy access }\end{array}$ \\
\hline
\end{tabular}




\section{Excerpts from Participants}

P5 "...it was quieter and I couldn't hear much from the rest of the museum. I spent most of my time in there [special exhibit]."

P14 "...there are exhibits that are quite crowded and I tend to avoid those..."

P2 "...they had virtually no sound dampeners in place..."

P7 "A space with a lot to interact with, such as the sound section of the new museum."

P10 "Signs are always helpful."

P10 "I believe that having exhibits extending out from a central area is often a better use of space, as it allows for easy access to all parts of the museum."

Figure 12: Analysis of the open-ended responses from the survey.

\subsection{Results and Analysis: Method 2-Observations}

\subsubsection{Museum Visit Observation Results}

\subsubsection{Museum Visit Observations Behavioural Mapping}

A total of 10 participants took part in the observation, where one visit included two participants. Before starting every observation session, I would offer participants the choice of using support items, such as ear plugs, a squeeze toy, as well as a map of the museum. During every visit I would ask for two maps at the front desk, one for me and one for the participant should they want to use one during their visit as maps were not publicly available throughout the facility. 


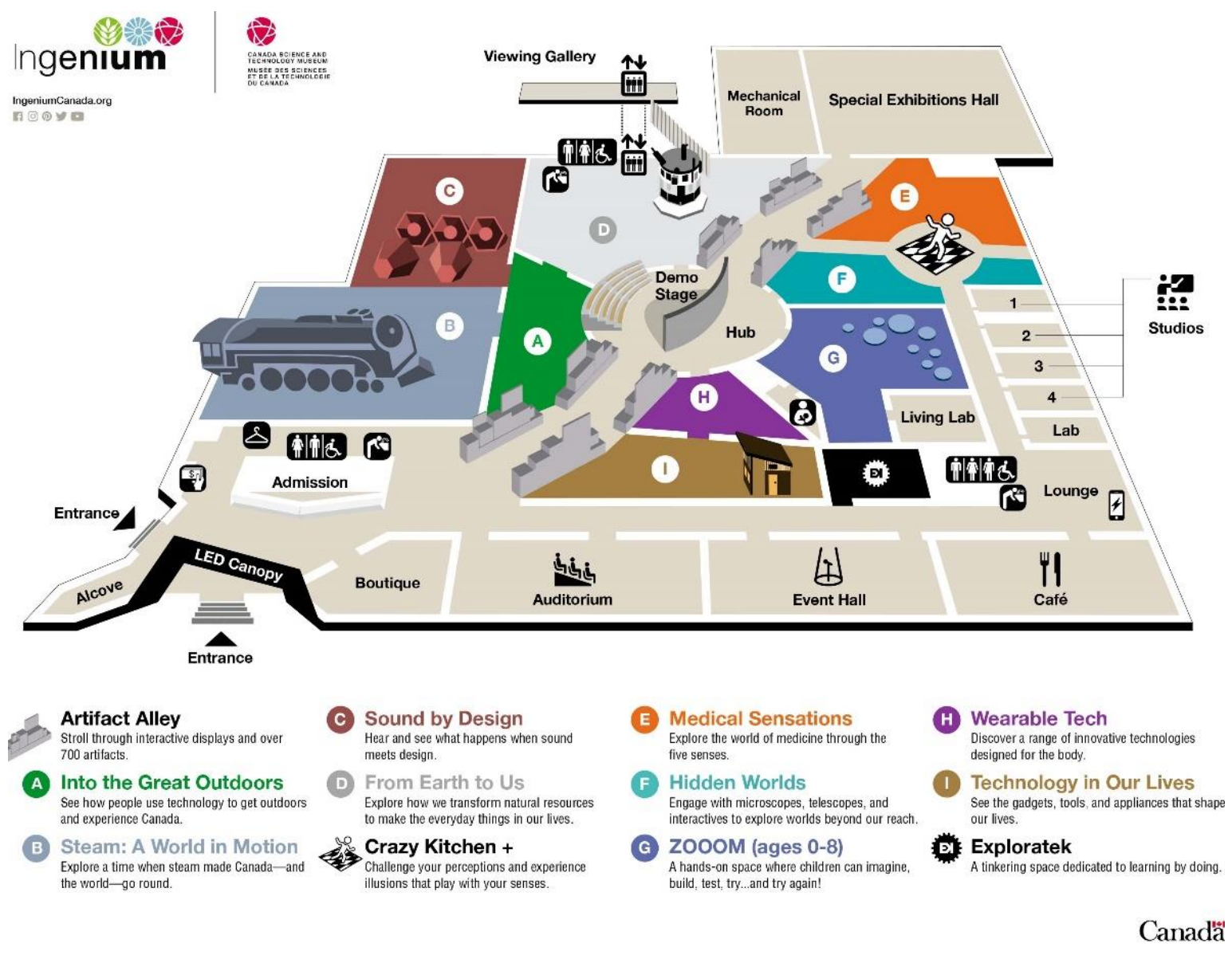

Figure 13: Map of the Canada Science and Technology Museum

The following figures illustrate each participant's navigation behaviour. This exercise helped me remember the trajectory taken by each participant and I was able to write down my observations according to where we (the participant and I) were according to the map. This helped me track comments or interactions related to navigation such as if the participant mentioned they were wondering how to get to section $\mathrm{C}$ - Sound by Design, or if they asked the staff about any special exhibits that may be going on or coming up. Additionally, having digitally recorded these behavioural maps allowed me 
to superimpose them and easily compare the most visited areas and the least visited areas in the museum.

P1

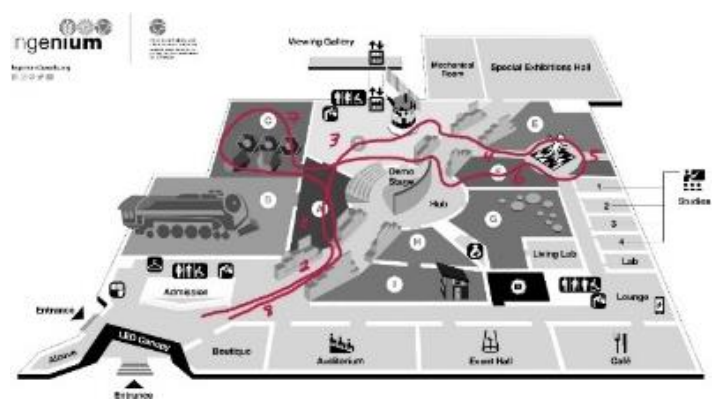

P3

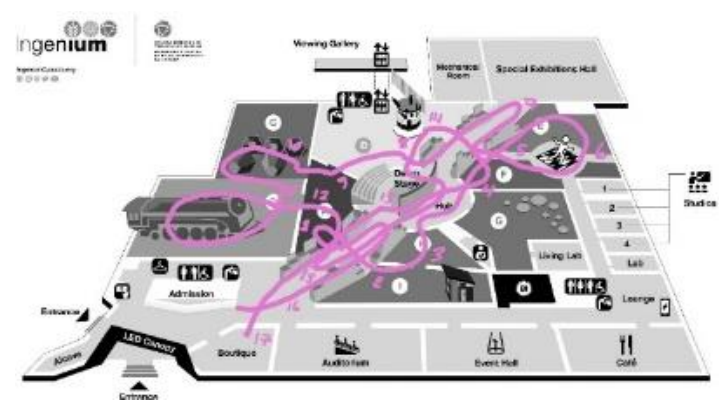

P6

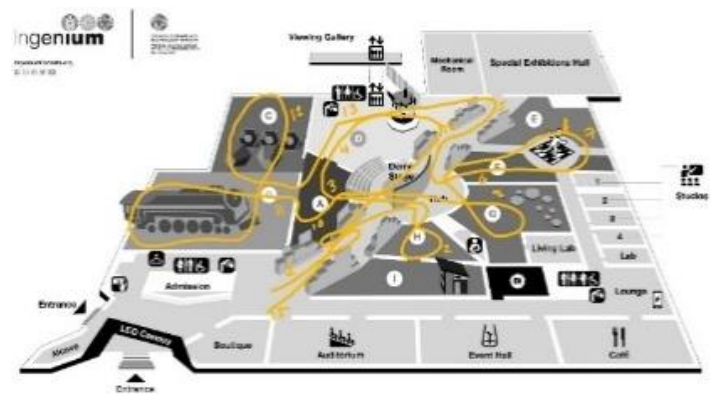

P2

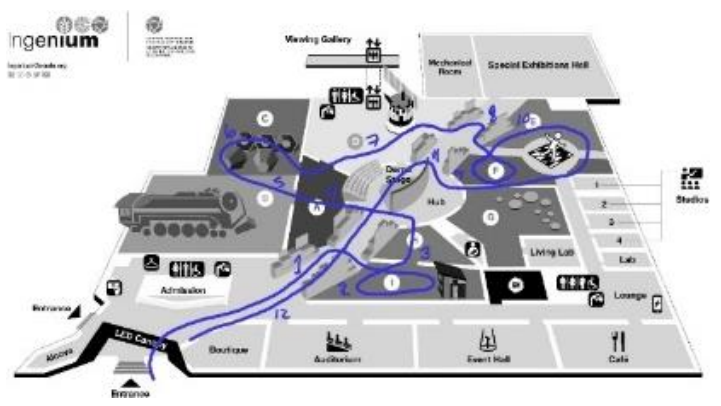

P4 \& P5

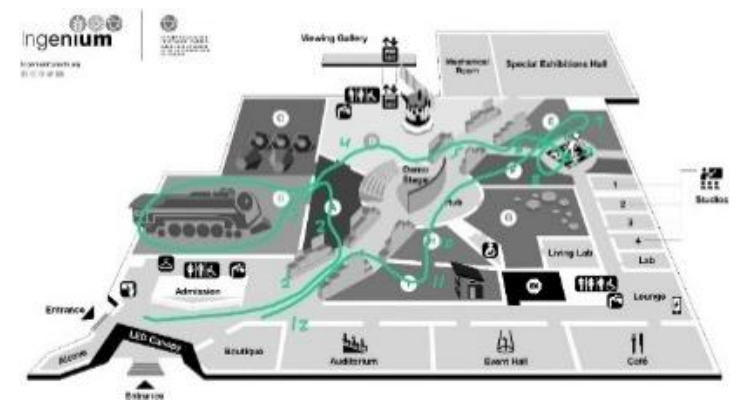

P7

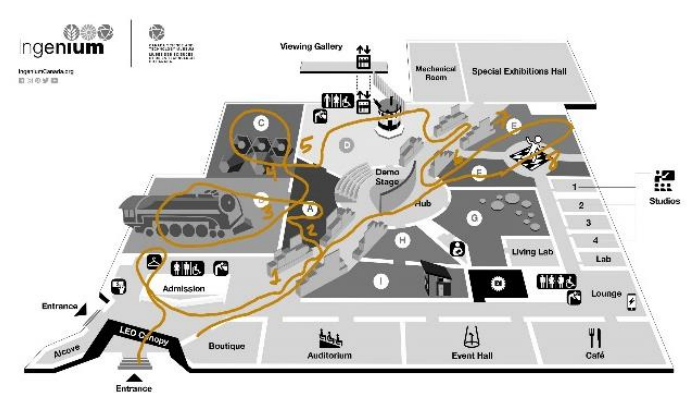


P8

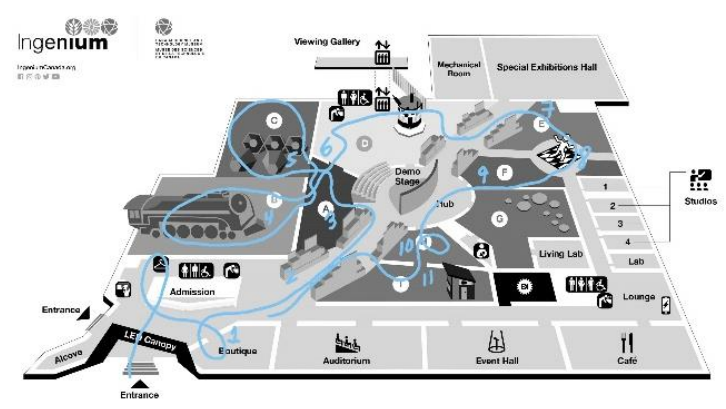

P9

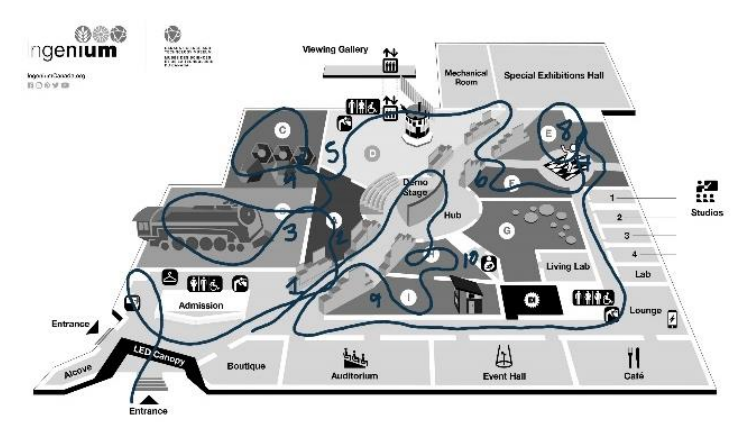

P10

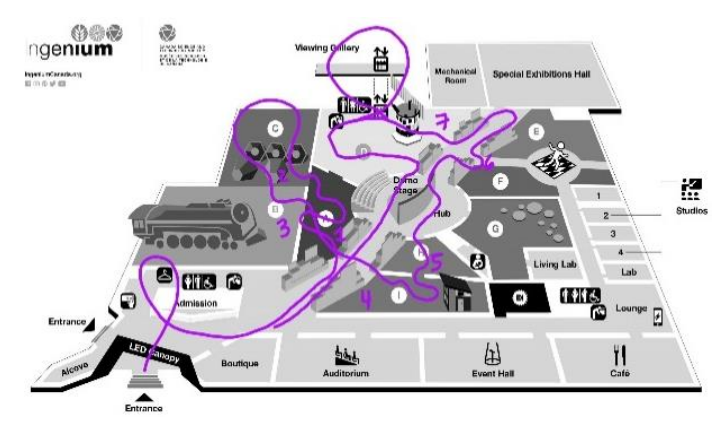

Figure 14: Illustration of behavioural map sketches of the 10 participants' movement through the museum.

This figure (Figure 14) illustrates the paths that each participant took at the CSTM, of which, one visit (P4 \& P5) included two participants. This map shows the areas that were most frequented by participants and the areas that were least frequented which may be related to preference, sensory aspects, interest, time allowance, or the fact that the area may have gone unnoticed and therefore was skipped during the visit. The main point of entrance at the CSTM brings visitors into Artifact Alley, a central hallway through the museum, and therefore, all nine observation visits went through this part of the exhibit. Another high traffic area where all visitors explored was area D - From Earth 
to Us, although some participants simply went through this exhibit as an access point to the next place they would visit. Seven of the visits included area $\mathrm{H}$ - Hidden Worlds. Seven visits also included the Crazy Kitchen, the only two participants that did not go into the Crazy Kitchen had not visited the CSTM before. Only one participant visited area G - Zooom. This participant did not take a map at the start of the activity. Of the seven participants that took the map, five used the map to guide them away from G - Zooom as it indicates ages $0-8$ beside the title of the exhibit. Also, only one participant went up the stairs to the Viewing Gallery which gives people an overview of the museum from a higher vantage point, but also brings employees to their office area. It is uncertain, but the corporate or commercial design of the Viewing Gallery may discourage visitors from experiencing this vantage point which gives a visual overview of the majority of the exhibits form above. The 'design language' used in this area may inadvertently give visitors cues that they are not supposed to have access to this zone. Finally, no participants visited Exploratek which is located in a hallway apart from the main exhibits. However, one participant did find themselves going through that hallway and looped around to get into area I - Technology in Our Lives.

The figure below (Figure 15) depicts the nine different trajectories taken by the participants on one map. Figure 16 is an illustration that highlights the most frequented and least frequented areas visited. High traffic areas (with eight or more visitors) consisted of Artifact Alley, exhibits A - Into the Great outdoors, B - Steam: A World in Motion, C - Sound by Design, D - From Earth to Us, E - Medical Sensations, and F Hidden Worlds. These areas included major entrance points to the museum, high 
interactive/sensory zones, high colour impact environments, and a way to reach

another area in the museum. The lower traffic areas (with six or less visitors) included

exhibits G - Zooom and I - Technology in Our Lives, as well as the Viewing Gallery and

Exploratek. These areas were either designated as a young zone, uninviting or unclear to participants, and/or not in the visitor's line of sight.

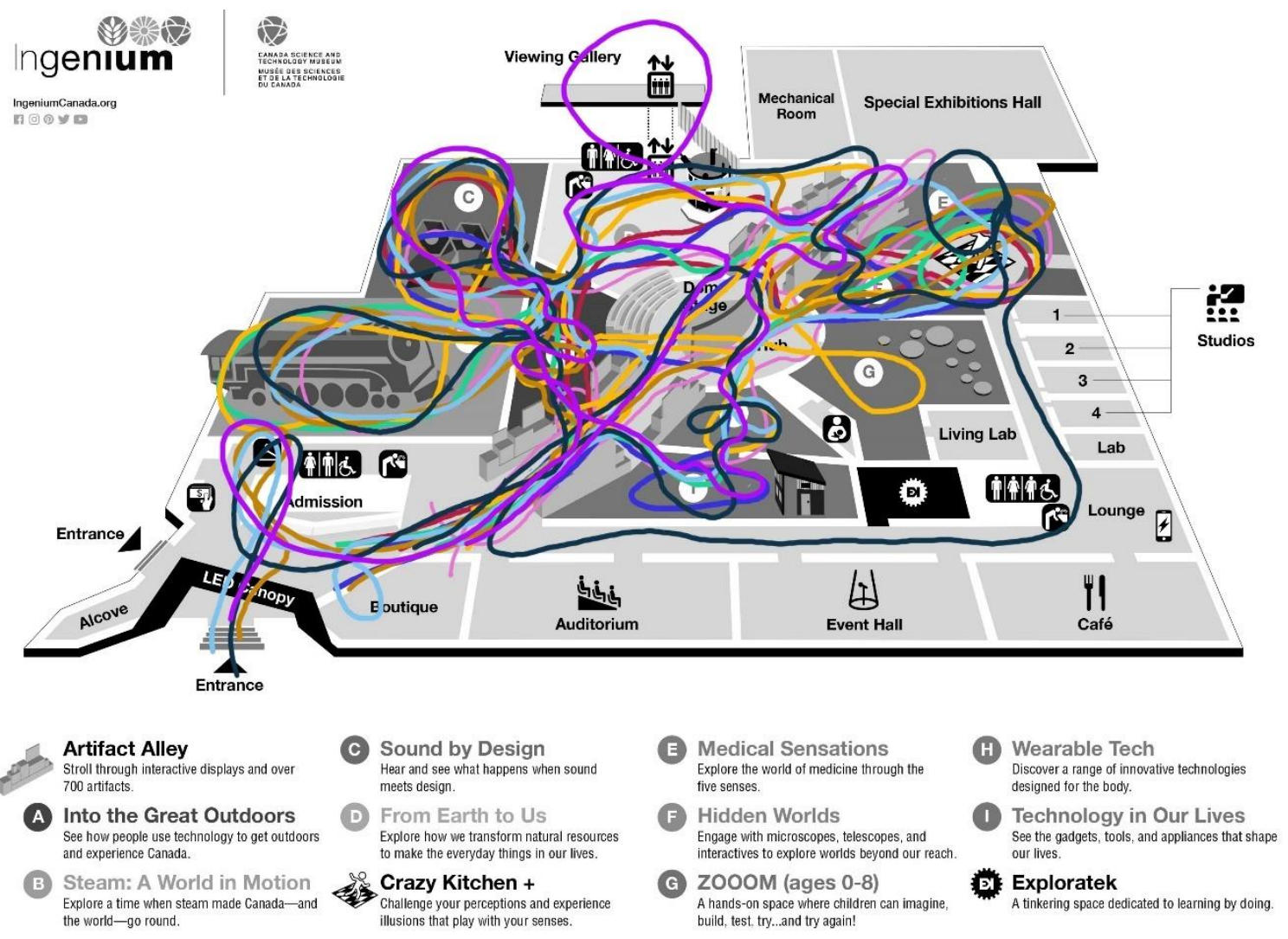

Canadằ

Figure 15: A representation of all the trajectories taken by 10 participants visiting the CSTM for a total of nine visits. 


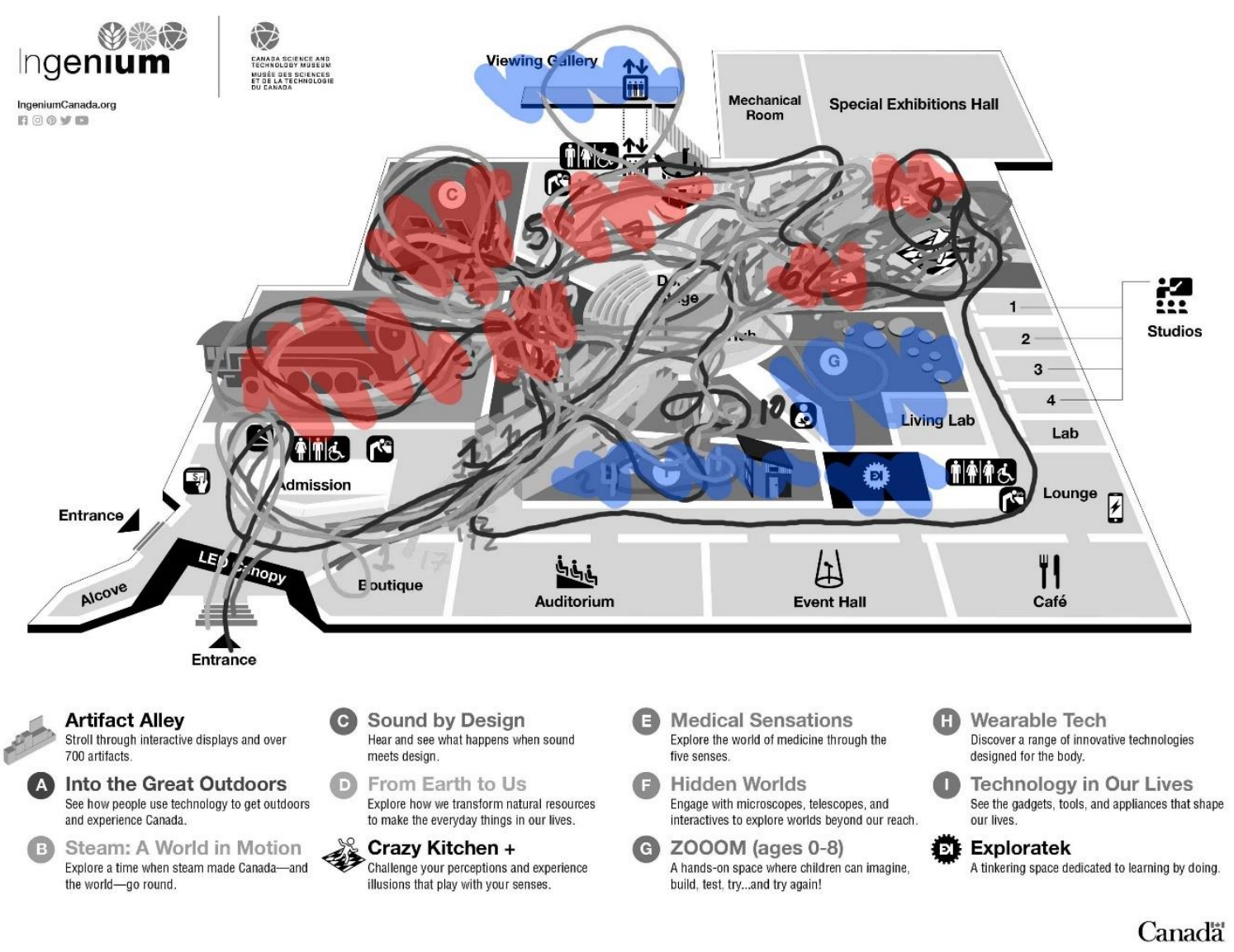

Figure 16: A representation of the high traffic areas in red and the low traffic areas in blue.

Other aspects that influenced participant journeys were whether they were accompanied by someone. For example, one of the participants that came with their parents initially followed their cues and direction. The spacious layout and design allowed for them to have a clear visual of their parents most of the time while in other exhibits they got separated due to higher walls and partitions. Another participant that visited with their friend acted as a guide throughout the CSTM showing their friend around while also enjoying the exhibits themselves. Further, once the participant (P3) and their friend arrived at an area, they looked up to a sign and said it is "not helpful" 
and continued finding their way from memory. Similarly, two other participants were accompanied by a family member who guided the visit a little and supported the participant.

Participants who visited on their own would sometimes express things out loud as I was around observing. For example, one participant (P9) mentioned how it is "kind of dark" while in area $B$ - Steam: $A$ World in Motion as it is a dim environment housing the locomotives. Another (P6) said "so that's where the music came from" when approaching area $\mathrm{C}-$ Sound by Design and realizing it is the sound exhibit. Another participant (P10) said "thank goodness for this map, it feels like I'm cheating" when taking a look at the map to find their way out of an exhibit.

\subsubsection{Results from the Observation Debriefing}

After completing the museum visit, I debriefed participants about their experience by asking a few questions. The following table shows categories of participant preferences (what participants expressed liking or choosing to do); participant concerns (what participants expressed not liking or avoiding); the possible influence of interaction design/the interactivity of exhibits on their experience; and finally, wayfinding and/or design elements that participants discussed. The categories summarize the responses from the debriefing sessions. Some relevant excerpts from participants are also reported along with the associated in vivo codes.

There were no in vivo codes in the debriefing sessions associated to the influence of interaction design on the user experience, therefore that category is blank. Overall, the 
findings from this activity revealed that participants appreciate wandering around the museum freely, relying on their memory and personal interests to guide them. However, six participants remarked that when relying on wayfinding elements to help them find their way, that there was not enough information present even though participants noticed signage and sometimes used the map. The wayfinding was described by a couple participants as confusing, commenting that the map was not translating visual accuracy. Participants recommended the use of directional arrows placed on the ground and having more obvious signage that clearly indicates how to exit or get to another area. These findings further underline the need to work with target populations during the design process which gives the opportunity to hear their voices and further study or implement suggestions which may improve the wayfinding experience. 


\section{Research Questions 2 \& 3}

"Do participants use the current wayfinding system? And if so, how?"

"What does wayfinding at the museum, and environmental elements potentially related to wayfinding, mean to participants?"








\section{Excerpts from Participants}

P1 "... f follow the same road and connect the angles, now I know where I am."

P3 "I'm the kind of person who would generally just wander..."

P5 "There were some points where it was easier for me to rely on memory of how I got to a location [rather than using the map] ..."

P2 "...even when I was pointed in the right direction I wasn't sure I was going in the right direction."

P3 "It can be a little frustrating that things don't transition smoothly and you don't know what is part of what exhibit."

P8 "...it was just really dark..."

P3 "...for the most part the exhibits I went to were kind of on a linear path so I was able to go from point a to point $b$ using the signs and even when I took a weird path I was able to course correct and find where I needed to go."

P2 "...when you're in a place where's there's [multiple] exhibits having... a thing that points out from the ceiling [overhead sign] ...helped..."

P3 "...the map has all these wonderful colours on it but the floors... the walls... or all the signage don't match correspondingly to the map [colours]..."

P5 "...there was not signs within an area about how to get out of an area..."

P5 "...the museum is designed that it has that central corridor, once you get to there you can go to many of the other exhibits that are directly off that corridor, and that design element did facilitate moving around."

P6 "I would suggest that they put the colour of said section on the floor or arrows pointing to different sections."

P9 "...looking at the map and looking at the colours of the areas and also, its good to have images of what was going on there it gave me a pretty good idea of where I was..."

P10 "...if the signage it not plentiful and big and honking obvious I just get lost all the time."

Figure 17: Data analysis of the ten debriefing interviews following the observation sessions. 


\subsection{Results and Analysis: Method 3 - Workshop}

A total of 10 participants completed the workshop which ranged between $60-90$

minutes. Each session comprised of a two-part card sorting activity and ended with a journey mapping activity.

\subsubsection{Card Sorting Results}
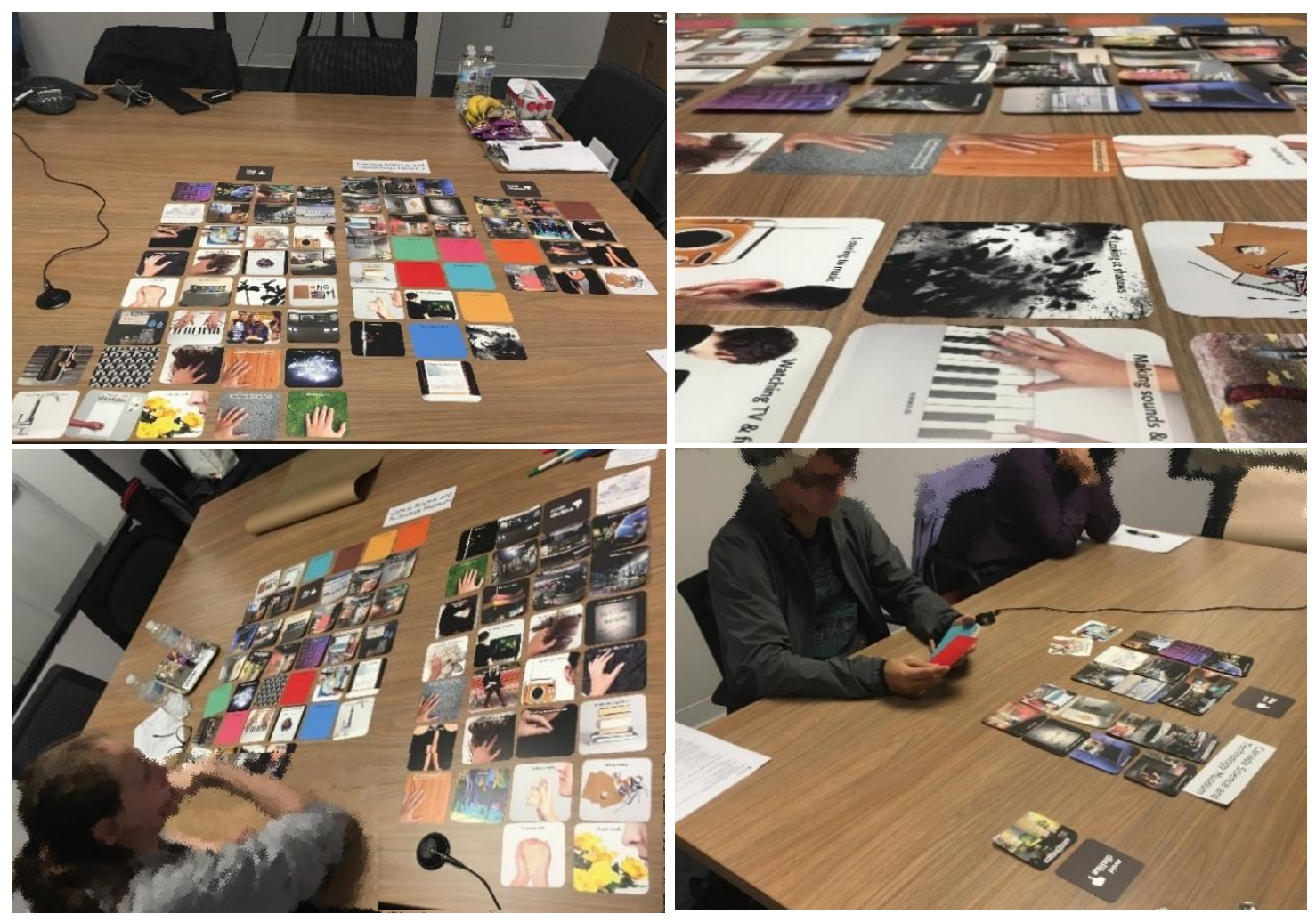

Figure 18-21: (18-19 top left to right, and 20-21 bottom left to right): 18-Card sorting activity sorted by a participant; 19-close up of card sorting images; 20,21-participants performing card sorting activities.

The following table (Table 3) demonstrates how participants organized the picture cards into three piles, namely Like (seek), Dislike (avoid), and OK under the categories of 'Daily Life' followed by the catgeory of 'CSTM'. The numbers represent how many participants placed a card in each section (Like, Dislike) and interestingly, all participants but three 
created their own middle pile that they considered neutral and labeled as the 'OK' section when organizing the picture cards.

Upon starting the card sorting activity, a participant (P8) said "I wish you had a middle [section]". Likewise, another participant (P9) asked, "if I'm impartial to something, I just put it in the middle?". These participants wanted another pile to sort cards under rather than just having the 'Like' or 'Dislike' options to sort. I also asked participants to tell me about the pile they created in between the 'Like' and 'Dislike' piles. The first participant (P1) said “I'm not very sure about this one. It [picture card] might change places...for example, the floral smell [picture card] is just like the perfume smell [picture card], I can't stand the perfume smell but the floral smell sometimes, occasionally [like it] but I can change my mind easily". Another participant (P2) said they "don't really have an opinion" on the cards they placed there. For example, they did not see a "Garbage Station' during their visit, so they placed that card in the middle between the 'Like' and 'Dislike' piles. Additionally, a participant (P7) said they created a middle pile because it is "hard to guess" where to place the cards as they put their hands up in an 'I do not know' motion. Similarly, a participant (P4) said that they created a middle pile when sorting the picture cards because they don't know, or “it really depends...really contextual...or I never thought about it".

This organization can be seen in the pictures above (Figure 18-21). 


\begin{tabular}{|c|c|c|c|c|c|c|}
\hline & \multicolumn{6}{|c|}{ Participant's responses per category and sections } \\
\hline & \multicolumn{3}{|c|}{ DAILY LIFE } & \multicolumn{3}{|c|}{ CSTM } \\
\hline & Like & OK & Dislike & Like & $\mathrm{OK}$ & Dislike \\
\hline Touching hair or fur & 10 & & & 6 & 2 & 2 \\
\hline Listening to music & 10 & & & 6 & & 4 \\
\hline Watching TV \& films & 10 & & & 4 & 1 & 5 \\
\hline Touching wooden surfaces & 9 & 1 & & 7 & 2 & 1 \\
\hline The colour green & 9 & 1 & & 8 & 2 & \\
\hline The colour dark blue & 9 & 1 & & 7 & 3 & \\
\hline The colour light blue & 9 & 1 & & 7 & 3 & \\
\hline Books \& Magazines & 8 & & 2 & 5 & 1 & 4 \\
\hline Spending time in groups & 8 & & 2 & 9 & & 1 \\
\hline Spending time alone & 8 & 1 & 1 & 4 & 1 & 5 \\
\hline Touching silky fabrics & 8 & 1 & 1 & 7 & 1 & 2 \\
\hline Playing board games & 8 & 2 & & 8 & 1 & 1 \\
\hline The colour red & 8 & 1 & 1 & 7 & 2 & 1 \\
\hline Arts \& Crafts & 7 & 1 & 2 & 7 & 1 & 2 \\
\hline Floral smells & 7 & 2 & 1 & 4 & 1 & 5 \\
\hline Bright natural light & 7 & 1 & 2 & 7 & 2 & 1 \\
\hline Looking at twinkling lights & 7 & 2 & 1 & 7 & 1 & 2 \\
\hline Darkness & 7 & 3 & & 4 & 2 & 4 \\
\hline Looking at shadows & 7 & 2 & 1 & 4 & 2 & 4 \\
\hline Looking at shiny surfaces & 7 & 2 & 1 & 8 & 1 & 1 \\
\hline Tidiness and order & 7 & 1 & 2 & 10 & & \\
\hline Touching feathery objects & 7 & 2 & 1 & 5 & 3 & 2 \\
\hline Geometric patterns & 7 & 2 & 1 & 9 & & 1 \\
\hline The colour pink & 7 & 2 & 1 & 5 & 4 & 1 \\
\hline Touching wooly surfaces & 6 & 2 & 2 & 5 & 3 & 2 \\
\hline Active touch & 6 & 2 & 2 & 6 & 2 & 2 \\
\hline Looking at small details & 6 & 1 & 3 & 7 & 1 & 2 \\
\hline Touching grass & 6 & 1 & 3 & 5 & 2 & 3 \\
\hline Making sound \& music & 6 & 2 & 2 & 7 & 2 & 1 \\
\hline Organic patterns & 6 & 2 & 2 & 7 & 1 & 2 \\
\hline Touching sand & 5 & 1 & 4 & 4 & 3 & 3 \\
\hline Touching stone surfaces & 5 & 2 & 3 & 7 & 2 & 1 \\
\hline The colour yellow & 5 & 2 & 3 & 7 & 2 & 1 \\
\hline The colour orange & 5 & 3 & 2 & 8 & 1 & 1 \\
\hline Looking at spinning objects & 4 & 2 & 4 & 6 & 2 & 2 \\
\hline Heights & 4 & 1 & 5 & 6 & 2 & 2 \\
\hline
\end{tabular}




\begin{tabular}{|c|c|c|c|c|c|c|}
\hline Perfume smells & 3 & 1 & 6 & 1 & 3 & 6 \\
\hline Passive touch & 3 & 2 & 5 & 4 & 1 & 5 \\
\hline The colour brown & 3 & 3 & 4 & 5 & 3 & 2 \\
\hline Being untidy & 2 & & 8 & & & 10 \\
\hline Discos & 2 & 2 & 6 & 4 & 1 & 5 \\
\hline Confined spaces & 1 & 1 & 8 & 1 & & 9 \\
\hline Water fountain & & & & 10 & & \\
\hline Staff around the museum & & & & 9 & 1 & \\
\hline Crazy kitchen & & & & 9 & & 1 \\
\hline Seating area & & & & 9 & & 1 \\
\hline Bathroom & & & & 9 & 1 & \\
\hline Quiet cube & & & & 8 & 2 & \\
\hline Colour coded exhibits & & & & 8 & 2 & \\
\hline Artifact alley & & & & 8 & & 2 \\
\hline Wearable tech & & & & 8 & 1 & 1 \\
\hline Front desk reception & & & & 8 & & 2 \\
\hline Garbage station & & & & 8 & & 2 \\
\hline Technology in our lives & & & & 7 & 1 & 2 \\
\hline Open space & & & & 7 & 2 & 1 \\
\hline From earth to us & & & & 7 & 1 & 2 \\
\hline Demonstration area & & & & 7 & 2 & 1 \\
\hline Map & & & & 7 & 1 & 2 \\
\hline Into the great outdoors & & & & 7 & & 3 \\
\hline Sound by design & & & & 7 & & 3 \\
\hline Hidden worlds & & & & 7 & & 3 \\
\hline Exhibit entrance signs & & & & 6 & 2 & 2 \\
\hline Signs on post & & & & 6 & & 4 \\
\hline Steam: a world in motion & & & & 6 & 2 & 2 \\
\hline Interactive display & & & & 6 & & 4 \\
\hline Overhead signs & & & & 5 & 2 & 3 \\
\hline Zooom exhibit & & & & 4 & 2 & 4 \\
\hline Medical sensations & & & & 4 & 2 & 4 \\
\hline
\end{tabular}

Table 3: Data collected from the two rounds of card sorting in the workshop.

As shown, many of the cards were sorted in the 'Like' pile under the 'Daily Life' category. Cards which were liked by eight or more participants include 'Touching hair or 
fur', 'Listening to music', 'Watching TV \& films', 'Touching wooden surfaces', 'The colour green', 'The colour dark blue', 'The colour light blue', 'Books \& Magazines', 'Spending time in groups', 'Spending time alone', 'Touching silky fabrics', 'Playing board games', and 'The colour red'. These elements pertain to wayfinding and museums in different ways whether it be through preferences for specific types of touch (texture), interaction, and colour. Most of the cool colours were liked by six or more participants, while five participants liked the warmer colours orange and yellow, and three participants liked the colour brown. However, the colours orange and yellow were liked by eight and seven participants respectively when sorted under the CSTM category. Participants would say (P10) “Colours don't really bother me", (P9) “I don't have any issue with colour", and (P5) "I don't dislike any colours". One participant (P3) sorting cards according to the 'CSTM' category, placed all the colours in the 'Like' pile "because I am not affected by other people's colour choices, it doesn't offend me. I won't not [go] to an area of the museum because of somebody else's colour choice". On a similar note, another participant (P4) said “I don't think there's any colour that's inappropriate for a museum, it's just a case of does it work with whatever is being displayed".

When sorting the sensory touch cards, a participant (P3) placed the majority in the 'Dislike' pile because of “germs, I don't know who picked their nose, I rather not do it [touch things]". In contrast, another participant (P4) placed most of the touch sensory cards in the 'Like' pile when organizing them according to the CSTM category and said "I'm going to like them more here [CSTM] that I do in general [daily Life]" since they are more inclined to touch and interact with items in a museum environment. 
One participant (P10) talked about their experience in exhibit A and said "I was wondering by and there was a big display case so I just walk up to the first thing I see and read them all [descriptive plaques of artifacts] and then I get to the introduction and I realize I probably should have read the introduction first, except I didn't see [it] first, I saw all the cool stuff and then saw the labels for the cool stuff". The participant wished to have been guided to the introduction before having seen all the things that came after in that section. This would have given a general idea of what the rest of the artifacts and information related to.

When organizing the museum picture cards, the majority (seven or more participants) placed almost all the cards in the 'Like' pile as they either enjoyed those elements or appreciated having them available at the CSTM. No cards were disliked by more than four participants which include the 'Signs on post' and 'Interactive display' picture cards, therefore, these elements were not well received by all the participants (Table 3).

The figure below (Figure 22) features the cards that had a high number of participants sorting them under the 'Like' or 'Dislike' piles for the 'Daily Life' category and 'CSTM' category. These cards are presented here as they ranked high with 'Likes' in the 'Daily Life' category (by seven or more participants) but then ranked high with 'Dislikes' in the CSTM category (by six participants or more) and vice versa. Some cards that were disliked in both the 'Daily Life' and 'CSTM' categories are shown in Figure 22 in both the 'Dislike' areas. 


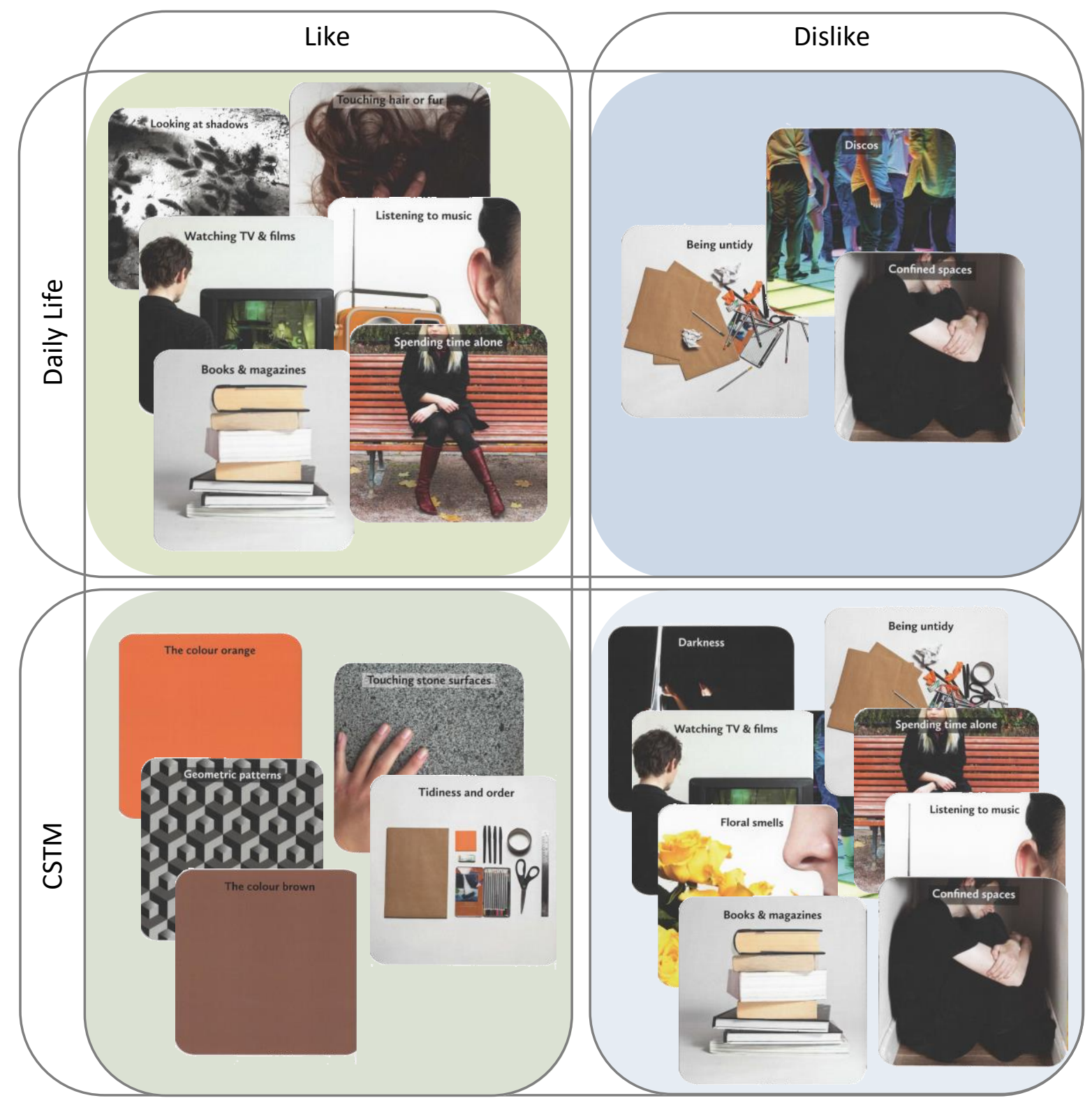

Figure 22: Picture cards that were commonly sorted into the Like or Dislike piles amongst the 10 participants, in the Daily Life or CSTM categories.

The following table (Table 4) highlights some of the comments from participants while they sorted the museum picture cards. As participants sorted the cards under the 'Like' or 'Dislike' sections, I asked them to talk about the images and the reasoning behind why they placed them under these sections. Key themes that emerged here were 
'attractors' and 'motivators' which brought participants to visit certain places because of their interest in specific exhibits or perhaps can identify with certain areas. This included area E - Medical Sensations, where three participants found a connection from their background or profession. On the contrary, there were areas that deterred participants because they do not relate to the area like in A - Into the Great Outdoors, where four participants were indifferent or uninterested to the outdoors section. Similarly, three participants did not enjoy or avoided area $\mathrm{C}-$ Sound by Design, because of the noise, and therefore, this aspect acted as a deterrent to movement or navigation in that area. Another pattern that emerged from this part of the study was 'facilitating' wayfinding elements. This comprised of the map, signs, and colour coding available throughout the museum. Participants mentioned how these elements helped them during their visit but also talked about improvements that could be applied to assist in wayfinding like having arrows on the ground to point you in the right direction.

\begin{tabular}{|c|c|}
\hline & In Vivo Excerpts \\
\hline $\begin{array}{l}\text { 艺 } \\
\text { 는 }\end{array}$ & $\begin{array}{l}\text { (P5) "It was nice and open." } \\
\text { (P10) "I like that it looks clean." }\end{array}$ \\
\hline  & $\begin{array}{l}\text { (P1) "Easy to lose yourself if you don't know if it's the same subject." } \\
\text { (P3) "I do like what's in it, I think it's location is very poor, it doesn't allow you to explore the } \\
\text { museum properly, it's very mismatched. The individual artifacts are interesting and cool and neat, } \\
\text { the alley itself is not a great set up." } \\
\text { (P5) "...kept getting distracted by the artifact alley." } \\
\text { (P6) "I liked the printing stuff." }\end{array}$ \\
\hline 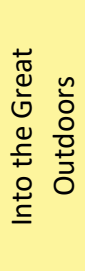 & $\begin{array}{l}\text { (P2) "I'm indifferent towards the outdoors." } \\
\text { (P3) "Doesn't really interest me because I'm not an outdoorsy person." } \\
\text { (P4) "More interesting than I thought it was going to be." } \\
\text { (P9) "Interesting stuff, not my interest." } \\
\text { (P10) "I'm not a big outdoors guy, but the content that was there was interesting, it was } \\
\text { presentable." }\end{array}$ \\
\hline
\end{tabular}




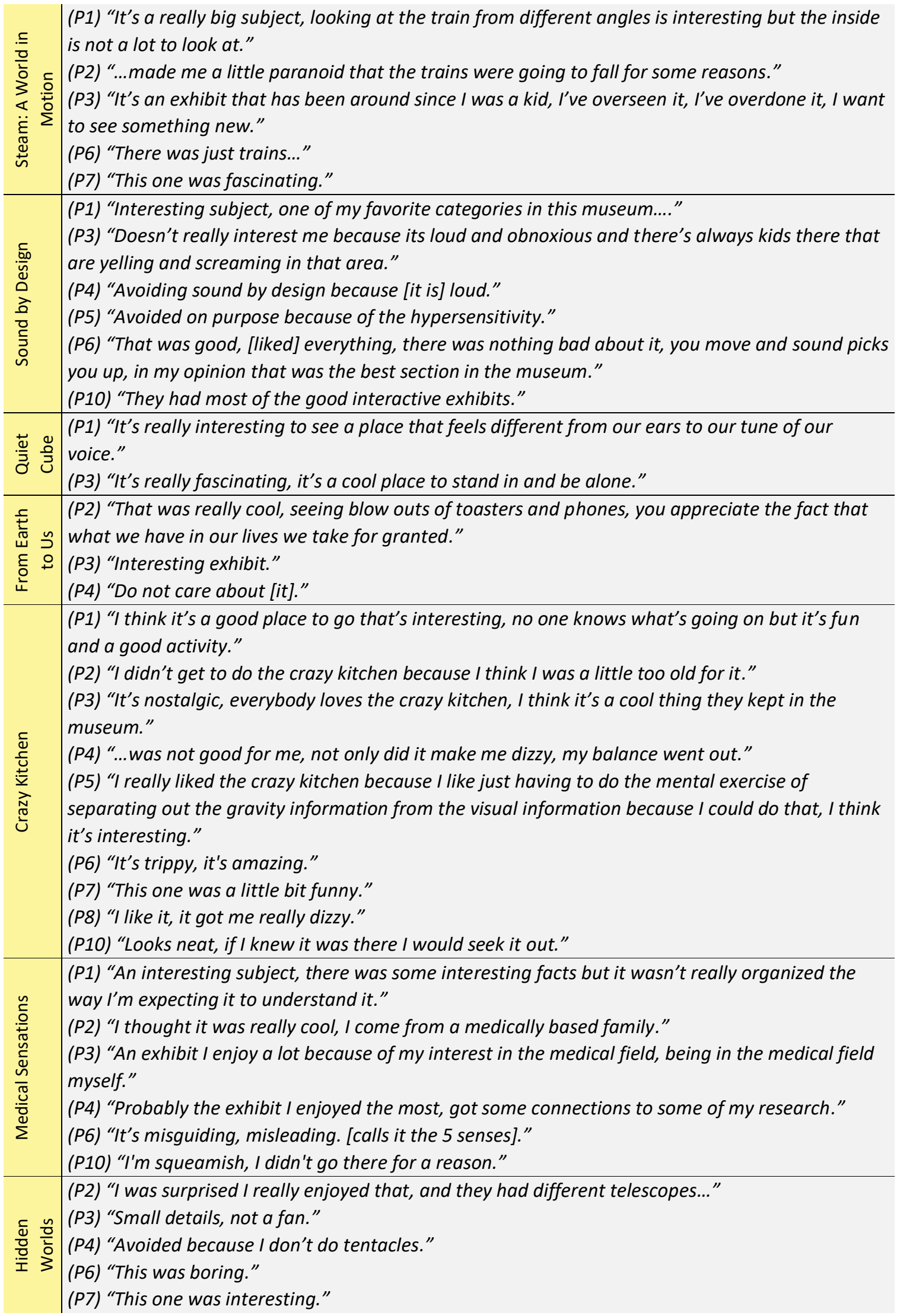




\begin{tabular}{|c|c|}
\hline 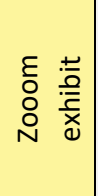 & \begin{tabular}{|l} 
(P3) "I like that they have an area for children." \\
(P5) "It's important to have something for all ages." \\
(P6) "It was well sectioned off." \\
(P10) "It was rated 0-8 so I didn't bother."
\end{tabular} \\
\hline 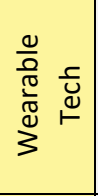 & $\begin{array}{l}\text { (P1) "Don't remember..." } \\
\text { (P4) "It was actually neat, I appreciate the diving suit and some of the helmets." } \\
\text { (P6) "This was pretty lame, [liked] the glasses." } \\
\text { (P10) "That was neat, when I come back, I'll spend more time here." }\end{array}$ \\
\hline 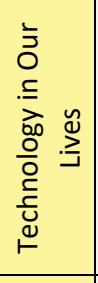 & $\begin{array}{l}\text { (P1) "It's mostly a subject to the present and not a lot to the past, it's still tools we use these days, } \\
\text { maybe if it was something into the future maybe it might grab interest." } \\
\text { (P2) "That one is really cool, you can see the history of everything we have now, like colour TV..." } \\
\text { (P3) "I think my favorite exhibit, it's an exhibit where I like to see the progression of technology, the } \\
\text { past and history is something that intrigues me and I like going through and seeing how } \\
\text { technology has advanced in our lifetime." }\end{array}$ \\
\hline$\sum^{\frac{2}{\pi}}$ & $\begin{array}{l}\text { (P1) "It's good to know where you are, good to have it because it's easy to lose yourself in this } \\
\text { museum." } \\
\text { (P2) "The map was actually really great, when I was able to pinpoint where I was it was great to } \\
\text { maneuver around the museum." } \\
\text { (P3) "I don't like the map that the museum gives you, it's confusing, it's not well laid out, I } \\
\text { personally think the general layout of the museum is not well thought out." } \\
\text { (P4) "Maps are useless to me because I cannot read maps." } \\
\text { (P5) "I really liked the map, I think it's well designed, and I found it really easy to use." } \\
\text { (P6) "IUseful] if you can't tell where you are." } \\
\text { (P8) "...if they [people] are new, they need that." } \\
\text { (P10) "... mixed feelings about map, it was a life saver." }\end{array}$ \\
\hline 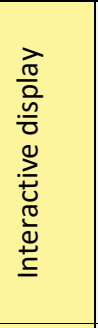 & $\begin{array}{l}\text { (P2) "Some of them, watching a video for } 10 \text { minutes it's like this is really awkward." } \\
\text { (P3) "A lot of time they don't work, I find extremely frustrating, they need to be maintained more, } \\
\text { or they just need to go." } \\
\text { (P4) "Tend to annoy me." } \\
\text { (P6) "I like it, like the music thing, it was cool." } \\
\text { (P8) "I like buttons." } \\
\text { (P10) "They were confusing, overall, they didn't grab me, the videos especially." }\end{array}$ \\
\hline 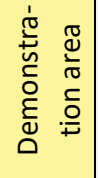 & (P1) “...It's on certain hours it was rare to have it on time." \\
\hline 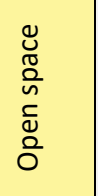 & $\begin{array}{l}\text { (P3) "I like museums with open space concepts, however the CSTM is little too open spaced, allows } \\
\text { for a little bit too much wandering." } \\
\text { (P4) "I don't do claustrophobic well." } \\
\text { (P10) "... I feel like it had too much, the hub area, that was confusing I didn't like it." }\end{array}$ \\
\hline
\end{tabular}




\begin{tabular}{|c|c|}
\hline & $\begin{array}{l}\text { (P1) "I do not recall seeing them at the entrance that would be a good place to put it." } \\
\text { (P2) "The only one I noticed was for [exhibit] Earth to us." } \\
\text { (P3) "The way the museum is laid out is that you can enter a different part of the museum at } \\
\text { multiple entrances and they only have the entrance signs at } 1 \text { or } 2 \text { of the entrances instead of all of } \\
\text { them, which I think is confusing and can really take away from the museum experience, if you're } \\
\text { going to design a free flow design like that I think you need to have entrance signs at all of the } \\
\text { entrances." } \\
\text { (P4) "Probably one of the few pieces of direction I can work with." } \\
\text { (P6) "I liked that, it was better than white on red." } \\
\text { (P9) "They were small I didn't really notice them but they were there." } \\
\text { (P10) "I just ignored these...they look very unremarkable." }\end{array}$ \\
\hline & $\begin{array}{l}\text { (P1) "Because there's so many of them it's hard to look at." } \\
\text { (P2) "That really helped at the beginning I was able to be like oh I'll go here it looks cool." } \\
\text { (P3) "I find helpful, they don't really bother me." } \\
\text { (P6) "White on red is disgusting, it was overload, it was small." } \\
\text { (P7) "This one might get a little bit too confusing." } \\
\text { (P8) "I always look at signs." } \\
\text { (P9) "I didn't like that as much, it was a bit weird, trying to find my way because each was } \\
\text { angled..." } \\
\text { (P10) "I like them, I like the colour, I like the fact that the arrows were very clear." }\end{array}$ \\
\hline & $\begin{array}{l}\text { (P1) "I easily ignore them, we're more focused into the exhibits rarely looking up, sometime it could } \\
\text { be the light sometime the roof is so dark that we don't see much." } \\
\text { (P2) "I used those a lot, one of them kind of tripped me out when I was trying to find sound by } \\
\text { design, but for the most part they really helped." } \\
\text { (P3) "I never really notice, I don't think to look up at the overhead signs, the ceiling in the museum } \\
\text { is very very high and so I don't generally think there is a sign above my head." } \\
\text { (P4) "Somewhat helpful to me..." } \\
\text { (P8) "I always look at it in stores too, if you don't have them in stores and people forgot their map } \\
\text { you can look there [at overhead signs]." }\end{array}$ \\
\hline $\begin{array}{l}\frac{y}{0} \\
\frac{0}{1} \\
x \\
0 \\
0 \\
\frac{0}{0} \\
0 \\
0 \\
\frac{0}{0} \\
\frac{0}{0}\end{array}$ & $\begin{array}{l}\text { (P1) "Hard to see it, looking at the map, for example, the sound exhibit we should expect a red } \\
\text { room because the map shows it's red but in reality it's a big room with a black carpet." } \\
\text { (P2) "That was really cool, I didn't go to more than the red coloured exhibits, it was cool to see it } \\
\text { sorted out in different sections." } \\
\text { (P3) "...also interesting because it's just an extra layer that ads to the eye, makes the map slightly } \\
\text { easier to follow." } \\
\text { (P4) "It's alright, it helps somewhat." } \\
\text { (P6) "It should be on the ground, or arrows, not on the exhibit itself but on the ground." } \\
\text { (P7) "We need colour to express the feeling." } \\
\text { (P8) "They should make the signs colour coded for [exhibits]." } \\
\text { (P9) "The colour coded exhibit and the map was very helpful for me figuring out where I was." } \\
\text { (P10) "I did not catch on that the exhibits were colour coded." }\end{array}$ \\
\hline 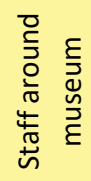 & $\begin{array}{l}\text { (P1) "It could be useful depending when." } \\
\text { (P3) "Seem friendly enough, easy to locate." } \\
\text { (P5) "The staff was lovely that I interacted with." }\end{array}$ \\
\hline
\end{tabular}




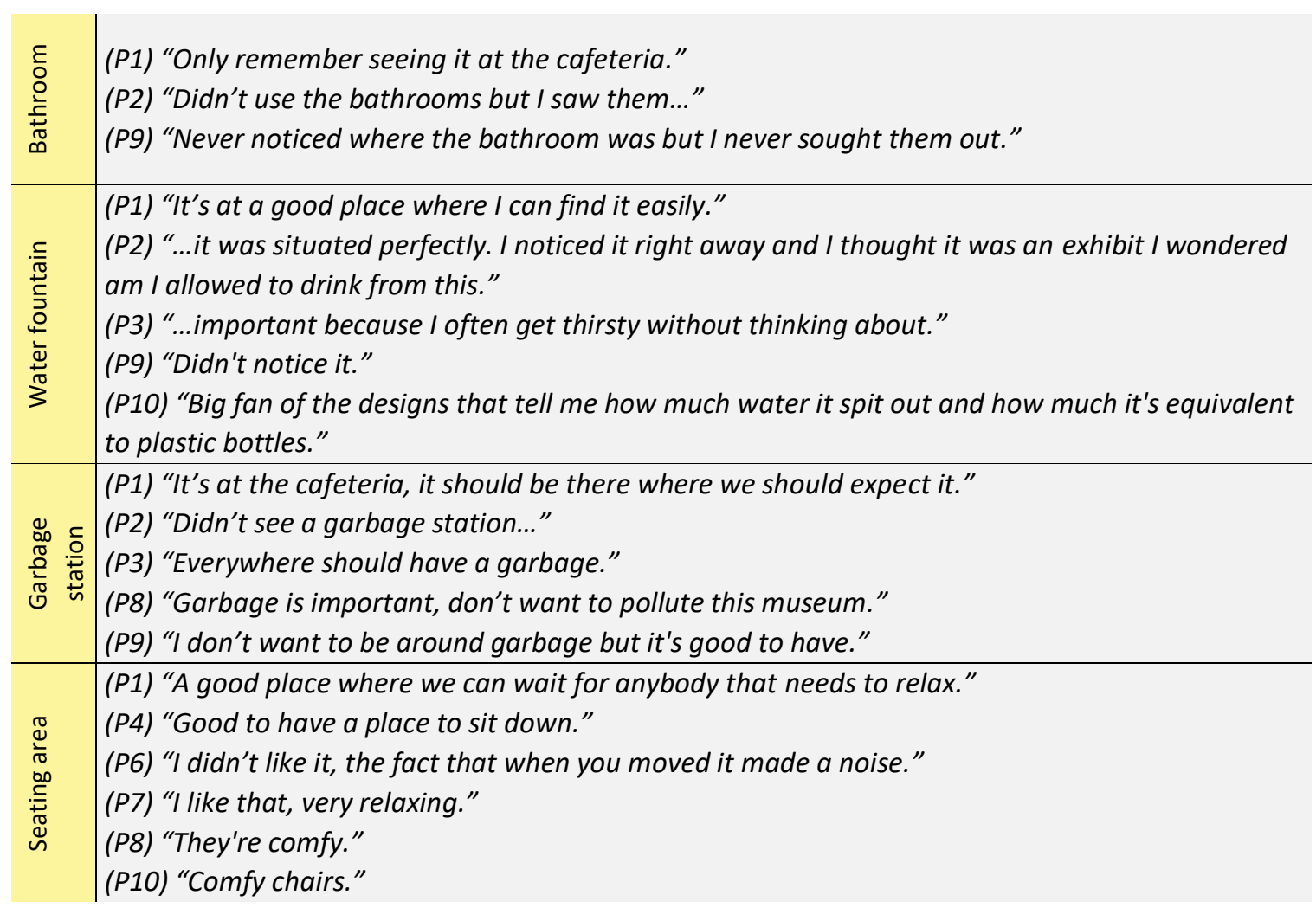

Table 4: Data collected during card sorting activity with museum picture cards

\subsubsection{Journey Mapping Results}

While completing the journey mapping exercise, participants would sometimes speak aloud during the activity. One participant (P1) said that "Just by hearing the titles [of the cards provided] it doesn't ring [a bell]...". I asked if the images look familiar, "just by looking at this, I've never seen it [Wearable Tech], but I do remember the colours of Technology in our Lives". Later on they (P1) noticed the Medical Sensations card and deduced that, “This one is E isn't it, so orange [points on map], orange [points to map legend], orange [points to picture card], it grabs [your attention] because it might be the only colour, it helps guide us". They also noticed that Hidden Worlds is " $F$ [is] blue, perfect" which is reflected on the map and the picture card as well. Likewise, another 
participant (P4) commented “the colour on the map doesn't always match the colour in the actual rooms, l'd make that match more".

The following journey map (Figure 23) and descriptions are of participants that planned out a journey that was different than the journey they took during the observation activity. For example, seven participants either omitted exhibits they did not want to see again on a future visit to the CSTM or added exhibits they may have missed but would like to have seen. Participants were guided by the map to a certain extent. They did not solely rely on it and would navigate the museum freely. This caused participants to sometimes miss exhibits or not visit them as they did not spark interest from viewing the map. During the workshop, participants would get intrigued by an unfamiliar exhibit seen in the cards provided which would influence them to add it to their 'future' journey map. Contrarily, when participants had a negative or unpleasant experience, they changed the course of their journey as well. Also, elements like the Cafeteria, water fountain, and bathroom, were sometimes added to a journey map as these could be used in a future visit to the museum if wanted/needed. Participants drew out their journey with drawing/writing tools provided and used numbered sticky notes to mark the order of their journey. Afterwards, in some cases where the participant's final map was faintly drawn or hard to see, I drew lines from the exhibit to the picture card to have a larger and more easily readable representation of a participant's journey map. The overall results from this activity in the workshop sessions were not particularly useful to the study, but a few interesting findings from select participants are included below. 


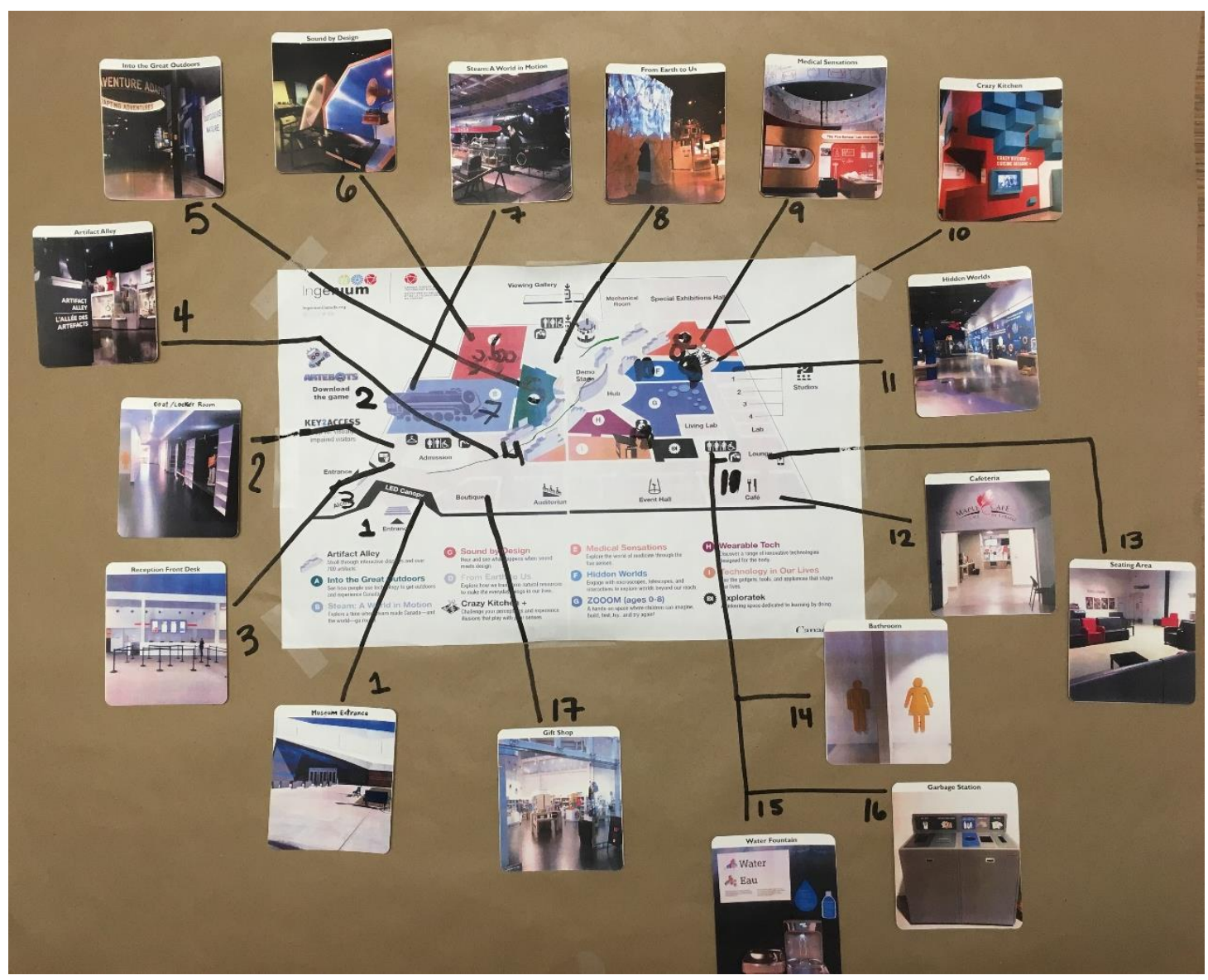

Figure 23: Journey map of participant 1 (P1)

P1 - This participant chose to add areas to their journey map that they did not visit during the observation activity as they realized they missed areas they would have liked to have seen. These include B - Steam: A World in Motion which they mentioned is an interesting subject, as well as the Cafeteria, the Bathroom, Water Fountain, and Garbage Station (as potential necessities), and the Gift Shop.

P2- This participant added a few areas they would have liked to visit the next time they were to visit the CSTM. These included the Crazy Kitchen since they missed this exhibit and did not realized they could have gone into it, Exploratek because they were 
intrigued and curious about what is offered there as they only noticed it in the cards provided for this activity, as well as the Cafeteria, the Water Fountain, and Bathroom (as potential necessities).

P4 - This participant chose to omit exhibits they visited during their observation visit. This included the Crazy Kitchen as this exhibit made them very dizzy and affected the rest of their visit negatively, and $\mathrm{H}$ - Hidden Worlds since they did not enjoy the content. One of the exhibits they did not visit and did not want to visit is $\mathrm{C}-$ Sounds by Design "because [it is] loud".

P9 - While drawing their journey map, this participant said "I think by following it by the letters [in order of the map], I'd like that". They added a few exhibits to their journey map that they did not visit during the observation activity. They included G - Zooom "maybe if that's possible, I noticed it's for ages 0-8", as well as the Demo Stage since they mentioned they would have liked to see a demo but there was no showing during their visit, the Water Fountain and Bathroom (if necessary), and would end their visit at the Gift Shop to see what they offer.

Another participant (P3) also mentioned "I don't like leaving sections incomplete or bouncing around [from one exhibit to another]". This participant added the mechanical room to their journey as they "think it's really neat how they added the mechanical room as a glass wall...but you can see because it is in fact a piece of technology that is keeping the place running". Adding the mechanical room to their journey demonstrates 
how they did not miss to include this attraction although it might not seem like an exhibit to visit, it is a location included on the map.

When concluding the workshop, a participant (P1) commented about their museum experience saying, "they're all really good subjects, there's a lot of interesting gadgets and things I wouldn't be able to see from different museums, so it's really interesting".

In the next section, I will synthesize the results from these three methods in a more cohesive framework and compare it to the literature review. 


\section{$5 \quad$ DISCUSSION}

This section discusses the results relative to the research questions stated in the Introduction as well as the Literature Review. As previously mentioned, wayfinding can be defined as "the cognitive and corporeal process and experience of locating, following or discovering a route through and to a given space" (Symonds et al., 2017, p.9).

A total of 15 participants took part in the survey and a total of 10 participants took part in the observation study followed by the workshop study. Participants ranged from the ages of 18 to 28 and six of them were accompanied by others during their visit to the CSTM like a partner, sister, parents, grandparent, or friend. Two of the 10 participants were female. This is fairly representative of the ratio of men to women with ASD which is 3:1 (Loomes, Hull, \& Mandy, 2017).

A few of my expectations or assumptions were that the colour coding available in the museum would be more memorable so I was surprised to observe that the map colours did not translate to the physical space as I had anticipated. Also, I thought signs would have more influence on navigation and orientation, and that memory would also play a large role in wayfinding since I personally relied on memory to navigate. But in the end, colour coding did not seem to be a memorable feature, while participants did rely on their memory when navigating the museum. 


\subsection{Research Questions}

This study aimed to develop a better understanding of how a group of people with ASD interacted in a specific museum setting with a focus on their interaction (or lack thereof) with wayfinding and related environmental elements. Four questions were explored using three qualitative methods.

\subsubsection{Research Question 1}

\section{How do participants move through and navigate the environment?}

This question was explored by observing participants moving through the CSTM and mapping their behaviour.

\subsubsection{Potential Influence of Environmental Factors on Experience and Navigation} Certain areas in the CSTM had very low traction or were not visited at all, while others were more popular with the participants. These areas of higher traffic versus lower traffic have certain environmental elements that may influence the preferences of persons on different points of the spectrum. This includes sensitivity to sound, lighting, and textures (American Psychiatric Association, 2018). For example, two participants chose not to visit $\mathrm{C}$ - Sound by Design because of their hypersensitivity to sound and noise while others were intrigued by the music resonating from the exhibit which led them to visit the space. With regards to lighting, many participants noted that they found the museum to be dark and dimly lit, however they appreciated that it was not overwhelmingly bright with artificial lighting as this would not have been desirable. 
Participants also noted that some exhibits were separate and quieter so they liked to spend their time there, whereas only one participant went into the outer hallways of the museum which were also seen as separate from the exhibits, making their function less explicit to visitors and perhaps less inviting as a result. Only one participant wandered into this area to then find their way to another exhibit. This is a similar scenario to the viewing gallery which is only accessible through one of the exhibits up a staircase. The viewing gallery also leads to the office area of the museum which may be misleading as it perhaps gives the appearance of a restricted area.



Figure 24 (for reference only, identical to figure 14): A juxtaposition representation of all the trajectories taken by ten participants visiting the CSTM 


\subsubsection{The Use of Maps}

The map was used by most participants. Seven of the 10 participants took a map and followed it to some degree to find exhibits that interested them. All looked at the map at least once during their visit or at least once in every exhibit to see where they were situated. I also noted that the maps were not easily accessible to visitors of the museum; however, as mentioned by Gibson (2009), maps are an important instrument for navigation. I had to ask the reception desk for the maps at each visit as they were not displayed anywhere. When I inquired about this, the staff indicated to me that visitors had to ask for maps at the front desk. This was interesting as often when visiting a place such as a museum, having the option of taking a map is essential for newcomers as well as persons with disabilities as it can inform them of areas of interest or any obstacles which may be unknown to them. Likewise, one participant commented that in their opinion, new or first-time visitors would require a map (Table 4). Staff members working throughout the space are not always readily available, therefore a map may be a useful tool in such cases. The map is discussed in more detail in section 5.1.2 where I discuss how participants used specific wayfinding elements.

\subsubsection{Memory and Landmarks}

As mentioned by Foltz (1998), other factors that help participants navigate through an environment are memory and landmarks. As participants navigated through the exhibits, most of them would use memory cues to help them find their way back through an exhibit or an entrance. Landmarks were also used to help find one's position and helped participants remember and identify a general location. Participants referred 
to different exhibits not by their given title as seen on the map, but rather, by the visible markers in the environment that stuck in their memory. For example, A - Into the Great Outdoors was to referred to as "the bikes", B - Steam: A World in Motion was coined "the trains", Artifact Alley was remembered as the place with the "printing press", E Medical Sensations was deemed as "the five senses", and $\mathrm{H}-$ Wearable Tech was recalled as the "helmets". These items were the most memorable articles that acted as a marker or landmark which visitors associated to a particular location which is an important wayfinding principle highlighted by Foltz (1998).

\subsubsection{Research Question 2}

\section{Do participants use the current wayfinding system? And if so, how?}

This research question was explored through observations of individuals with ASD moving through the museum followed by a debriefing where participants shared their thoughts about the wayfinding system.

\subsubsection{The Use of Maps and Associated Landmarks}

The first wayfinding tool participants had access to was the map. The thoughts shared about the map were both positive and negative. Four participants said it was useful, well designed, and easy to use while three participants said it was confusing, not well laid out, and useless in one participant's view because the latter expressed having difficulty reading maps. This is in line with Foltz's (1998) wayfinding principle of using "survey cues" (p.60). He goes on to say that having a map "places the entire space 
within the navigator's view" (Foltz, 1998, p.67). However, Hund \& Gill (2014) believe that a 'good' sense of direction can increase one's wayfinding performance which can help them adapt to an environment and easily learn a map. One participant noticed a landmark illustrated on the map, specifically in area C - Sound by Design. The map in this area has a few hexagonal shapes with a letter $\mathrm{C}$ above it which corresponds to a large hexagonal structure which is a prominent feature in that specific exhibit area. This participant looked at the map to see where they were located and noticed that image on the map which they confirmed indicated they were in area $\mathrm{C}-$ Sound by Design. Landmarking illustrations on the map were also used to identify exhibit area B - Steam: A World in Motion, D - From Earth to Us, Crazy Kitchen, G - Zooom, and I - Technology in Our Lives. An image of the landmark featured on the map helped a couple visitors locate these areas based on their surroundings.

\subsubsection{The Use of Landmarks from Memory}

Participants' memory of their environment and landmark identification helped them navigate their way back through the exhibits they had already visited. This has been observed in previous studies by Hund \& Gill (2014) and Foltz (1998). Foltz (1998) explained that effective wayfinding can be done by using "landmarks to provide orientation cues and memorable locations" (p.60). Participants also mentioned they remembered the way they came and did not always use the map to retrace their steps. This points to the effectiveness of visual landmarks, however the majority of participants were drawn to or deterred by the sound coming from area $\mathrm{C}$ - Sound by Design. This can be viewed as an auditory landmark or as described by Hund \& Gill 
(2014), a striking feature. Most participants knew they were near this particular exhibit when they heard the musical elements coming from the interactive displays.

\subsubsection{Space Organization}

Foltz (1998) believes that "creat[ing] well-structured paths" and the "use [of] sight lines to show what's ahead" are essential wayfinding principles, and these principles emerged in participants' comments throughout the study (p.60). For example, one participant (P3) mentioned that they liked to follow a linear path during their visit: "for the most part the exhibits I went to were kind of on a linear path so I was able to go from point A to point B using the signs and even when I took a weird path I was able to course correct and find where I needed to go". Participants also mentioned in the openended questions, they (P6) preferred to have "open space to limit crowding" and (P15) to use a "linear design, so as to have a sense of progression" and (P10) that "hallways...should...be distinguishable...through dimensions, furniture, or even a line of sight that reaches the next room".

\subsubsection{Research Question 3}

\section{What does wayfinding at the museum, and environmental elements potentially related to wayfinding, mean to participants?}

\subsubsection{The Role of Signs}

The use of signs is an essential and common wayfinding principle. Decision points where people may change paths (e.g. at an entrance to an exhibit) are key locations for the use 
of signage (Foltz, 1998). In the observation and workshop sessions, participants shared their thoughts about the wayfinding available at the CSTM. They mentioned that the signage was useful, however five participants mentioned that the signs were small, that there should be more available, or should have better visibility. For example, in area BSteam: A World in Motion, one can get to another exhibit by either exiting the space through the central Hub area or by going around a locomotive, but there are no signs indicating this second option and the area is also dimly lit with limited sight lines to this other space around the locomotive. One participant (P1) also mentioned that artifacts and their descriptions were hard to find and hard to see as they were often blocked by other visitors.

One participant (P10) said they usually have issues when a sign or a person is simply pointing in a general direction with the intent of helping someone identify an object or a location. This participant was more appreciative of the overhead signage and the arrows that pointed towards areas in the exhibit (Figure 25). It was important to participants that the signage was large and obvious as they felt it was not noticeable in some cases and could have been very useful to guide or inform them. They also remarked that the overhead signs require you to walk around them to see the direction they are pointing to and get close to them, concluding that they "need to be bigger and more obvious". Signs are mentioned by Gibson (2009) as an organization's brand identity which is projected through signage in an environment. The use of colour, symbols, and landscape reinforces the identity of the brand and gives the sense of being somewhere in particular. 
Another important element that can support the effectiveness of signs is lighting (Gaines et al., 2016). What people see is affected by the lighting, colour, and space organization. In area A - Into the Great Outdoors, one participant shined their phone's flashlight on exhibit descriptions in order to see and read the information more comfortably.

Although these are technically not considered wayfinding signs, they are still effectively a form of signage whose function is to bring people through the exhibit narrative. The visibility of signage also depends on the space organization, meaning where it is placed and among what other things in the surrounding environment. The placement of signs in the museum, which are located on a column upon entering the main entry point of the exhibits, to the right or left at the entrance of exhibits, coming down from the ceiling, and on walls near entry points, may explain why some participants did not notice the signs or said they were not memorable. As for the colour of some signs, one participant (P6) commented that having white writing on a red background is "a bad idea and it gives me a headache just trying to read it".
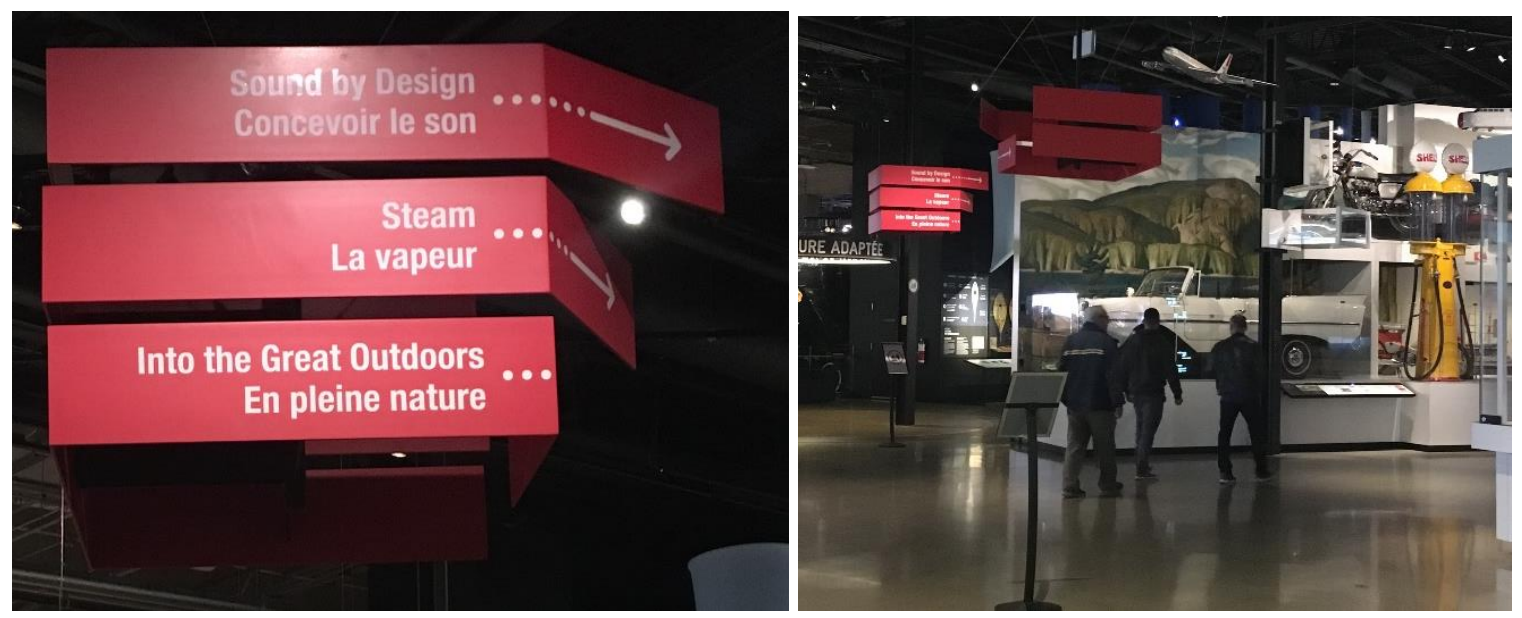

Figure 25, 26: Images of overhead signs taken at the CSTM. 


\subsubsection{The Role of Colour}

Few participants found the colour coding used in the wayfinding elements useful while others stated they did not notice this feature when thinking back on their museum visit during the workshop. This includes the colours on the map and designated colour coding for each area in the overall exhibit. Gibson (2009) mentioned that colour can be associated to brand identity. In this case, we can interpret the exhibit identity as being associated with a particular colour when looking at the map. However, participants noted that the colour coding was not a memorable feature of the museum itself, but rather was more obvious when looking at the map itself. During the workshop, one participant (P5) mentioned "I'd paint arrows on the ground on the concrete in the various sections, pointing this way to this [exhibit], just because I was having some trouble and I have very good [sense of] direction, it would be useful in A to have a red arrow pointing to $C$, silver arrow point to $D^{\prime \prime}$ according to the colours representing those areas on the map. They also commented, "I was expecting these [colours on the map] to actually match how it was in the physical space". Finally, another colour coded system which exists at the CSTM which was not discussed by participants is: a column with grey, red and orange signs found at the entrance of the museum, as shown in figures 27 and 28. 

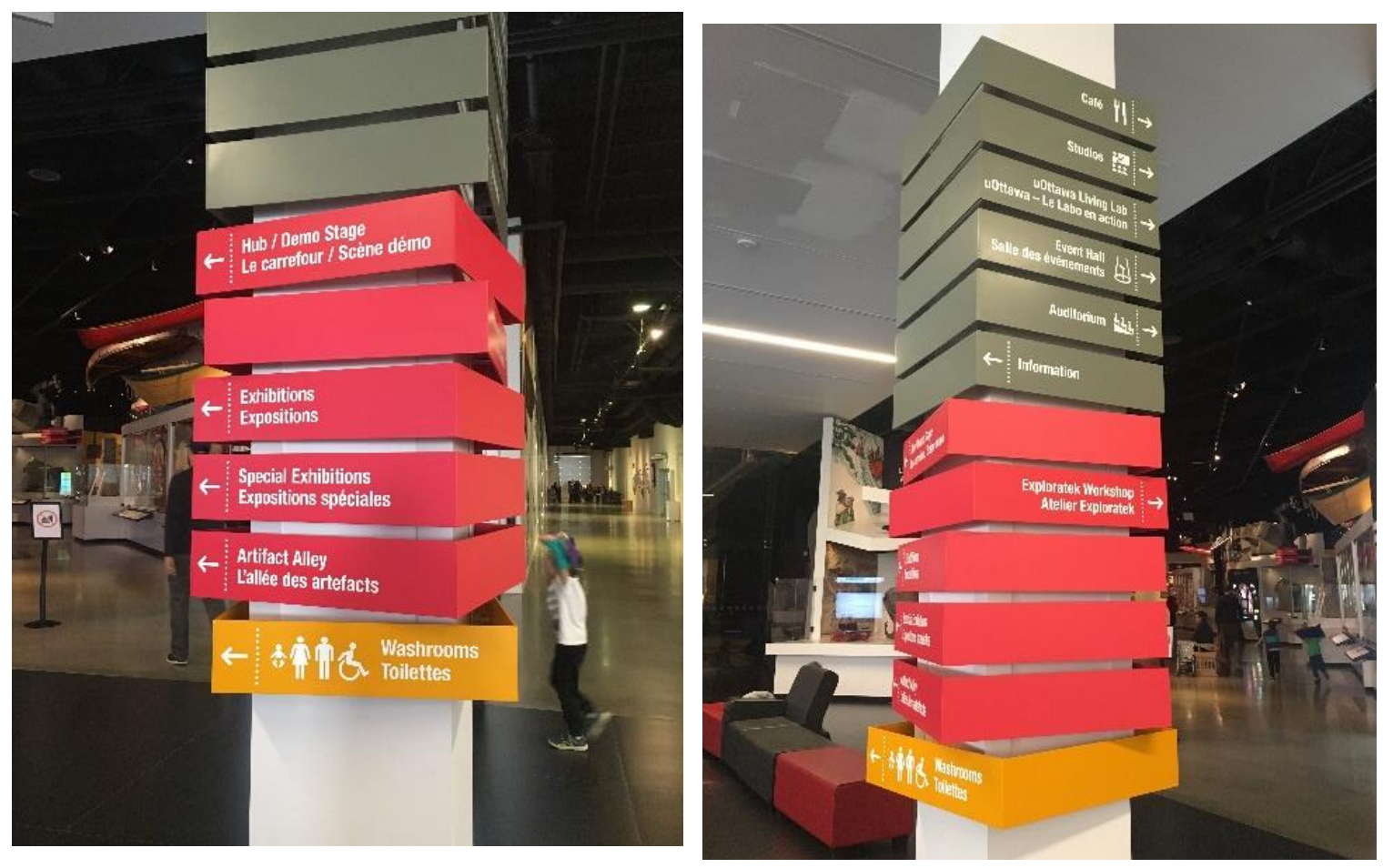

Figure 27, 28: Signage post present at the entrance of the museum before entering Artifact Alley.

\subsubsection{The Role of Sound}

As mentioned in the literature review, there may be a need for more than one method of communication or orientation in a space for persons on the spectrum. Certain people may have an aversion to bright lights while others may enjoy them (American Psychiatric Association, 2018). The C - Sound by Design exhibit was avoided "because of hypersensitivity" by a couple of participants (P4 and P5) while two other participants (P1 and P6) enjoyed it commenting "in my opinion, that was the best section in the museum" with other comments such as "one of my favourite categories". High pitched noises such as background noise from electronics and machinery may also be deterring (Gaines et al., 2016). The background noise produced by the interactives in area C- 
Sound by Design was noted to be irritating to one participant (P3) who mentioned that "it's loud and obnoxious and there's always kids there that are yelling and screaming in that area". Similarly, in the open-ended questions participants (P7 and P2) commented that "noise from other attendants is a personal problem" and that "kids all screaming their heads [off] can be unpleasant". This perhaps points to the importance of sound in museum design and the potential for influencing how people on the spectrum may navigate museums.

\subsubsection{Research Question 4}

\section{What may designers need to pay attention to in order to support future research and design development in museum wayfinding in consideration of ASD?}

All three methods - the survey, observation sessions and workshop sessions - explored this research question.

Although the case study sample was small, six of 10 participants had previously visited the CSTM museum and they all had visited other museums highlighting the need to consider this demographic in future research studies in museum design.

\subsubsection{Sensory Aspects}

In the open-ended questions of the survey, participants discussed environmental elements which impact their experience in museums such as sound and lighting. It was mentioned that "sound suppression" and a "quieter" environment are appreciated (Table 1). Furthermore, a participant mentioned having "hearing sensitivities" and 
another suggested the use of "sound dampeners" (Table 2). The card sorting workshop showed a clear preference for sound in 'Daily Life' (10 participants liked 'listening to music' and six liked 'making sound and music'). Interestingly, in sorting cards into 'Likes' and 'Dislikes' in 'the 'CSTM' category, only six participants put 'listening to music' in their 'Likes' pile. This shows that even though listening to music was an important part of all participants' daily lives, it was not enjoyed by all participants during their CSTM visit.

In discussing lighting, one participant mentioned preferring a "well lit" environment while another mentioned preferring the "darkness" in the "quietest section" (see Appendix D, section D.1). Additionally, in the observations one participant used their cellphone flashlight to better read an artifact description. We can conclude that lighting may have a functional or memorable effect on the overall user experience. As well, we should consider that the possible shadowing can affect neighbouring areas. Therefore, designers need to pay close attention to lighting as it pertains to the design layout.

The sense of touch did not seem to be a factor in participants' navigation through the museum other than engagement with the interactives. However, Gaines et al. (2016) note that persons with ASD may "rely on the sense of touch to make their way through a space" which may support the touch-based nature of the interactives themselves being a motivator for making choices on how to navigate through the museum (p. 103). The card sorting workshop highlighted participants' sensitivities and discomfort to certain elements. The sense of touch was categorized under 'Like' for the majority of 
participants (seven out of 10 placed all but two of the touch picture-cards in the 'Like' or 'OK' pile) (Table 3) which points to the possibility of exploring touch in future wayfinding studies as an alternative means to support flow and navigation through a museum, for persons on the spectrum and people in general.

\subsubsection{Participant Identity and Interests}

A few participants found themselves navigating towards certain exhibits due to their own interests and backgrounds. For example, participants identified with area EMedical Sensations as they (P2) "come from a medically based family", (P3) "being in the medical field myself", and another participant (P4) mentioned "connections to some of my research". This is particularly interesting because it may indicate that having a larger variety of exhibits may cater to a larger population and draw people to move throughout the environment through a less explicit and natural form of 'wayfinding'. In addition, when comparing the card sorting activity from 'Daily Life' to the 'CSTM' differences that emerged like 'listening to music' favoured by all in their 'Daily Life' but not at the 'CSTM' was related to participants' preference for listening to music when they have control over the situation, and being able to select what they like and prefer according to personal taste, which could not be controlled in the museum environment. This is similar to the fact that some participants liked the sensory touch cards mostly in their 'Daily Life' versus at the 'CSTM'. In their daily living they know what tactile surfaces they come in contact with and can control these (e.g. participants discussed germs, tidiness, cleanliness) whereas controlling the condition or their interaction with tactile surfaces in a museum would be difficult. These insights underline the preferences 
participants have according to their interests and identity. Part of their identity relates to being on the spectrum and there may be characteristics common to ASD that affects preferences. One example of this is a hypersensitivity to noise, (Gaines et al., 2016), which was mentioned by participants throughout the study and observed when debriefing a participant who covered their ears in discomfort as a visitor was screaming loudly nearby. If we know more about people's characteristics, identity or interests, we can perhaps implement the concept of variety, diversity and/or personalization in the design of exhibits and motivate people to explore museums more fully or to their preference. These considerations are less obvious in wayfinding design and more research may be needed here.

\subsection{Study Design and Limitations}

In the future, as the ethics clearance was granted for the current study by higher education institutions and an education consultancy, it is recommended to reach out to more institutions to facilitate the recruitment of more participants. This proved to be a great difficulty and a time-consuming process as it was hard to find adults who are high functioning and who self-identify as having ASD to participate in the study. This also presented a challenge as results could not be generalized due to the small study sample of participants.

As there were changes made to the debriefing questions that were asked after the observation sessions, this posed the possibility that results were affected by answers prior and after the updated questions. 
Some of the workshop activities should also be reconsidered if others were to conduct this study. For example, since participants recalled exhibits differently than the official exhibit names (by using the names of landmarks they found memorable, for example) the journey map activity proved to be challenging for participants. This affected the recognition between the cards I created, the titles of the exhibits, and their placement on the map.

Furthermore, although the map legend provided participants with the titles of each exhibit, it would be interesting to have the journey map activity solely completed without the help of the legend. I would consider omitting the map legend during the workshop activity to see how and if participants would be able to draw out their journey. This would further investigate memory recall and better see if participants were impacted by the exhibits through location, landmarks, and colour coding.

\subsection{Summary and Opportunities}

Participants enjoyed their tour of the CSTM and offered constructive feedback. Since I offered participants maps to the museum, they did not realize that these maps could only be found at the main reception desk. They may not have known to ask for a map or may not have asked for a map at all before starting their tour. This could impact the accessibility of the museum for some visitors who may depend on or benefit from such environmental aids. Also, there are no posters to indicate your whereabouts in the museum as you make your way through the exhibits. Although participants appreciated 
the use of colour-coded mapping, it was not felt to be well reflected in the environment. It could have been improved by adding more colour-coded elements to the space.

Regarding the layout, it was found that having a single entrance to area $\mathrm{G}-$ Zooom was helpful as it delineated the space well. Participants commented that the $\mathrm{C}$-Sound by Design exhibit was quite noisy and distracting as they made their way through the museum or nearby exhibits. It was, however, strategically placed in the corner of the layout, distant from other exhibits and possibly reducing the noise level reaching farther into the museum. Perhaps introducing more sound proofing would help decrease the distraction.

Participants also noted that more descriptive signage would help guide them to and from the different exhibits and to locate one's place in the museum. Signage, landmarks, and staff from the museum should ideally be within the line of sight of the visitor to help people navigate. Of note, there is a viewing gallery, as seen on the map, which offers a bird's eye view of the museum which only one participant visited. The other visitors may have felt that is was only meant for museum staff as there are offices nearby. Improving signage for this space would encourage visitors to take advantage of this viewing perspective.

The interactive displays seemed to receive the most attention from participants. However, a few of these displays were not functioning at the time, were occupied by other visitors or described as not engaging. Nevertheless, the majority of participants still put the interactive display card from the workshop activity in the 'Like' pile which 
indicates that this is a feature that acts as an attraction or motivator in movement throughout the museum and could be improved upon to enhance visitor experience. Those few that put this card in the 'Dislike' pile still gravitated towards the interactives during their visit, however, they did not find the quality of the exhibit displays satisfactory.

Although some common wayfinding elements were noticed, discussed or used during this study (signs, landmarks, map, etc.) what is of interest are some underlying elements that influenced participant navigation and exploration in the museum that are not commonly discussed in wayfinding design. This includes sound, for example, and the effect on people with hearing sensitivities. Related to this, having a therapeutic environment (like the 'Quiet Cube' in the museum) can help people find an area to reduce their stress level or provide a positive distraction, and a sense of control (Gaines et al., 2016). Another interesting factor that influenced participants' interest/association or dissociation to an area and the route they followed relates to their identity. This was emphasized when participants mentioned how they appreciated certain areas they visited according to personal factors relating to their identity. Studying such factors can contribute and widen what we know and define as wayfinding elements, and potentially help designers reach or assist a wider population. The CSTM, for example, is interested in implementing a command-based mapping system that could aid visitors with vision impairment. This would enable visitors to connect using a personal device which would announce which area in the museum they are located in, acting as a guide. This type of sensory map can help overcome obstacles that visitors may face and provide 
preference-based mapping according to their needs. This leads to question, can maps be personalized and more preference-based?

Although there were great differences between participants when it came to their preferences and needs, there is always room for improvement even if it does not and cannot accommodate everyone. Applying changes and altering environments whether it be a minimal or more extensive change is a step forward to improving the experience of people as we learn more about them. These steps only bring us closer to achieving the goal of universal design.

Finally, having a variety of individuals with different backgrounds walk through future physical models, prototypes or virtual versions of the space and comment on their experience could be a way to increase feedback and test out wayfinding principles for future projects and exhibits. 


\section{CONCLUSION}

Through this research study, I set out to identify the means and preferences by which a group of high functioning persons who identify with Autism Spectrum Disorder experience wayfinding in a museum environment. Through qualitative methods, a case study was created to develop a better understanding of how a group of adult participants with ASD navigate the CSTM with a specific focus on the design of the museum's wayfinding and general environment. There were four research questions that helped shape and guide the study to further develop the knowledge to serve persons on the spectrum within the context of museum design. These questions were:

1. How do participants move through and navigate the environment? 2. Do participants use the current wayfinding system? And if so, how? 3. What does wayfinding at the museum, and environmental elements potentially related to wayfinding, mean to participants? 4 . What may designers need to pay attention to in order to support future research and design development in museum wayfinding in consideration of ASD?

\subsection{Key Findings and Contributions}

The literature review presented fundamental wayfinding principles to accommodate a diverse population. This includes persons with ASD. By bringing further awareness about ASD and universal design to the museum context and wayfinding design field, we can increase the accessibility of an environment through new approaches to wayfinding. No two individuals are the same, just as no two individuals on the spectrum are the same. We cannot assume that a one-size-fits-all approach is appropriate or conclude a project 
without having extensively researched and re-evaluated possible scenarios with the people we are intending to serve. Once a design is complete, it must also be tested to ensure fluidity, adaptability and accessibility, among other principles.

I investigated the possible needs and wants of participants with ASD through the use of a survey method, observation method, and workshop method. The results captured participants' voices by using in vivo codes, brought attention to their behaviour within a museum visit and influential aspects from surrounding elements, and revealed environmental preferences and aversions that differed between individuals. The findings shed light on the use of the map and how it was an essential tool for some participants, but not for others. Memory and landmarks played a large role in navigation as well as space organization which facilitated open sightlines and a sense of progression. The use of signage and associated color coding, an essential wayfinding element, was underappreciated and sometimes unnoticed in the space in contrast to our existing knowledge of wayfinding. Sound proved to be a common interest or deterrent that guided participants towards or away from an exhibit depending on hearing sensitivities which should be explored in the future development of wayfinding principles. Finally, participant identity and interest were strong influences acting as a unique, more personalized and less explicit component of wayfinding experience. Simple elements like sound and user preferences guided participants and influenced their experience throughout the museum, but curiously are not discussed well or extensively in the wayfinding literature. These are interesting factors to consider in future wayfinding studies where personalizing an experience based on sensory aspects 
and personal interests, characteristics or identity may render it more pleasant and memorable for visitors. The findings of this case study support the notion that it is challenging to design a space to support a diversity of needs and preferences, but that improving our knowledge of diversity and commonalities can better support the movement and aspiration toward universal design.

\subsection{Future Research}

This project focused on the general museum, but more specifically, navigation experience of adults with ASD within a specific museum context. Future research should involve persons with ASD from a larger age range, including children, to better encompass the demographic of the museum visitors. It is also possible that people on different ends of ASD may have different wayfinding preferences or expectations which should be explored further. Moreover, introducing a comparative study of people with ASD with people who are not on the spectrum may be an interesting approach to investigate further to highlight if there are differences of needs and what they may be.

Also, the use of Snoezelen ${ }^{\circledR}$ rooms throughout the museum should be investigated for people with certain sensitivities. Snoezelen rooms provide a multisensory environment and are "relaxing spaces that help reduce agitation and anxiety, but they can also engage and delight the user, stimulate reactions and encourage communication" (Snoezelen, 2020). Their use and usefulness within the museum experience could complement future studies focused on respite spaces or flow through museums. 
Finally, we are seeing increased use of handheld devices in museums. An interactive 3D preference-based map or hologram map may be interesting mapping interactives to explore with the ASD community. 


\section{REFERENCES}

American Psychiatric Association (APA). (2018). What is Autism Spectrum Disorder? Retrieved from https://www.psychiatry.org/patients-families/autism/what-isautism-spectrum-disorder

Americans with Disabilities Act (ADA). (2010). Part 36 Nondiscrimination on the Basis of Disability by Public Accommodations and Commercial Facilities. Retrieved from https://www.ada.gov/regs2010/titlelll_2010/titlelll_2010_withbold.htm

Anagnostou, E., Zwaigenbaum, L., Szatmari, P., Fombonne, E., Fernandez, B. A., Woodbury-smith, M., ... Scherer, S. W. (2014). Autism spectrum disorder: advances in evidence-based practice. CMAJ, 186(7), 509-519. https://doi.org/DOI:10.1503 /cmaj.121756

Augustyn, M. (2019). Autism spectrum disorder: Clinical features. Retrieved from UpToDate website: https://www.uptodate.com/contents/autism-spectrumdisorder-beyond-the-basics?search=autistic spectrum disorder\&source=search_result\&selectedTitle=1 5\&usage_type=default\&display_r ank=1

Autism at Kingwood. (2019). Visual sensory profiling cards available from Autism at Kingwood. Retrieved from https://www.kingwood.org.uk/free-training-materialsin-autism-sexuality-and-relationships-2/

Autism Canada. (2019). About Autism. Retrieved from https://autismcanada.org/aboutautism/characteristics/

Autism Speaks. (2018). Oh, the Places You'll Go... With These 10 Travel Tips. Retrieved from https://www.autismspeaks.org/blog/oh-places-youll-gowith-these-10-traveltips\%0D 
Autism Support Louth. (2016). Storyboard. Retrieved from http://www.autismsupportlouth.com/storyboard.html

Banks, T. (2015). Designing " with and not for " people with autism. Design Week (Online), 1-2. Retrieved from http://proxy.library.carleton.ca/login?url=https://search-proquestcom.proxy.library.carleton.ca/docview/1681192113?accountid=9894

Centers for Disease Control and Prevention. (2019). Diagnotstic Criteria for 299.00 Autism Spectrum Disorder. Retrieved from https://www.cdc.gov/ncbddd/autism/hcp-dsm.html

Connell, B. R., Jones, M., Mace, R., Mueller, J., Mullick, A., Ostroff, E., ... Vanderheiden, G. (1997). The Principles of Universal Design. The Center for Universal Design. Retrieved from https://projects.ncsu.edu/ncsu/design/cud/pubs_p/docs/poster.pdf

de Paolis, R., \& Guerini, S. (2015). Wayfinding Design and Accessibility Experiemental Research of new ways to approach the Landscape and Cultural Heritage for wider range of users. International Journal of Engineering Technology, 3(2). https://doi.org/10.5176/2251-3701_3.2.129

Department of Justice. (2019). Charter Statement - Bill C-81: An Act to ensure a barrierfree Canada. Retrieved from https://www.justice.gc.ca/eng/csj-sjc/pl/chartercharte/c81.html.

Foltz, M. A. (1998). Designing Navigable Information Spaces. Washington University.

Gaines, K., Bourne, A., Pearson, M., \& Kleibrink, M. (2016). Designing for autism spectrum disorders. New York, NY: Routledge.

Gibbons, S. (2017). Service Desing 101. Retrieved from https://www.nngroup.com/articles/service-design-101/ 
Gibson, D. (2009). The Wayfinding Handbook: Information Design for Public Places (1st ed.). New York: Princeton Architectural Press.

Gillespie-Lynch, K. (2013). Response to and initiation of joint attention: overlapping but distinct roots of development in autism? OA Autism, 1(2), 13. Retrieved from http://www.oapublishinglondon.com/article/596

Golledge, R. G. (1999). Wayfinding behavior: cognitive mapping and other spatial processes. Baltimore: The John Hopkins University Press.

Goodman, E., Kuniavsky, M., \& Moed, A. (2012). Observing the User Experience: A Practitioner's Guide to User Research (2nd ed.). Elsevier Science \& Technology.

Government of Canada. (2019). Proposed Accessible Canada Act - Summary of the bill. Retrieved from https://www.canada.ca/en/employment-socialdevelopment/programs/accessible-people-disabilities/act-summary.html\#section39

Hanington, B., \& Martin, B. (2012). Universal Methods of Design. Rockport Publishers.

Howard, T. (2014). Journey mapping: A Brief Overview. Communication Design Quarterly Review, 2(3), 10-13. https://doi.org/10.1145/2644448.2644451

Hund, A. M., \& Gill, D. M. (2014). What constitutes effective wayfinding directions: The interactive role of descriptive cues and memory demands. Journal of Environmental Psychology, 38, 217-224. https://doi.org/10.1016/j.jenvp.2014.02.006

Kulik, T. K., \& Fletcher, T. S. (2016). Considering the Museum Experience of Children with Autism. Curator: The Museum Journal, 59(1), 27-38. https://doi.org/10.1111/cura.12143

Lamantia, J. (2003). Analyzing Card Sort Results with a Spreadsheet Template. Retrieved from boxesandarrows.com/analyzing-card-sort-results-with-a-spreadsheet- 
template $/ \% 0 \mathrm{D}$

Loomes, R., Hull, L., \& Mandy, W. (2017). What Is the Male-to-Female Ratio in Autism Spectrum Disorder? A Systematic Review and Meta-Analysis. American Academy of Child and Adolescent Psychiatry, 466-474. https://doi.org/10.1016/j.jaac.2017.03.013

Lussenhop, A., Mesiti, L. A., Cohn, E. S., Orsmond, G. I., Goss, J., Reich, C., ... LindgrenStreicher, A. (2016). Social participation of families with children with autism spectrum disorder in a science museum. Museums and Social Issues, 11(2), 122137. https://doi.org/10.1080/15596893.2016.1214806

Manning, J. (2017). In Vivo Coding. In The International Encyclopedia of Communication Research Methods (J, pp. 1-2). https://doi.org/10.1002/9781118901731.iecrm0270

Martin, C. S. (2016). Exploring the impact of the design of the physical classroom environment on young children with autism spectrum disorder (ASD). Journal of Research in Special Educational Needs, 16(4), 280-298.

https://doi.org/10.1111/1471-3802.12092

Milton, A., \& Rodgers, P. (2013). Research Methods for Product Design. London: Laurence King Publishing Ltd.

Morrow, S. L. (2005). Quality and Trustworthiness in Qualitative Research in Counseling Psychology. Journal of Counseling Psychology, 52(2), 250-260. https://doi.org/10.1037/0022-0167.52.2.250

Nicholas, H. (2000). The art and science of wayfinding. Access by Design, (85), 5-7.

Ofner, M., Coles, A., \& Decou, M. L. (2018). Autism Spectrum Disorder Among Children and Youth in Canada 2018: a Report of the National Autism Spectrum Disorder Surveillance System. 
Ontario. (2015). 2012 Building Code Compendium. Toronto: Ontario Ministry of Municipal Affairs and Housing, Building and Development Branch.

Ontario. (2019). How to make public spaces accessible. Retrieved from https://www.ontario.ca/page/how-make-public-spaces-accessible\%0D

Oxford Dictionary. (2019). Wayfinding. Retrieved from https://www.lexico.com/en/definition/wayfinding

Persson, H., Åhman, H., Yngling, A. A., \& Gulliksen, J. (2015). Universal design, inclusive design, accessible design, design for all: different concepts - one goal? On the concept of accessibility-historical, methodological and philosophical aspects. Universal Access in the Information Society, 14(4), 505-526. https://doi.org/10.1007/s10209-014-0358-z

Picanza, S. (2018). Top 5 Benefits of Wayfinding in Design. Retrieved January 24, 2020, from https://www.interiorsandsources.com/news/design-news/newsdetail/articleid/21925/title/top-5-benefits-of-wayfinding-in-design-\%OD

Pyramid Educational Consultants. (2019). Picture Exchange Communication System (PECS). Retrieved from https://pecsusa.com/pecs/

Saldana, J. (2016). The Coding Manual for Qualitative Researchers (3rd ed.). London: SAGE Publications Ltd.

Silverman, F., \& Tyszka, A. C. (2017). Supporting participation for children with sensory processing needs and their families: Community-based action research. American Journal of Occupational Therapy, 71(4), 1-9. https://doi.org/10.5014/ajot.2017.025544

Smith, A. D. (2015). Spatial navigation in autism spectrum disorders: A critical review. Frontiers in Psychology, 6(31), 1-8. https://doi.org/10.3389/fpsyg.2015.00031 
Snoezelen. (2020). What is Snoezelen. Retrieved from https://www.snoezelen.info/

Sparacino, F., Davenport, G., \& Pentland, A. (2000). Media in performance : Interactive spaces for dance, theater, circus, and museum exhibits. IBM System Journal, 39(3\&4), 479-510. https://doi.org/doi:10.1147/sj.393.0479

Spencer, D. (2009). Card Sorting: Designing Usable Categories. Brooklyn, New York: Louis Rosenfeld.

Symonds, P., Brown, D. H. K., \& Lo lacono, V. (2017). Exploring an absent presence: Wayfinding as an embodied sociocultural experience. Sociological Research Online, 22(1).

https://doi.org/doi:http://dx.doi.org.proxy.library.carleton.ca/10.5153/sro.4185

Tamara. (2016). Joint Attention: What is it and Why is it Important. Retrieved from https://teisinc.com/blog/joint-attention-important/

United Nations. (2006). Convention on the Rights of Persons with Disabilities (CRPD) Article 2 - Definitions. Retrieved from https://www.un.org/development/desa/disabilities/convention-on-the-rights-ofpersons-with-disabilities/article-2-definitions.html

Wolbers, T., \& Hegarty, M. (2010). What determines our navigational abilities? Trends in Cognitive Sciences, 14(3), 138-146. https://doi.org/10.1016/j.tics.2010.01.001 
APPENDICES

Appendix A-Ethics 


\section{Carleton}

U N I V E R S I T Y

Canada's Capital University

Office of Research Ethics

503 Robertson Hall | 1125 Colonel By Drive

Ottawa, Ontario K1S 5B6

613-520-2600 Ext: 4085

ethics@carleton.ca

\section{CERTIFICATION OF INSTITUTIONAL ETHICS CLEARANCE}

The Carleton University Research Ethics Board-B (CUREB-B) has granted ethics clearance for the research project described below and research may now proceed. CUREB-B is constituted and operates in compliance with the TriCouncil Policy Statement: Ethical Conduct for Research Involving Humans (TCPS2).

Ethics Protocol Clearance ID: Project \# 110898

Research Team: Amina Balaa (Primary Investigator)

Boris Vukovic (Research Supervisor)

Chantal Trudel (Research Supervisor)

Project Title: Wayfinding Experience of Persons with Autism Spectrum Disorders within a Museum Context

Funding Source (If applicable):

Effective: June 26, 2019

Expires: June 30, 2020.

Please ensure the study clearance number is prominently placed in all recruitment and consent materials: CUREB-B Clearance \# 110898. 


\section{A. 1 Ethics Clearance}

\section{Restrictions:}

This certification is subject to the following conditions:

1. Clearance is granted only for the research and purposes described in the application.

2. Any modification to the approved research must be submitted to CUREB-B via a Change to Protocol Form. All changes must be cleared prior to the continuance of the research.

3. An Annual Status Report for the renewal of ethics clearance must be submitted and cleared by the renewal date listed above. Failure to submit the Annual Status Report will result in the closure of the file. If funding is associated, funds will be frozen.

4. A closure request must be sent to CUREB-B when the research is complete or terminated.

5. During the course of the study, if you encounter an adverse event, material incidental finding, protocol deviation or other unanticipated problem, you must complete and submit a Report of Adverse Events and Unanticipated Problems Form, found here: https://carleton.ca/researchethics/forms-and-templates/

Failure to conduct the research in accordance with the principles of the TriCouncil Policy Statement: Ethical Conduct for Research Involving Humans 2ndedition and the Carleton University Policies and Procedures for the Ethical Conduct of Research may result in the suspension or termination of the research project.

Upon reasonable request, it is the policy of CUREB, for cleared protocols, to release the name of the $\mathrm{PI}$, the title of the project, and the date of clearance and any renewal(s).

Please contact the Research Compliance Coordinators, at ethics@carleton.ca, if you have any questions.

CLEARED BY:

Date: June 26, 2019

Bernadette Campbell, PhD, Chair, CUREB-B

Natasha Artemeva, PhD, Vice-Chair, CUREB-B 


\section{A. 1 Ethics Clearance}

\section{ALGOAYQIA | Research \\ COLLEGE Ethics Board}

\section{Algonquin College Research Ethics Board Certificate of Approval to Conduct Research}

\section{Protocol \#: 2019-DEC-TRUDEL}

This is to certify that the Algonquin College Research Ethics Board (REB) has approved the application for the research project titled:

\section{"Wayfinding Experience of Persons with Autism Spectrum Disorders within a Museum Context "}

to be conducted by:

\section{Chantal Trudel, Boris Vukovic, and Amina Balaa.}

The members of the REB are satisfied that this research project, as described in the application package, meets the appropriate ethical standards as set out in Algonquin College Policy REO3 - Research Involving Human Subjects.

This certification is valid for one year from the date indicated below. If the researcher(s) wish to continue their study beyond the date indicated below, they will be required to submit an Annual Research Renewal Form.

If at any time during the course of the study the participants or researcher(s) encounter any adverse events, they are required to report them to the REB immediately, per RE03 - Research Involving Human Subjects.

If at any time researchers wish to change any aspect of the study (e.g. data collection, recruitment procedures, research personnel), the researchers must inform the REB of the proposed changes and request their approval prior to implementing any changes.

Upon completion of the project, and no later than one year from the date indicated below, the principal investigator is required to submit a Project Completion Form to the REB.

The members of the Algonquin College REB would like to wish the researcher(s) well in their research.

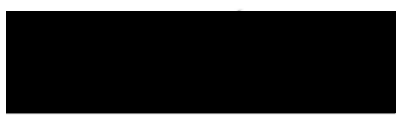

Jan 10, 2020

Janna Holmes

Chair, REB

Algonquin College 
Carleton

Canada's Capital University

$\underline{\text { Research Consent Text for Questionnaire }}$

Project Title

"Wayfinding Experience of Persons with Autism Spectrum Disorders within a Museum Context"

\section{Carleton University Project Clearance}

Clearance \#: $110898 \quad$ Date of Clearance: June 26, 2019

\section{Invitation}

We are asking you to complete this questionnaire because you selfidentify as a person with Autism Spectrum Disorder, are Englishspeaking, and are at least 18 years of age.

This questionnaire is being conducted by Amina Balaa of the Carleton University School of Industrial Design, Faculty of Engineering and Design (aminabalaa@cmail.carleton.ca) under the supervision of Professor Chantal Trudel and co-supervision of Dr. Boris Vukovic.

\section{Objectives and Summary}

This study will investigate the wayfinding at the Canada Science and Technology Museum to:

a) develop insight on how the current wayfinding system is being used and

b) to help us understand how that may be impacting persons on the spectrum

We estimate that the questionnaire will take about 10 minutes to complete. Your participation in this questionnaire is voluntary, and you may choose not to take part or answer any of the questions. With your consent to participate in this study you acknowledge this, therefore, participants cannot withdraw after they submit online. 


\section{Risks and Benefits}

We do not anticipate any risks from taking the survey, nor do we anticipate that you will derive any benefit.

\section{Confidentiality and Data Storage}

We will treat your personal information as confidential, although absolute privacy cannot be guaranteed. Your data will be stored and protected by Qualtrics on Toronto-based servers but may be disclosed via a court order or data breach. This is an anonymous questionnaire. All or any data will be kept in a password-protected file on a secure computer/password protected USB. We will password protect any research data that we store or transfer. With your consent to participate in this study you acknowledge this, as a result, participants cannot withdraw after they submit online. De-identified data will be shared with the Canada Science and Technology Museum as they are a collaborator in this research and may use the data to further their research on autism in museum design.

\section{Data Retention}

After the study is completed, the anonymous data will be retained for future research use.

\section{REB Review and Contact Information}

This project was reviewed and cleared by the Carleton University Research Ethics Board [B], which provided clearance (CUREB-B Clearance \# 110898) to carry out the research (Clearance expires on June 30, 2020). If you have any ethical concerns with the study, please contact Dr. Bernadette Campbell, Chair, Carleton University Research Ethics Board (by phone at 613-520-2600 [ext. 4085 for CUREB B] or by email at ethics@carleton.ca).

\section{Direct Consent}

I voluntarily agree to participate in this study.

Yes

No 


\section{Carleton}

U N I V E R S I T Y

Canada's Capital University

$\underline{\text { Research Consent Text for Observations }}$

Name and Contact Information of Researcher

Amina Balaa, Carleton University, School of Industrial Design, Faculty of Engineering and Design

Email: aminabalaa@cmail.carleton.ca

\section{Supervisor/Co-Supervisor}

Chantal Trudel / Dr. Boris Vukovic

\section{Project Title}

"Wayfinding Experience of Persons with Autism Spectrum Disorders within a Museum Context"

\section{Carleton University Project Clearance}

Clearance \#: $110898 \quad$ Date of Clearance: June 26, 2019

\section{Invitation}

You are invited to take part in a research project because you:

- self-identify as a person with Autism Spectrum Disorder,

- are English-speaking,

- are at least 18 years of age

The information in this form is intended to help you understand what we are asking of you so that you can decide whether you agree to participate in this study. Your participation in this study is voluntary, and a decision not to participate will not be used against you in any way. As you read this form, and decide whether to participate, please ask all the questions you might have, take whatever time you need, and consult with others as you wish.

\section{What is the purpose of the study?}

This study will investigate the wayfinding at the Canada Science and Technology Museum to: 
a) develop insight on how the current wayfinding system is being used and

b) to help us understand how that may be impacting persons on the spectrum

\section{What will I be asked to do?}

If you agree to take part in the study, we will ask you to:

- participate in a 30-60 min observation session.

- do a one on one walk through, with the researcher, of the Canada Scince and Technology Museum.

- the researcher will document your interactions with the environment and objects.

- you may be asked some questions regarding your interactions.

- with your consent, the session will be photographed and audio recorded.

\section{Risks and Inconveniences}

We do not anticipate any risks to participating in this study.

\section{Possible Benefits}

You may not receive any direct benefit from your participation in this study. However, your participation may allow researchers to better understand the wayfinding needs for persons with autism and may bring improvements/solutions to current wayfinding options in museum settings.

\section{Compensation/Incentives}

Each participant will be given a free entrance to the Canada Museum of Science and Technology (located at 1867 St Laurent Blvd.). You will also receive a family pass to enjoy at a later time.

Should you wish to participate with a friend, support person, family member, etc. an entrance pass for the guest will also be provided. Parking passes will be provided if required.

\section{No waiver of your rights}

By signing this form, you are not waiving any rights or releasing the researchers from any liability. 


\section{Withdrawing from the study}

If you withdraw your consent during the course of the study, all information collected from you before your withdrawal will be discarded. You may request that your data be removed from the study and deleted within 3 weeks after the completion of the observations, by notice given to the Principal Investigator (named above).

\section{Confidentiality}

We will remove all identifying information from the study data as soon as possible, which will be after completion of the analysis. We will treat your personal information as confidential, although absolute privacy cannot be guaranteed. No information that discloses your identity will be released or published. Research records may be accessed by the Carleton University Research Ethics Board in order to ensure continuing ethics compliance. All data will be kept confidential, unless release is required by law (e.g. child abuse, harm to self or others). De-identified data (including blurred/blocked faces in picture if applicable) will be shared with the Canada Science and Technology Museum as they are a collaborator in this research and may use the data to further their research on autism in museum design.

The results of this study including de-identified (blurred/blocked faces) photos may be published or presented at an academic conference or meeting, but the data will be presented so that it will not be possible to identify any participants. You will be assigned a code [or pseudonym] so that your identity will not be directly associated with the data you have provided. All data, including coded information, will be kept in a password-protected file on a secure computer/password protected USB. We will password protect any research data that we store or transfer.

\section{Data Retention}

After the study is completed, your de-identified data (transcriptions and analysis) will be retained for future research use. Any identifiable data (photos) will be retained for a period of 5 years and then securely destroyed.

\section{New information during the study}

In the event that any changes could affect your decision to continue participating in this study, you will be promptly informed. 


\section{A.3 Observation Consent Form}

\section{Ethics review}

This project was reviewed and cleared by the Carleton University Research Ethics Board [B], which provided clearance (CUREB-B Clearance \# 110898) to carry out the research (Clearance expires on June 30, 2020). If you have any ethical concerns with the study, please contact Dr. Bernadette Campbell, Chair, Carleton University Research Ethics Board (by phone at 613-520-2600 [ext. 4085 for CUREB B] or by email at ethics@carleton.ca).

\section{Statement of consent - print and sign name}

I voluntarily agree to participate in this study.

I agree to be photographed

I agree to be audio recorded

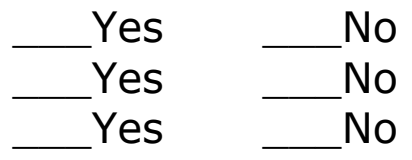

(If applicable) I agree to be contacted for follow up research Yes No

The researcher may contact me (the participant at) Email:

I want a report (or summary) of the research findings once the study is complete. Yes No

The researcher may contact me (the participant at) Email:

Signature of participant

Date

Research team member who interacted with the subject

I have explained the study to the participant and answered any and all of their questions. The participant appeared to understand and agree. I provided a copy of the consent form to the participant for their reference.

Signature of researcher

Date 


\title{
Carleton
}

U N I V E R S I T Y

Canada's Capital University

$\underline{\text { Research Consent Text for Workshop }}$

\section{Name and Contact Information of Researcher}

Amina Balaa, Carleton University, School of Industrial Design, Faculty of Engineering and Design

Email: aminabalaa@cmail.carleton.ca

\section{Supervisor / Co-Supervisor}

Chantal Trudel / Dr. Boris Vukovic

\section{Project Title}

"Wayfinding Experience of Persons with Autism Spectrum Disorders within a Museum Context"

\section{Carleton University Project Clearance}

\author{
Clearance \#:110898 Date of Clearance: June 26, 2019
}

\section{Invitation}

You are invited to take part in a research project because you:

$\checkmark$ are working with, have knowledge of or are in the field of ASD

$\checkmark$ may or may not have ASD

$\checkmark$ are English-speaking

$\checkmark$ are above the age of 18 $\checkmark$ self-identify as a person

OR with Autism Spectrum Disorder

$\checkmark$ are English-speaking

$\checkmark$ are above the age of 18

The information in this form is intended to help you understand what we are asking of you so that you can decide whether you agree to participate in this study. Your participation in this study is voluntary, and a decision not to participate will not be used against you in any way. As you read this form, and decide whether to participate, please ask all the questions you might have, take whatever time you need, and consult with others as you wish. 


\section{A.4 Workshop Consent Form}

\section{What is the purpose of the study?}

This study will investigate the wayfinding at the Science and Technology Museum to:

a) develop insight on how the current wayfinding system is being used and

b) to help us understand how that may be impacting persons on the spectrum.

\section{What will I be asked to do?}

If you agree to take part in the study, we will ask you to:

- participate in a 90 min design workshop.

- reflect on your individual experience and share those experiences with a group of people

- The workshop will take place at the Canada Science and Technology Museum.

- The workshop will be audio and video recorded. If you choose to be a part of this workshop, you may decline to be video recorded however, as part of the group exercise, audio recording is a necessary component.

\section{Risks and Inconveniences}

We do not anticipate any risks to participating in this study.

\section{Possible Benefits}

You may not receive any direct benefit from your participation in this study. However, your participation may allow researchers to better understand the wayfinding needs for persons with autism and may bring improvements/solutions to current wayfinding options in museum settings.

\section{Compensation/Incentives}

Each participant will be given a free entrance to the Canada Museum of Science and Technology (located at 1867 St Laurent Blvd.). You will be provided with light refreshments during the workshop. Parking passes will be provided if required.

\section{No waiver of your rights}

By signing this form, you are not waiving any rights or releasing the researchers from any liability. 


\section{Withdrawing from the study}

If you withdraw your consent during the course of the study, all information collected from you before your withdrawal will be discarded. You may request that your data be removed from the study and deleted within 3 weeks after the completion of the workshop, by notice given to the Principal Investigator (named above).

\section{Confidentiality}

We will remove all identifying information from the study data as soon as possible, which will be after completion of the analysis. We will treat your personal information as confidential, although absolute privacy cannot be guaranteed. No information that discloses your identity will be released or published. Research records may be accessed by the Carleton University Research Ethics Board in order to ensure continuing ethics compliance. All data will be kept confidential, unless release is required by law (e.g. child abuse, harm to self or others). De-identified data (including blurred/blocked faces in picture and recordings if applicable) will be shared with the Canada Science and Technology Museum as they are a collaborator in this research and may use the data to further their research on autism in museum design.

The results of this study including de-identified (blurred/blocked faces) photos and recordings may be published or presented at an academic conference or meeting, but the data will be presented so that it will not be possible to identify any participants. You will be assigned a code [or pseudonym] so that your identity will not be directly associated with the data you have provided. All data, including coded information, will be kept in a password-protected file on a secure computer/password protected USB. We will password protect any research data that we store or transfer.

\section{Data Retention}

After the study is completed, your de-identified data (transcriptions and analysis) will be retained for future research use. Any identifiable data (photos and videos) will be retained for a period of 5 years and then securely destroyed.

\section{New information during the study}

In the event that any changes could affect your decision to continue participating in this study, you will be promptly informed. 


\section{A.4 Workshop Consent Form}

\section{Ethics review}

This project was reviewed and cleared by the Carleton University Research Ethics Board [B], which provided clearance (CUREB-B Clearance \# 110898) to carry out the research (Clearance expires on June 30, 2020). If you have any ethical concerns with the study, please contact Dr. Bernadette Campbell, Chair, Carleton University Research Ethics Board (by phone at 613-520-2600 [ext. 4085 for CUREB B] or by email at ethics@carleton.ca).

\section{Statement of consent - print and sign name}

I voluntarily agree to participate in this study. I agree to be photographed

I agree to be video recorded

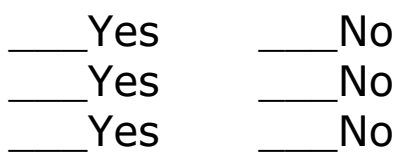

Please note, video recording of the workshop is optional, however, since this is a group activity, audio recording is necessary.

(If applicable) I agree to be contacted for follow up research Yes No

The researcher may contact me (the participant at) Email:

I want a report (or summary) of the research findings once the study is complete. Yes No

The researcher may contact me (the participant at) Email:

Signature of participant

Date

Research team member who interacted with the subject

I have explained the study to the participant and answered any and all of their questions. The participant appeared to understand and agree. I provided a copy of the consent form to the participant for their reference. 


\section{Appendix B - Recruitment}




\section{B.1 Survey Recruitment Email}

Subject: Invitation to participate in a research project on "Wayfinding Experience of Persons with Autism Spectrum Disorders within a Museum Context".

Please be advised that the PMC is not affiliated with the researcher. The PMC is sending the following message regarding this research opportunity on behalf of the research team.

Dear Sir or Madam,

My name is Amina Balaa and I am a Master's in Design student in the Department of Industrial Design at Carleton University. I am working on a research project under the supervision of Assistant Professor Chantal Trudel.

I am writing to you today to invite you to participate in a study entitled "Wayfinding Experience of Persons with Autism Spectrum Disorders within a Museum Context".

This study will investigate the wayfinding at the Canada Science and Technology Museum to:

a) develop insight on how the current wayfinding is being used and

b) to help us understand how that may be impacting persons with autism.

To be eligible, you must self-identify as a person Autism Spectrum Disorder, be English-speaking, and be at least 18 years of age.

This study involves a brief questionnaire that is available at the link https://carletonu.az1.qualtrics.com/jfe/form/SV 6M64kSePXxMtl53.

You will be asked to answer a series of open and close ended question. The study will take place online and should take approximately 10 minutes to complete.

The PMC is not involved in the research, your decision to participate or not will not affect any of the services currently receive through the PMC.

You will see a consent form at the beginning of the questionnaire. Once you consent, the questionnaire will begin. Care will be taken to protect your identity. This will be done by keeping all responses anonymous. Your data will be stored and protected by Qualtrics on Toronto-based servers but may be disclosed via a court order or data breach. With 
your consent to participate in this study you acknowledge this, as a result, participants cannot withdraw after they submit them online.

All research data will be password protected. Any hard copies/printed copies of data (including any handwritten notes) will be kept in a locked cabinet. Research data will only be accessible by the researcher and the research supervisors.

The ethics protocol for this project was reviewed by the Carleton University Research Ethics Board, which provided clearance (CUREB-B Clearance \# 110898) to carry out the research. (Clearance expires on June 30, 2020).

\section{CUREB-B:}

If you have any ethical concerns with the study, please contact Dr. Bernadette Campbell, Chair, Carleton University Research Ethics Board$B$ (by phone at $613-520-2600$ ext. 4085 or via email at ethics@carleton.ca).

For any further questions, please contact me at aminabalaa@cmail.carleton.ca.

Sincerely,

Amina Balaa 


\section{B.2 Observation Recruitment Email}

Subject: Invitation to participate in a research project on "Wayfinding Experience of Persons with Autism Spectrum Disorders within a Museum Context".

Please be advised that the PMC is not affiliated with the researcher. The PMC is sending the following message regarding this research opportunity on behalf of the research team.

Dear Sir or Madam,

My name is Amina Balaa and I am a Master's in Design student in the Department of Industrial Design at Carleton University. I am working on a research project under the supervision of Assistant Professor Chantal Trudel.

I am writing to you today to invite you to participate in a study entitled "Wayfinding Experience of Persons with Autism Spectrum Disorders within a Museum Context".

This study will investigate the wayfinding at the Canada Science and Technology Museum to:

a) develop insight on how the current wayfinding system is being used and

b) to help us understand how that may be impacting persons on the spectrum.

To be eligible, you must self-identify as a person with Autism Spectrum Disorder, be English-speaking, and be at least 18 years of age.

This study involves a one on one, 30-60 min shadowing/observing session. The researcher and the participant will tour the Canada Science and Technology Museum; the researcher will document observations about the participant's interactions and maneuvering around the exhibits. You will be asked to answer questions about your experiences in/related to wayfinding, space orientation and ease/comfort.

Each participant will be given a free entrance to the Canada Museum of Science and Technology (located at 1867 St Laurent Blvd.). You will also receive a family pass to enjoy at a later time. Should you wish to participate with a friend, support person, family member, etc. an 


\section{B.2 Observation Recruitment Email}

entrance pass for the guest will also be provided. Parking passes will be provided if required.

The PMC is not involved in the research, your decision to participate or not will not affect any of the services currently receive through the PMC.

You will be asked to sign a consent form at the beginning of the session. Once you consent, the session will begin. With your consent, the session will be photographed, and audio recorded. Care will be taken to protect your identity. This will be done by keeping your identity anonymous (names will be coded as P1, P2, P3...).

You will have the right to end your participation in the study at any time, for any reason, up until 3 weeks after your participation. If you choose to withdraw, all the information you have provided will be destroyed.

As a token of appreciation, you will be given a free entrance to the Canada Museum of Science and Technology and a family pass to enjoy at a later time. Parking passes will be provided, if required.

All research data will be password protected. Any hard copies/printed copies of data (including any handwritten notes) will be kept in a locked cabinet. Research data will only be accessible by the researcher and the research supervisors.

The ethics protocol for this project was reviewed by the Carleton University Research Ethics Board [B], which provided clearance (CUREB-B Clearance \# 110898) to carry out the research. (Clearance expires on June 30,2020 ).

CUREB-B:

If you have any ethical concerns with the study, please contact Dr. Bernadette Campbell, Chair, Carleton University Research Ethics Board$B$ (by phone at 613-520-2600 ext. 4085 or via email at ethics@carleton.ca).

If you would like to participate in this research project, or have any questions, please contact me at aminabalaa@cmail.carleton.ca.

Sincerely, Amina Balaa 
Subject: Invitation to participate in a research project on "Wayfinding Experience of Persons with Autism Spectrum Disorders within a Museum Context".

Please be advised that the PMC is not affiliated with the researcher. The PMC is sending the following message regarding this research opportunity on behalf of the research team.

Dear Sir or Madam,

My name is Amina Balaa and I am a Master's in Design student in the Department of Industrial Design at Carleton University. I am working on a research project under the supervision of Assistant Professor Chantal Trudel.

I am writing to you today to invite you to participate in a study entitled "Wayfinding Experience of Persons with Autism Spectrum Disorders within a Museum Context".

This study will investigate the wayfinding at the Science and Technology Museum to:

a) develop insight on how the current wayfinding system is being used and

b) to help us understand how that may be impacting persons on the spectrum.

To be eligible, you:

$\checkmark$ are working with, have knowledge of or are in the field of ASD

$\checkmark$ may or may not have ASD

$\checkmark$ are English-speaking

$\checkmark$ are above the age of 18 $\checkmark$ self-identify as a person

OR with Autism Spectrum Disorder

$\checkmark$ are English-speaking

$\checkmark$ are above the age of 18

This study involves one 90-minute Design Thinking Workshop that will take place at the Canada Science and Technology Museum. With your consent, the workshop session will be audio and video recorded. Care will be taken to protect your identity. This will be done by providing an option of remaining anonymous (names will be coded as P1, P2, P3...). 
The PMC is not involved in the research, your decision to participate or not will not affect any of the services currently receive through the PMC.

You will have the right to end your participation in the study at any time, for any reason, up until 3 weeks after your participation. If you choose to withdraw, all the information you have provided will be destroyed.

As a token of appreciation, you will be given a free entrance to the Canada Museum of Science and Technology and a family pass to enjoy at a later time. Should you wish to participate with a friend, support person, family member, etc. an entrance pass for the guest will also be provided. Parking passes will be provided if required.

I will also be providing you with light refreshments during the workshop. Parking passes will be provided, if required.

The workshop will be audio and video recorded. If you choose to be a part of this workshop, you may decline to be video recorded however, as part of the group exercise, audio recording is a necessary component.

All research data will be password protected. Any hard copies/printed copies of data (including any handwritten notes) will be kept in a locked cabinet. Research data will only be accessible by the researcher and the research supervisors.

The ethics protocol for this project was reviewed by the Carleton University Research Ethics Board [B], which provided clearance (CUREB-B Clearance \# 110898) to carry out the research. (Clearance expires on June 30, 2020).

CUREB-B:

If you have any ethical concerns with the study, please contact Dr. Bernadette Campbell, Chair, Carleton University Research Ethics Board$B$ (by phone at 613-520-2600 ext. 4085 or via email at ethics@carleton.ca).

If you would like to participate in this research project, or have any questions, please contact me at aminabalaa@cmail.carleton.ca.

Sincerely, Amina Balaa 


\section{B.4 Observation and Workshop Recruitment Poster}
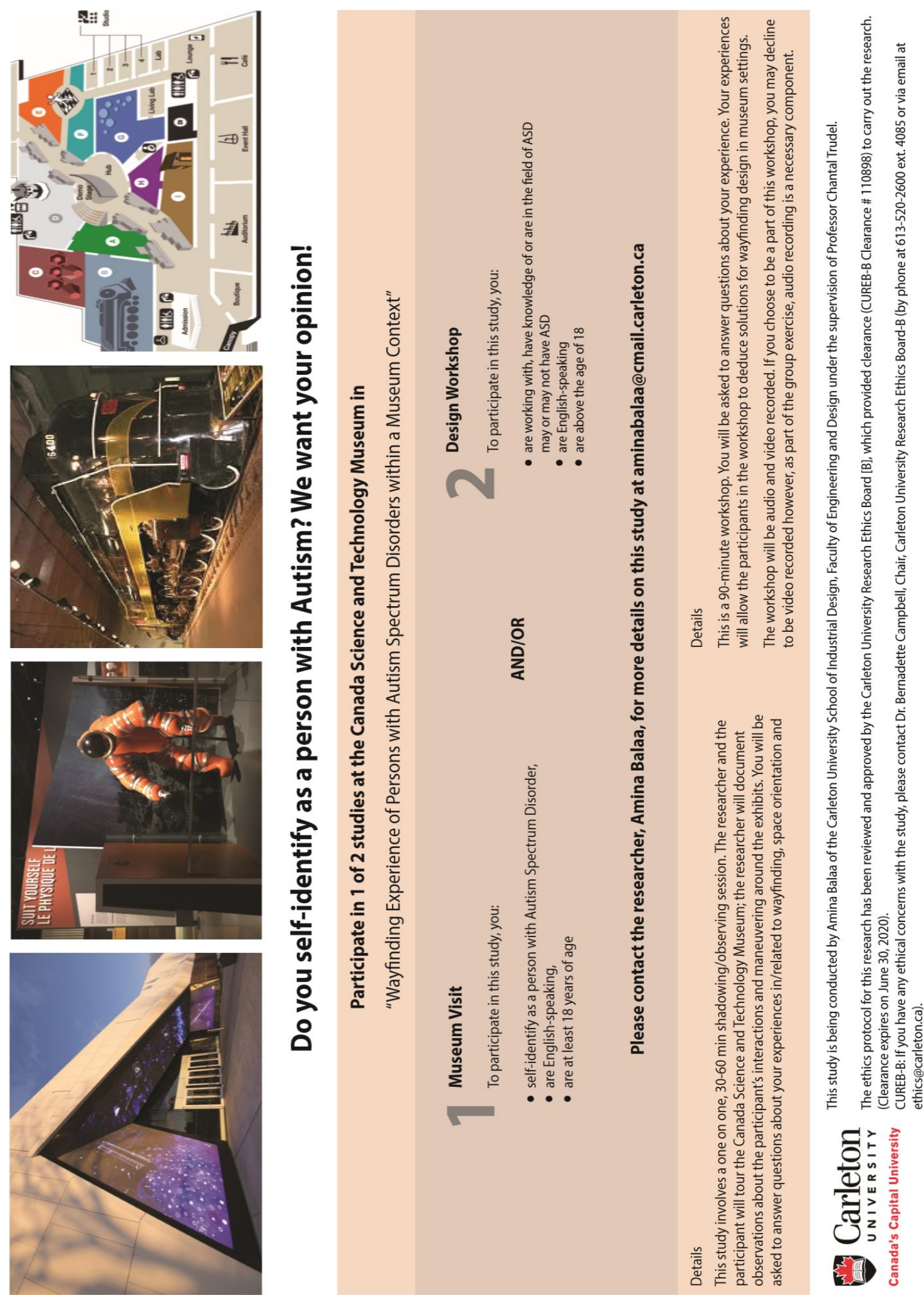
Appendix C - Survey 


\section{C.1 Survey Questions}

Following consenting to the survey:

Q. 1

$0 \%-100 \%$

Carleton

Do you self identify as a person with Autism Spectrum Disorder?

Yes

No

$\leftarrow$ Back

$\rightarrow$ Next

Exit survey 


\section{C.1 Survey Questions}

Q. 2

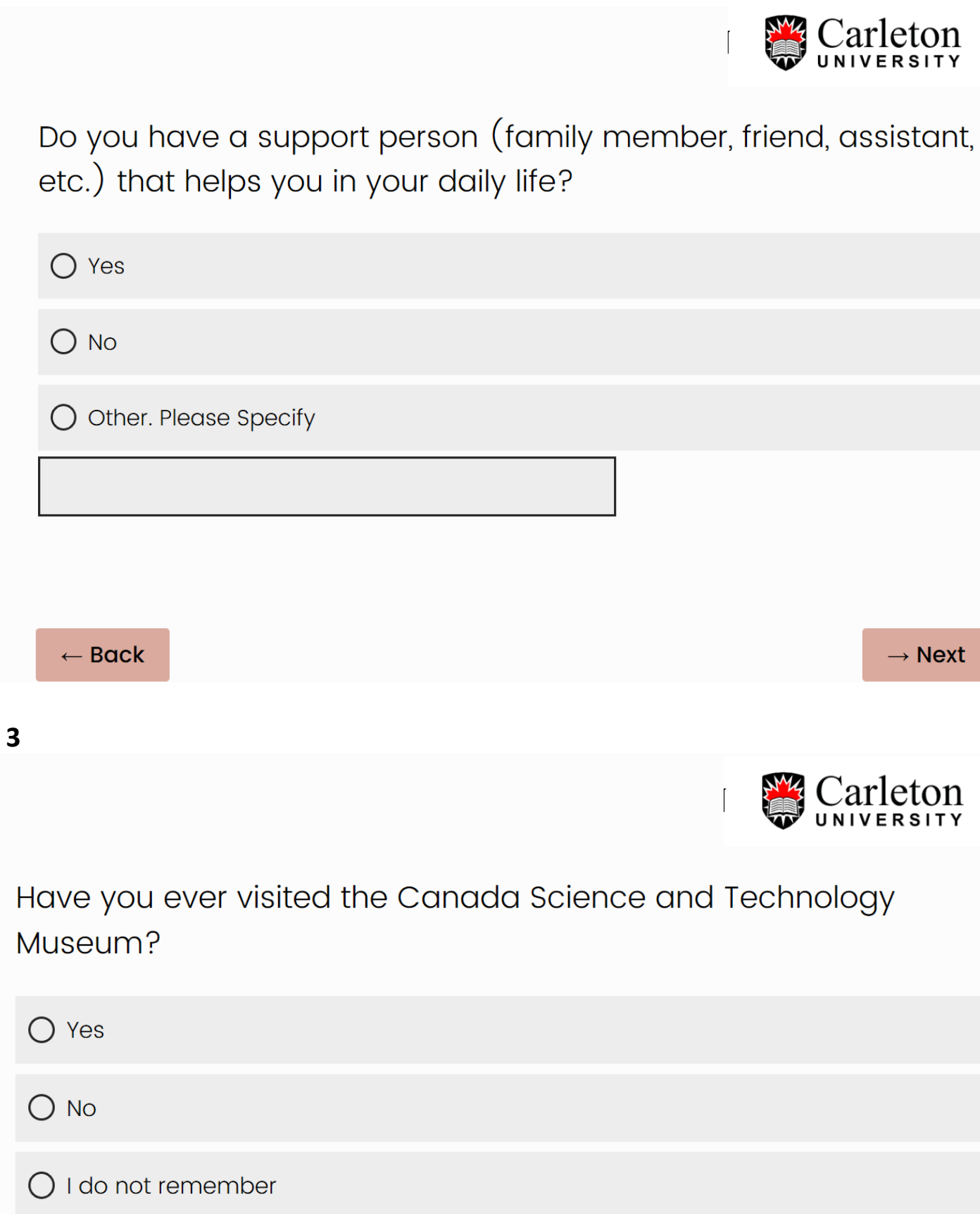




\section{C.1 Survey Questions}

Q. 4

UNIVERSIIY

How would you rate your most recent visit to the Canada Science and Technology Museum on a scale of 1-5? (move the circle along the bar)

1 being not engaging at all.

2 being a little engaging.

3 being engaging.

4 being very engaging.

5 being extremely engaging.

O 


\section{C.1 Survey Questions}

Q. 5

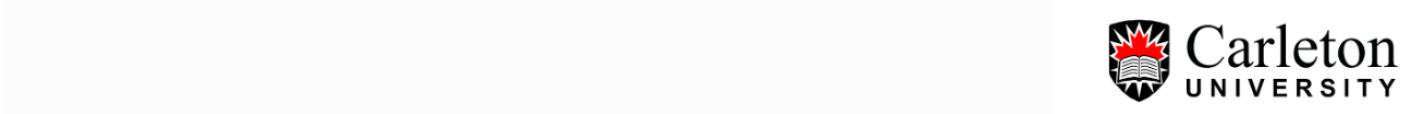

When is the last time you visited the Canada Science and Technology Museum?

This year (2019)

When it reopened in 2017

I do not remember

Other. Please specify

$$
\leftarrow \text { Back }
$$

Q. 6

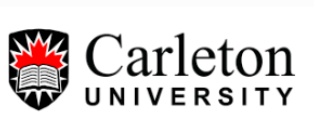

Have you visited other museums?
Yes
No

$\leftarrow$ Back

$\rightarrow$ Next 


\section{C.1 Survey Questions}

Q.7

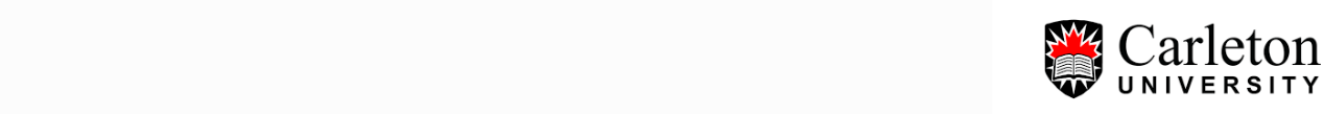

Did you bring along a support person with you on your visit(s) (ex. Family, friend, etc.)?

Yes I had a support person (family, friend, etc) with me

No I did not have anyone with me

$\leftarrow$ Back

Q.8

Did you bring along or use any items or devices that supported your visit? (Ex: headphones, fidget gadget...)

$\bigcirc$ Yes I had an item(s)/device(s) to help me. Please Specify what items:

No I did not 


\section{C.1 Survey Questions}

Q. 9

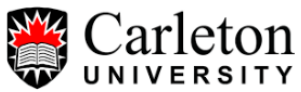

Would you like to visit the Canada Science and Technology Museum?
$\bigcirc$ Yes
$\bigcirc$ No
Maybe

$$
\leftarrow \text { Back }
$$

Q. 10

Would you like to visit the Canada Science and Technology Museum again?
$\bigcirc$ Yes
$\bigcirc$ No
Maybe

$$
\leftarrow \text { Back }
$$




\section{C.1 Survey Questions}

Q.11

Carleton

If given the chance, what type of museum would you love to visit and/or invent? Think about what would be an ideal space for you to be most comfortable in when navigating new surroudings.

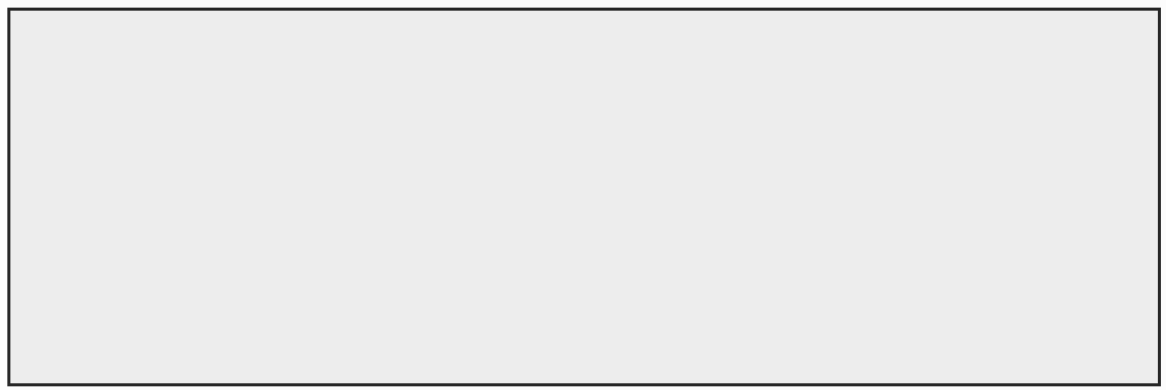

Q. 12

\section{Carleton \\ U N I VERSITY}

Please feel free to comment on any other relevant information or story that you would like to share about your experience visiting museums. 


\section{C.2 After the Survey}

\section{Carleton UNIVERSITY}

\section{Thank you for participating in this Questionnaire!}

For my research project, conducting this Questionnaire was one of the first steps toward accomplishing my objectives. After evaluation of this questionnaire, I would like to carry out two more data collection methods;

1) a museum visit (Observation) at the Canada Science and Technology Museum and

2) a Workshop at the museum.

I invite you to continue participating in the upcoming methods. If you wish to participate in any/or both methods, you may contact me for details, at: aminabalaa@cmail.carleton.ca

As a token of appreciation, you will receive a family pass to the Canada Science and Technology Museum for your participation in Museum Visit (Observation) and/or Workshop. If you participate in both methods, 2 passes will be given. Parking passes will be provided, if required.

DETAILS:

During the Museum Visit (Observations), you (and a friend or family member as you wish) will visit the Canada Science and Technology Museum and I will accompany you on your visit to observe/shadow your experience. I will simply document your interactions with the space and the exhibits and will ask a few debriefing questions afterwards. This is a one on one session and will take 30-60 minutes.

In the Design Workshop, a small group of participants work together with the help of design method tools to discuss the current wayfinding available at the Canada Science and Technology Museum. This will take approximately 90 minutes to complete.

To be eligible, you:

- Self identify as a person with Autism Spectrum Disorder,

- are English-speaking,

- are at least 18 years of age

OR (for the workshop)

- Are working with, have knowledge of, or are in the field of Autism Spectrum Disorder,

- are English-speaking,

- are above the age of 18

The ethics protocol for this research has been reviewed and approved by Carleton University Research Board [B], which provide clearance (CUREB-B Clearance \# 110898). Clearance expires on June 30, 2020.

CUREB-B: If you have any ethical concerns with the study, please contact Dr. Bernadette Campbell, Chair, Carleton University Research Ethics Board-B (by phone at $\underline{613-520-2600}$ ext. 4085 or via ethics@carleotn.ca). 
Appendix D - First Cycle Coding Results from Questionnaire 
Q. 10

First Cycle coding

\begin{tabular}{|c|c|}
\hline Participant Excerpts & In Vivo Codes \\
\hline $\begin{array}{l}\text { "...be preferable to have some level of sound suppression..." } \\
\text { "...go to an area of the museum that is quieter." }\end{array}$ & $\begin{array}{l}\text { - Sound suppression } \\
\text { - Quieter }\end{array}$ \\
\hline $\begin{array}{l}\text { "Quieter } \\
\text { "... separate rooms so the sound doesn't spread as far." } \\
\text { "Well lit..." }\end{array}$ & $\begin{array}{l}\text { - Quieter } \\
\text { - Separate rooms } \\
\text { - Well lit }\end{array}$ \\
\hline $\begin{array}{l}\text { "Interactive exhibits..." } \\
\text { "...open space to limit crowding..." } \\
\text { "...limits on noise levels..." }\end{array}$ & $\begin{array}{l}\text { - Interactive exhibits } \\
\text { - Open space } \\
\text { - Noise levels }\end{array}$ \\
\hline $\begin{array}{l}\text { "A space with a lot to interact with..." } \\
\text { Noise from other attendants is a personal problem }\end{array}$ & $\begin{array}{ll}\text { - } & \text { Interact with } \\
\text { - } & \text { Noise }\end{array}$ \\
\hline $\begin{array}{l}\text { "I find more radial floor plans are best for ease of navigation. I } \\
\text { believe that having exhibits extending out from a central area } \\
\text { is often a better use of space, as it allows for easy access to all } \\
\text { parts of the museum." } \\
\text { "...open concept designs are a preferable option to } \\
\text { labyrinthine hallways." } \\
\text { "Signs are always helpful. ... would enjoy getting lost there." }\end{array}$ & $\begin{array}{ll}\text { - } & \text { Radial floor plan } \\
\text { - } & \text { Easy access } \\
\text { - } & \text { Open concept } \\
\text { - } & \text { Signs are helpful } \\
\text { - } & \text { Enjoy getting lost }\end{array}$ \\
\hline "...from what I've heard the spaces are very open and linear." & - Open and linear \\
\hline $\begin{array}{l}\text { "I liked the darkness of that section with the rocks lit up in their } \\
\text { cases." } \\
\text {...It was also the quietest section. }\end{array}$ & $\begin{array}{l}\text { - Darkness } \\
\text { - Quiet }\end{array}$ \\
\hline $\begin{array}{l}\text { "I would have my museum have a linear design, so as to have } \\
\text { a sense of progression." }\end{array}$ & $\begin{array}{l}\text { - Linear design } \\
\text { - Progression }\end{array}$ \\
\hline
\end{tabular}

Table 5: Q. 10 first cycle coding 


\section{Q.11}

\section{First cycle of coding}

\begin{tabular}{|c|c|}
\hline Participant Excerpts & In Vivo Codes \\
\hline $\begin{array}{l}\text { "I found out that they had virtually no sound dampeners in } \\
\text { place...if they decided to install something like carpets onto } \\
\text { the roof of the museum, it may reduce the level of } \\
\text { discomfort for those of us with hearing sensitivities and } \\
\text { allow us to explore more of the museum rather then just the } \\
\text { quiet areas." }\end{array}$ & $\begin{array}{l}\text { - } \text { No sound dampeners } \\
\text { - } \text { Discomfort } \\
\text { - } \text { Hearing sensitivities } \\
\text { museum rather then just the } \\
\text { quiet areas }\end{array}$ \\
\hline $\begin{array}{l}\text { "... The main area of the [museum] was loud mainly because } \\
\text { of the children's groups. The special exhibit was in a } \\
\text { separate part with less people, so it was quieter... I spent } \\
\text { most of my time in there." }\end{array}$ & $\begin{array}{ll}\text { - } & \text { Loud } \\
\text { - } & \text { Separate part } \\
\text { - } & \text { Quieter } \\
\text { - } & \text { Spent most time in there }\end{array}$ \\
\hline $\begin{array}{l}\text { "The architecture should complement the subject } \\
\text { matter...not distract from it." } \\
\text { "The exhibits still get your undivided attention. The National } \\
\text { Art Gallery, for the most part, is very minimalist... There are } \\
\text { spots there... where the art gallery asserts its own identity, } \\
\text { with tall walkways and rooms... which complement and add } \\
\text { to it's calm, restful character." }\end{array}$ & $\begin{array}{l}\text { - } \text { [architecture] Not distract } \\
\text { - } \text { Urom it [subject matter] } \\
\text { - } \text { Minimided attention } \\
\text { - } \quad \text { Calm, restful }\end{array}$ \\
\hline $\begin{array}{l}\text { "Sometimes there are exhibits that are quite crowded and I } \\
\text { tend to avoid those exhibits... it's also a bit too stimulating." }\end{array}$ & $\begin{array}{l}\text { - } \quad \text { Crowded } \\
\text { - } \quad \text { Too stimulating }\end{array}$ \\
\hline
\end{tabular}

Table 6: Q. 11 first cycle coding 
Appendix E-Observations 
Participants were given the consent form (see Appendix A.3) to sign before starting the study. I explained the activity and answered any questions they may have.

Participants were given the choice of using support tools during their museum visit.

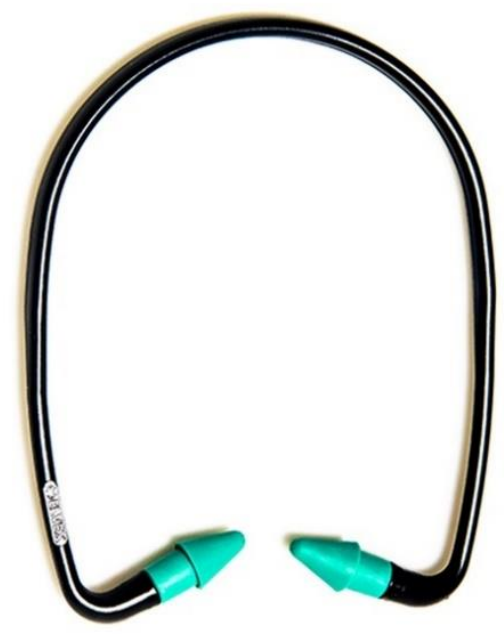

Figure 29: Ear plugs

(purchased from https://www.nationalautismresources.com/eas y-find-band-ear-plugs/)

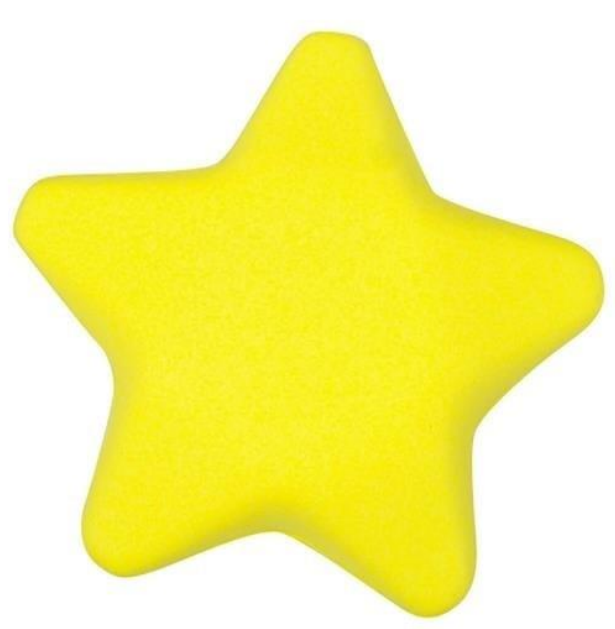

Figure 30: Squeeze star

(purchased from

https://www.nationalautismresources.com/squeez e-star/)

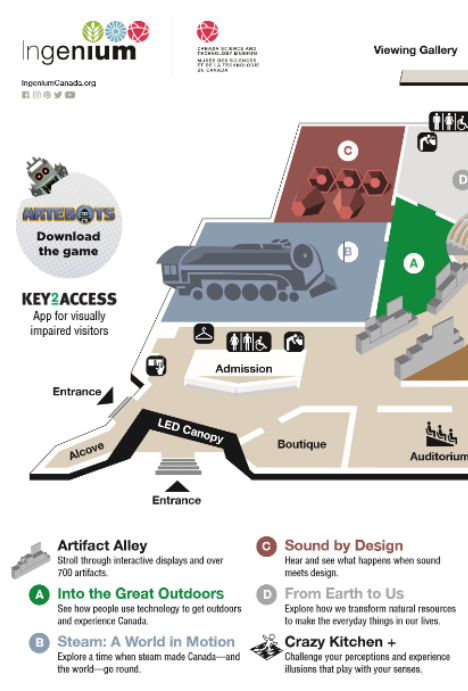

Figure 31: Map of the museum

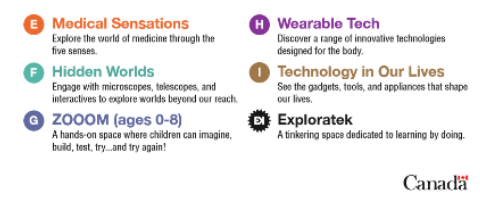


Appendix F-Workshop 
The card sorting activity had the following two categories that were sorted into the sections below.

\section{Daily Life}

Figure 32: Daily Life category Title

\section{Canada Science and Technology Museum}

Figure 33: Canada Science and Technology Museum category title
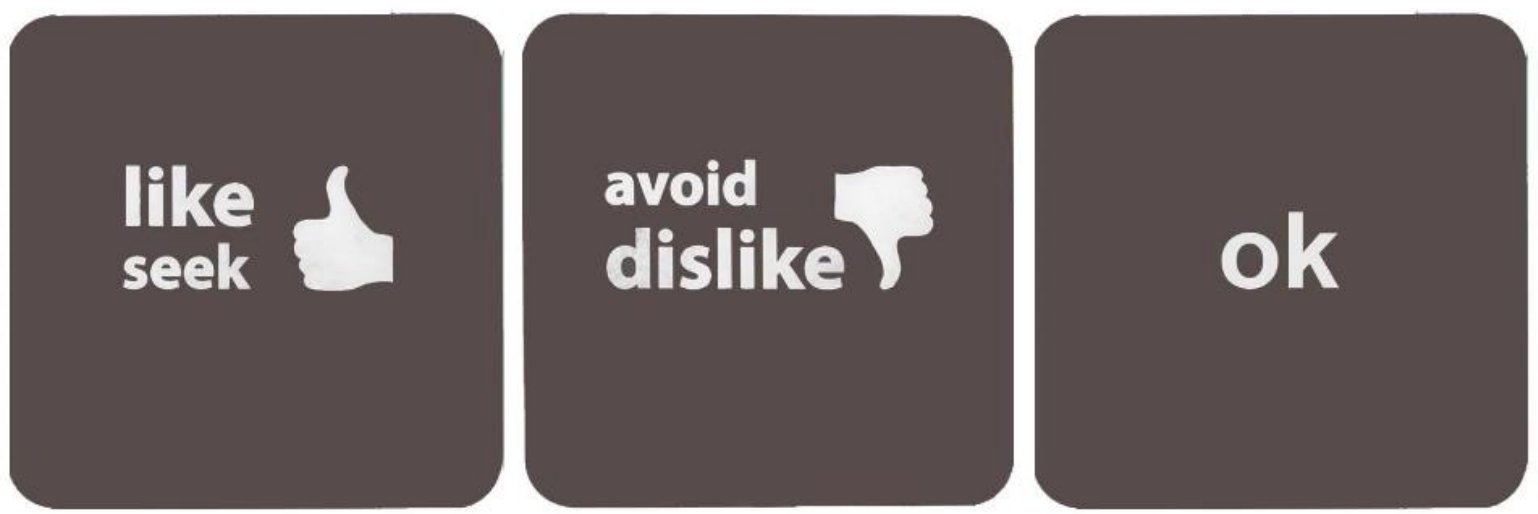

Figure 34: Like (seek), Dislike (avoid), and OK pile titles 


\section{F. 2 Kingwood Sensory Picture Cards}

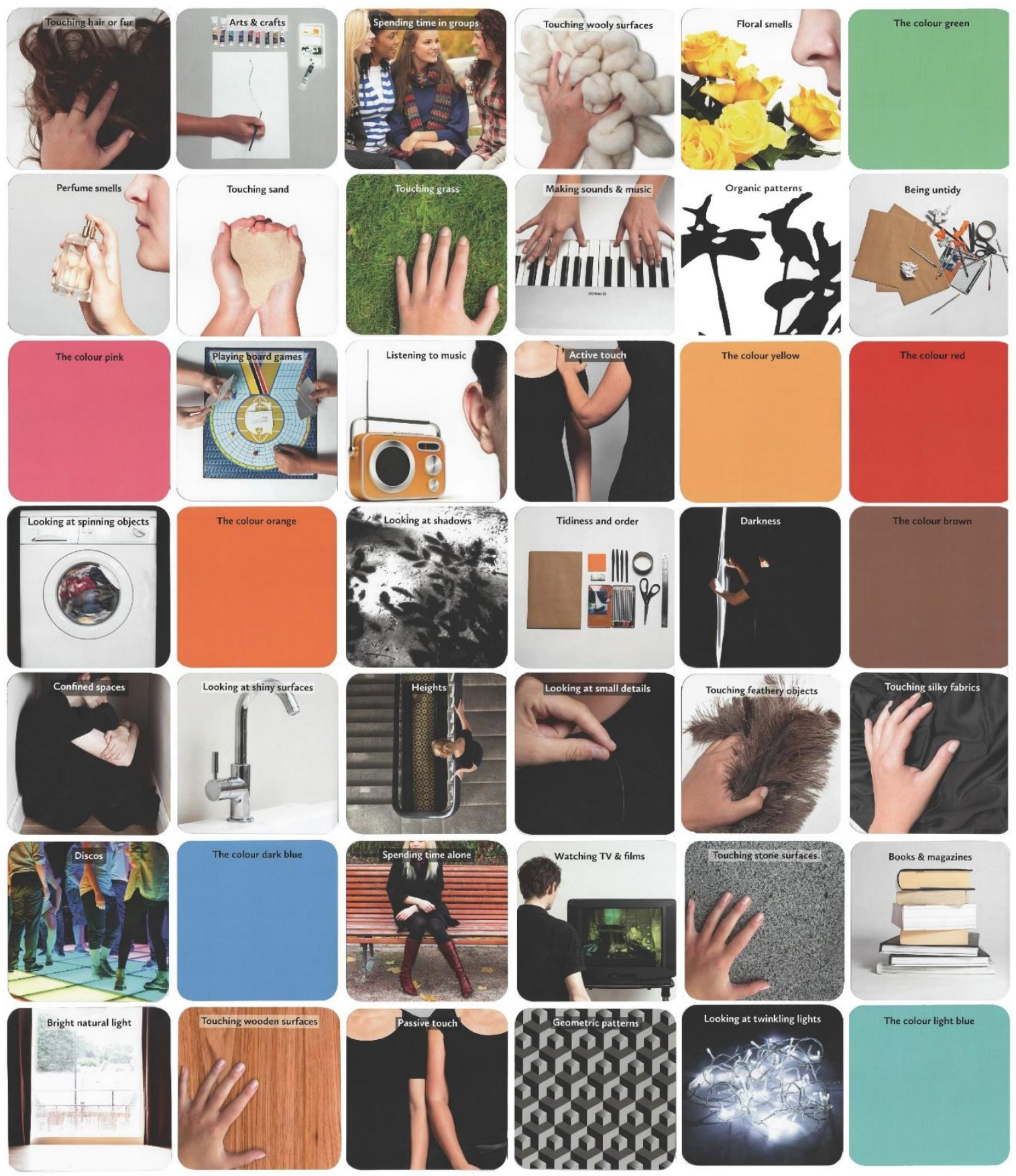

Figure 35: Kingwood Sensory Picture Cards 


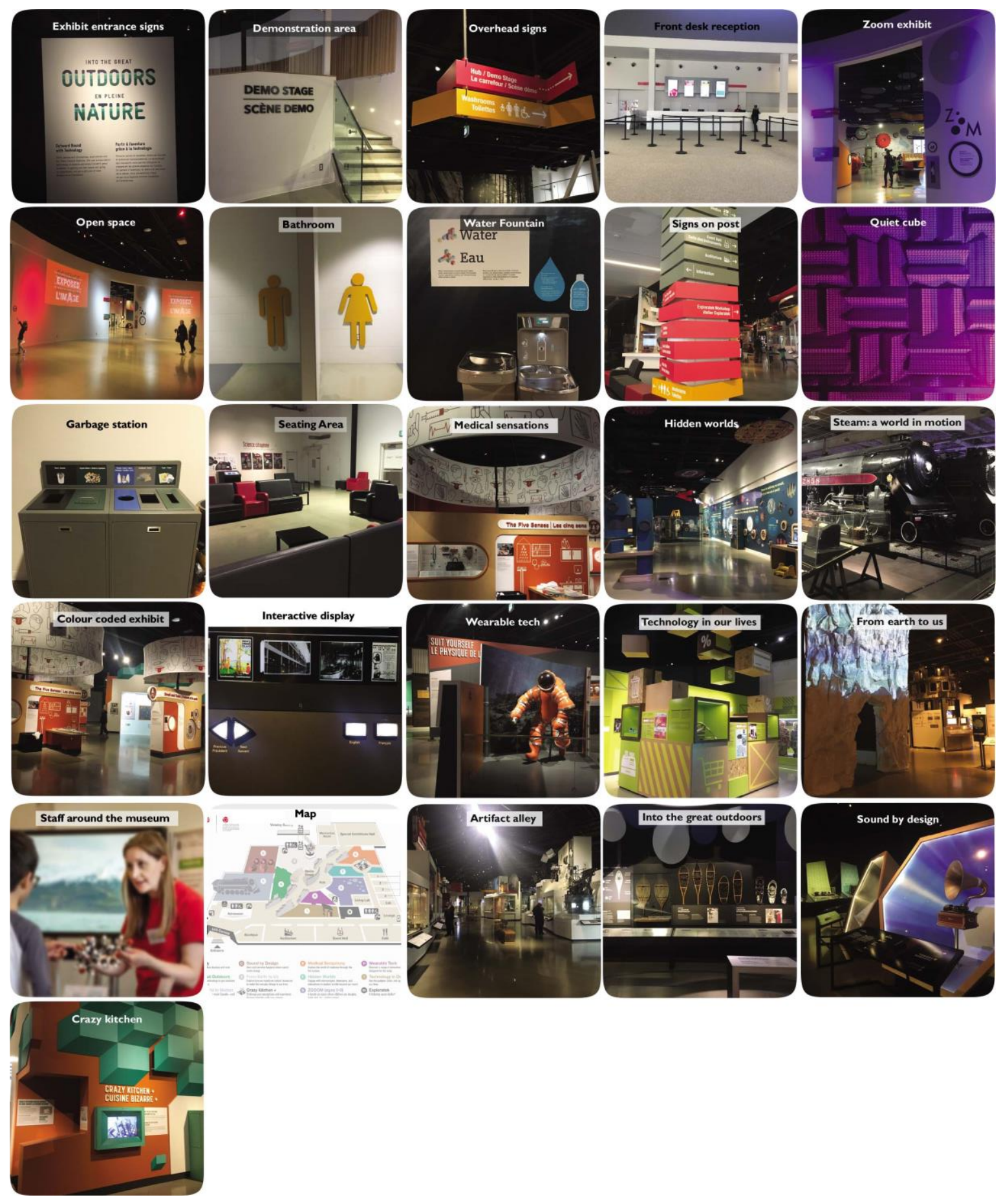

Figure 36: Museum Picutre Cards 

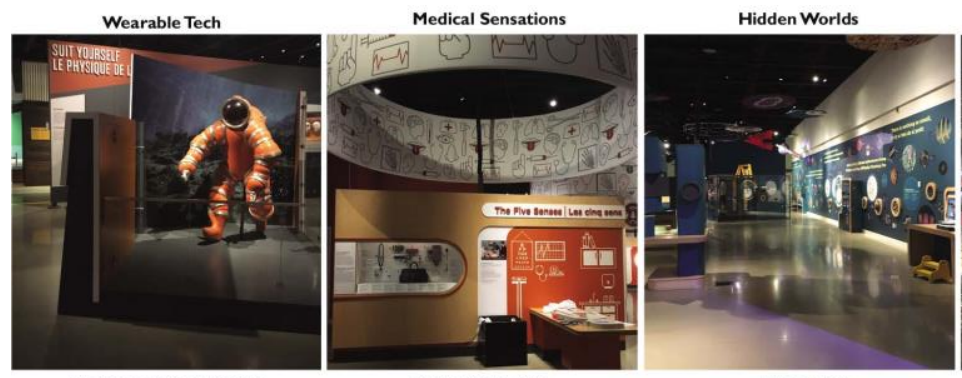

Steam: A World in Motion
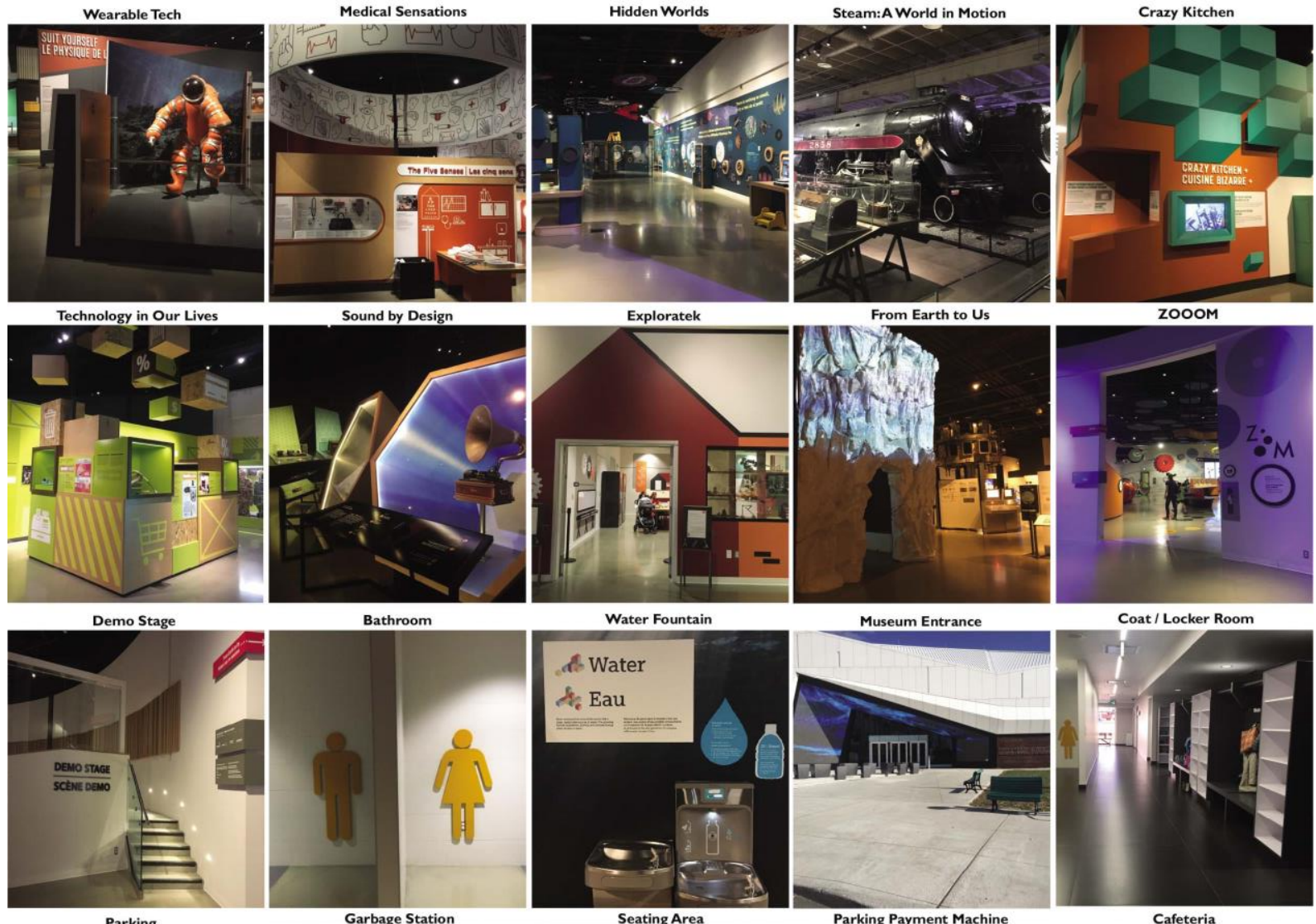

Museum Entrance

Coat / Locker Room
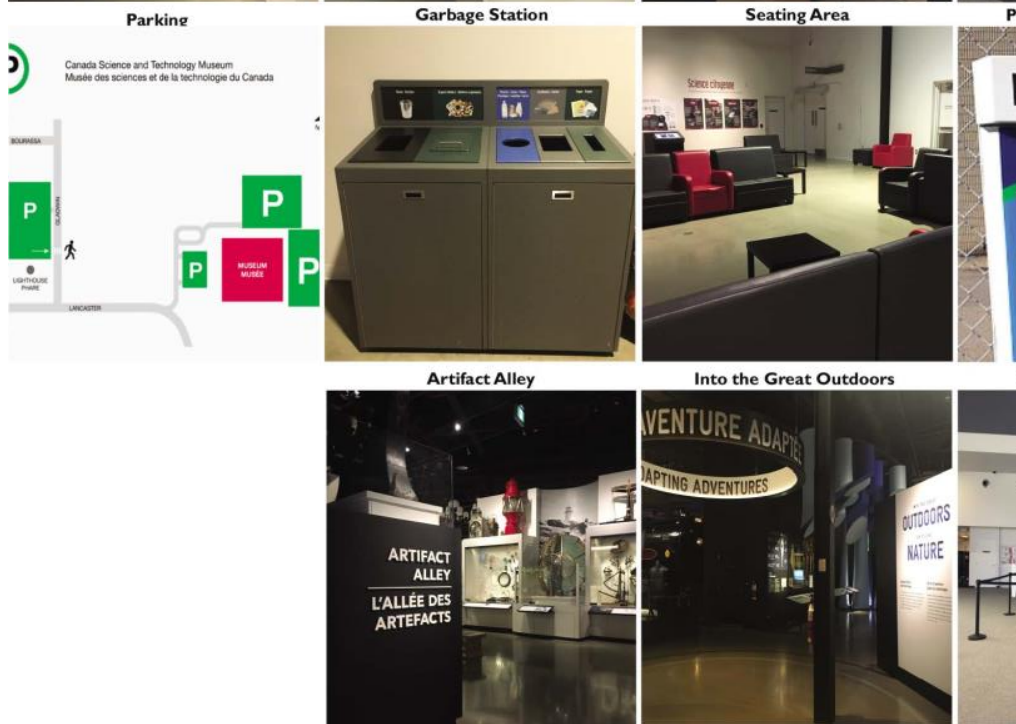

Into the Great Outdoors

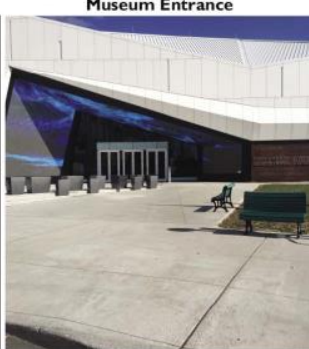

Parking Payment Machine

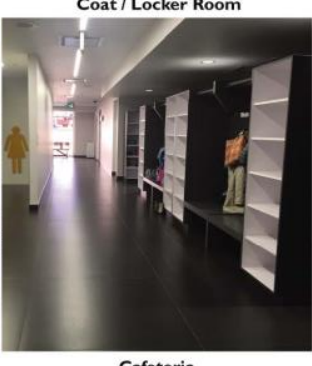

Cafeteria

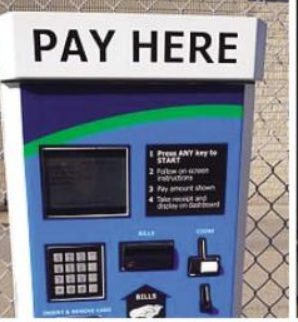

Reception Front Desk
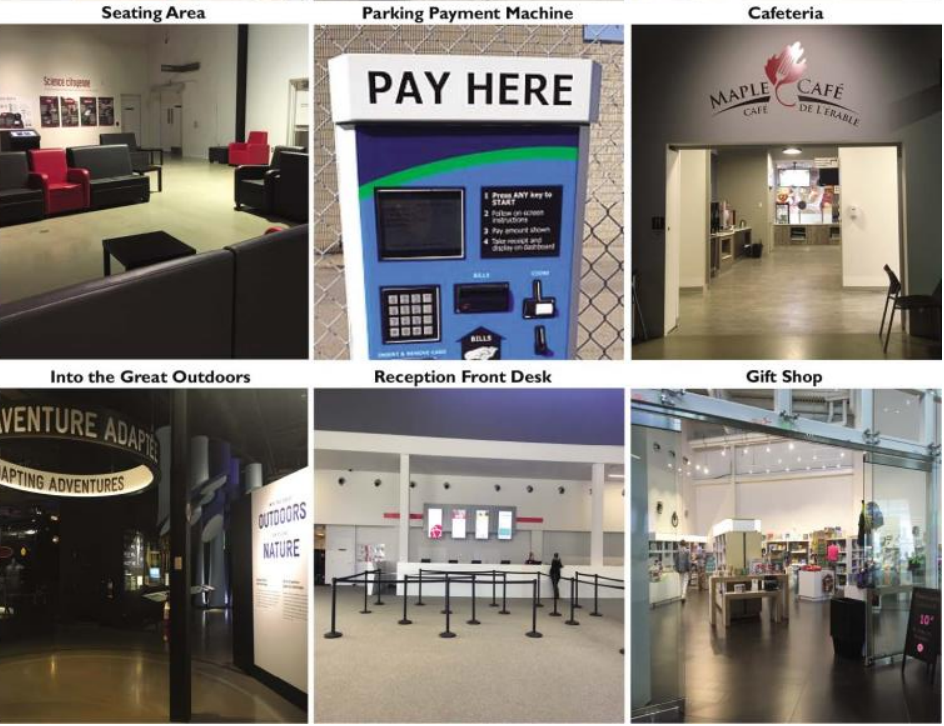

Figure 37: Journey Mapping Cards 


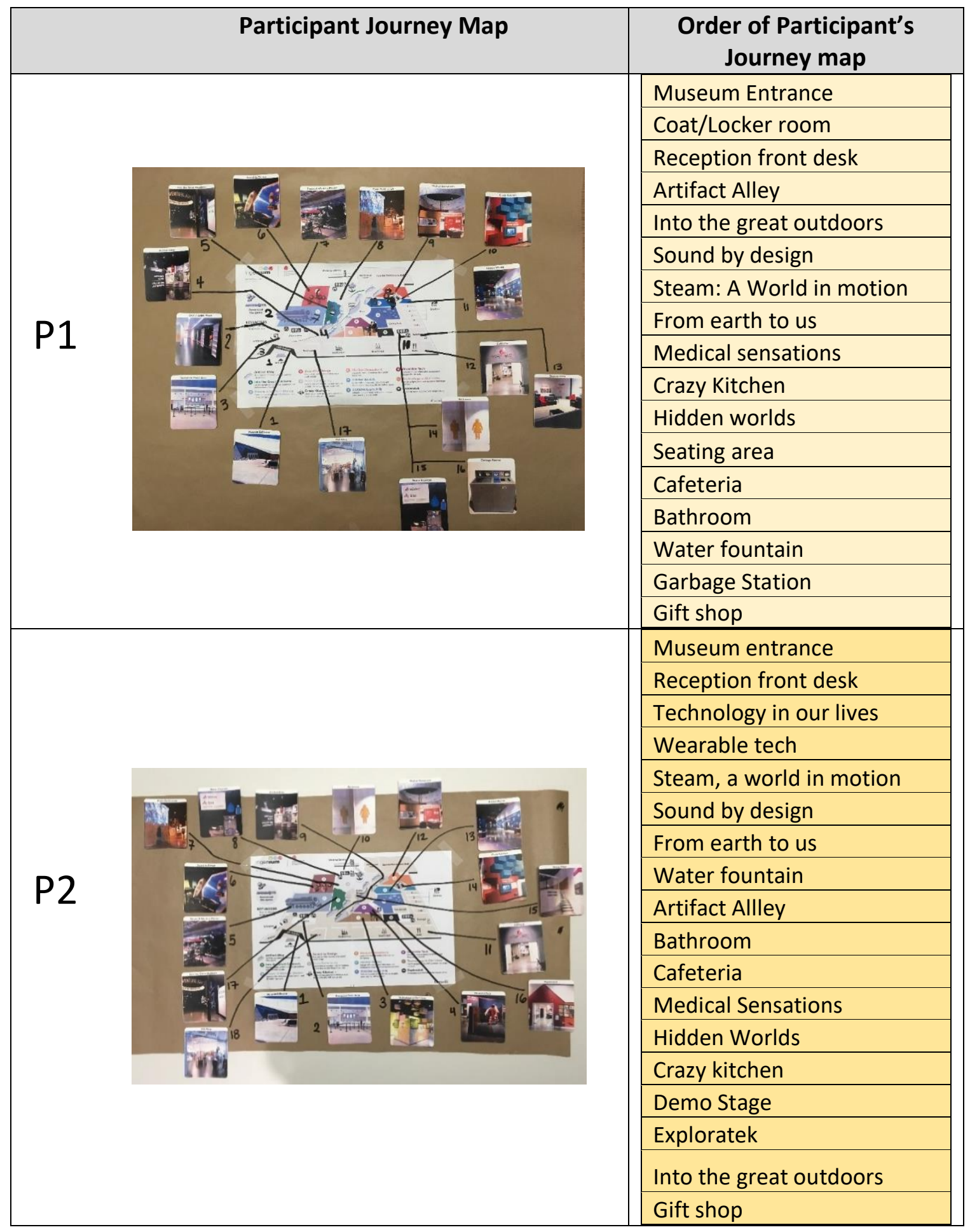




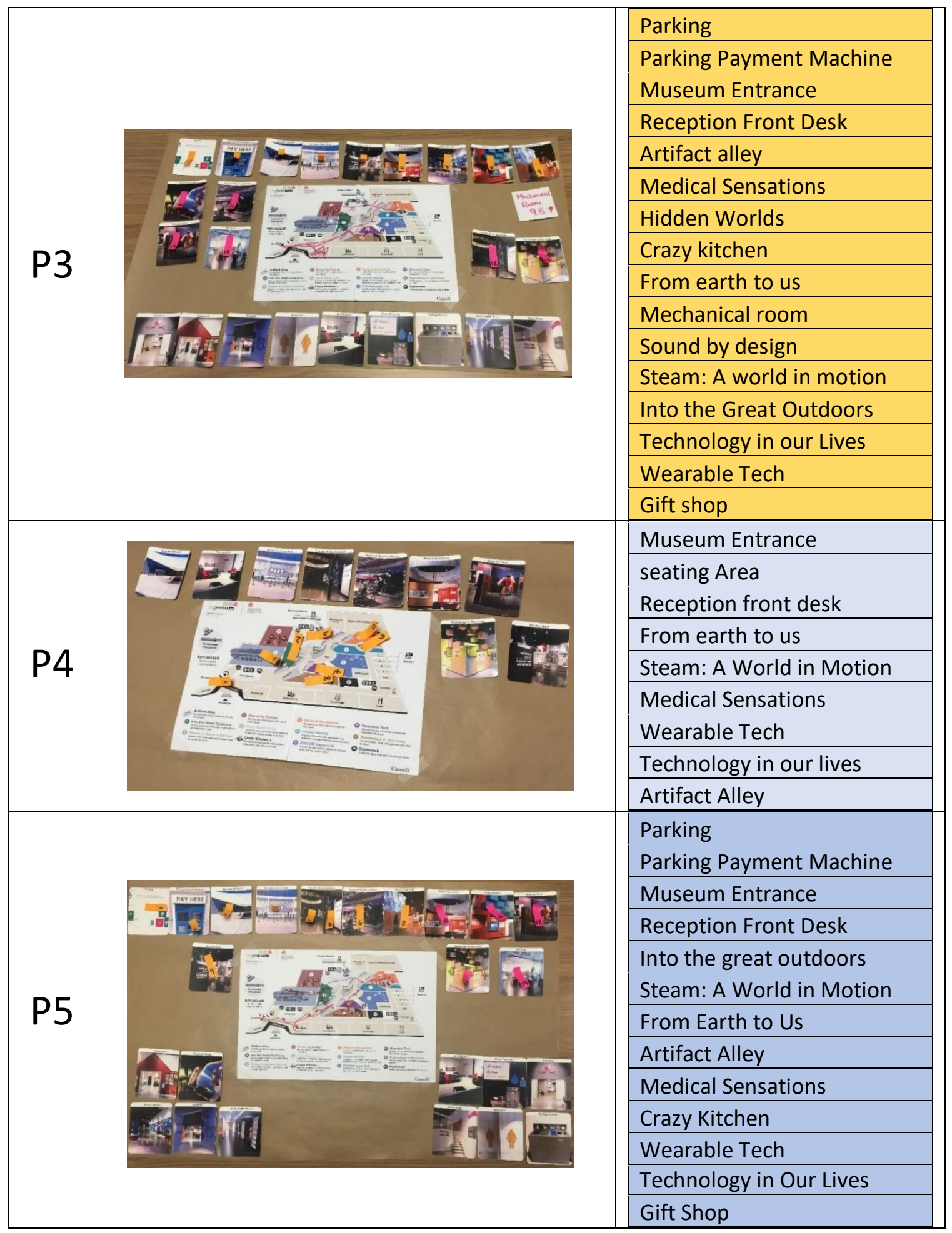




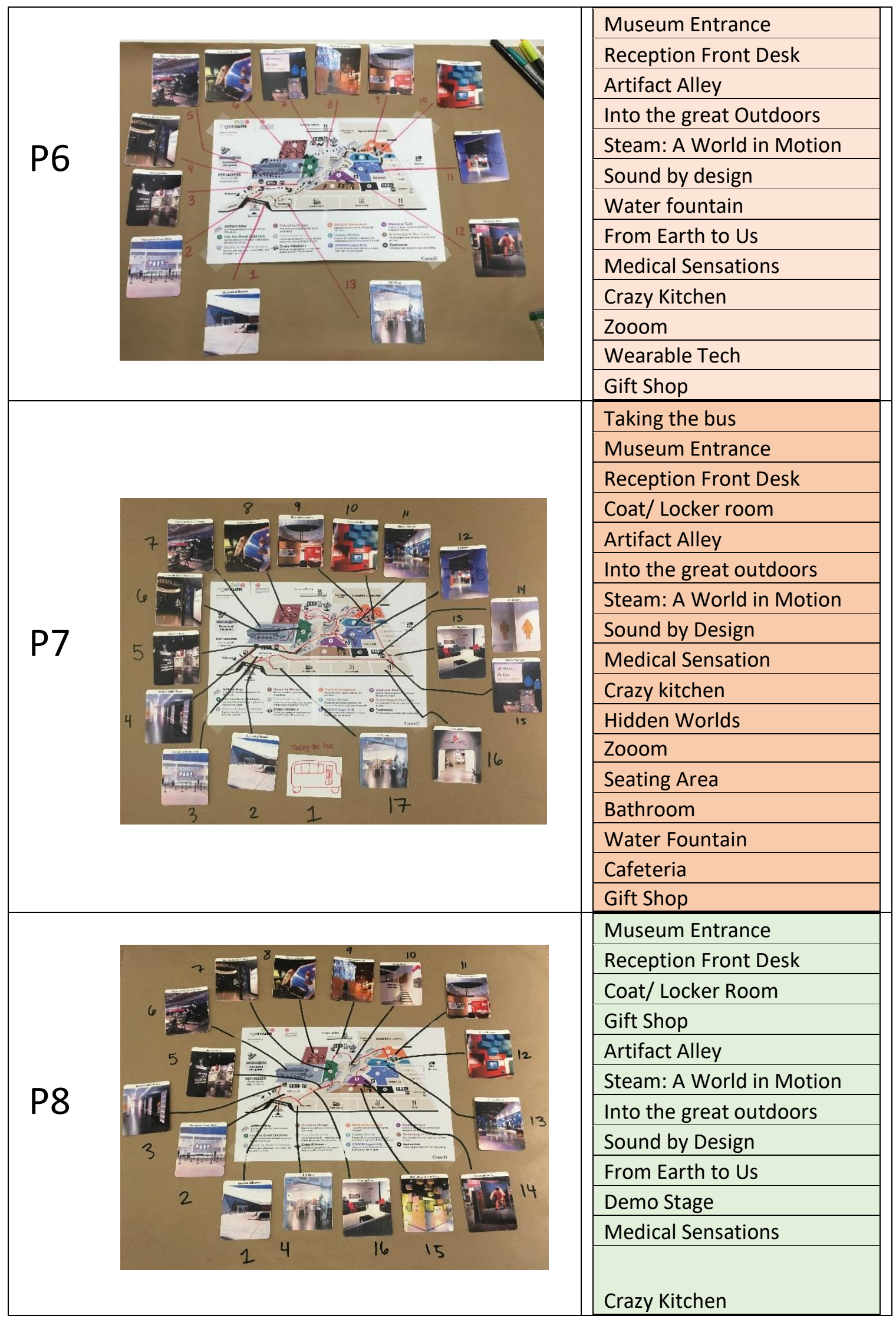




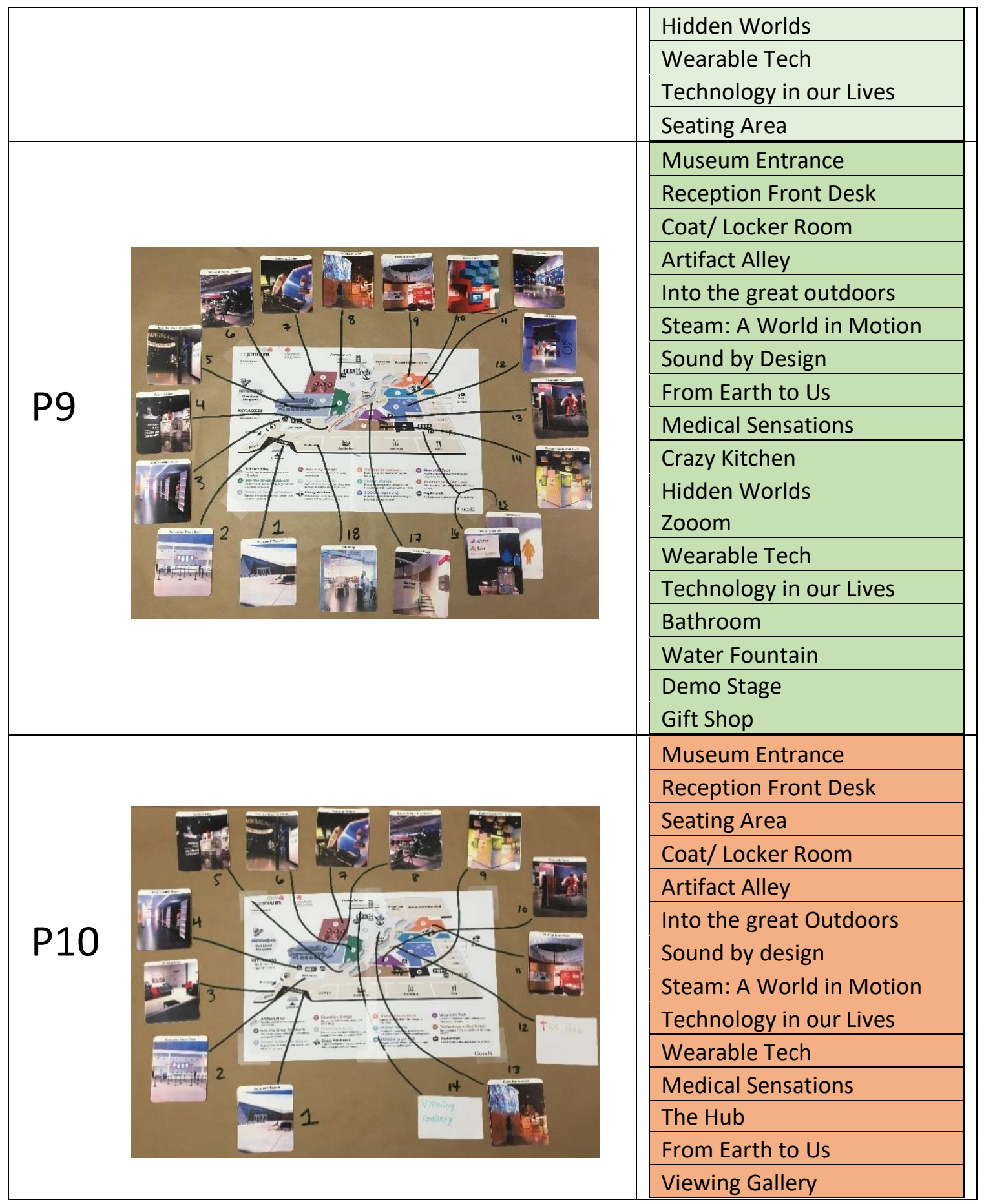

Table 7: Journey map data of ten participants, enumerating the steps/places taken in the right column. 